\title{
An EXPERIMENTAL STUdy OF THE EARTh PRESSURE Distribution ON CYLINDRICAL SHAFTS
}

\author{
by \\ TATIANA TOBAR VALENCIA \\ A thesis submitted to McGill University \\ in partial fulfilment of the requirements \\ of the degree of
}

\section{MASTer of Civil ENGineERING}

Department of Civil Engineering \& Applied Mechanics

McGill University

Montréal, Québec, Canada

March, 2009

()Tatiana Tobar Valencia, 2009 
•

○ 


\section{ABSTRACT}

Cylindrical shafts are often used as earth retaining structures for different geotechnical engineering applications (e.g. underground tunnels, pumping stations and hydroelectric projects). Due to their simplicity, classical earth pressure theories are usually used for shaft design. These theories were developed for two-dimensional plane strain problems. Several theoretical methods have been proposed to estimate the axisymmetric active earth pressure on cylindrical shafts, however there is no general agreement on the radial earth pressure distribution along the shaft. In addition, the wall movement needed to reach the calculated pressures is not completely understood. In this thesis, an experimental investigation has been conducted to study the distribution of earth pressure on a cylindrical wall embedded in dry sand and subjected to radial displacements. The initial and progressive changes in earth pressure along the shaft were continuously measured for different wall displacements. The results indicated a rapid decrease in the lateral earth pressure when a small wall movement was introduced. The earth pressure distribution along the shaft reached a minimum uniform value and became independent of any additional wall displacement, when a movement of about $2.5 \%$ of the shaft radius, or $0.2 \%$ of the wall height, was applied. It was concluded that present design standards overestimate the active earth pressure around cylindrical walls, and the difference between design and actually pressure values increases with depth. The experimental results were also compared with some of the available theoretical solutions for axisymmetric conditions; it was found that at wall movements greater than or equal to about $1 \%$ of the wall height, the measured pressures fell into the pressure range calculated using Cheng and $\mathrm{Hu}(2005)$ method. 


\section{RÉSUMÉ}

Les puits cylindriques sont souvent utilisés comme structures de soutènement de sol dans différentes activités géotechniques (ex. tunnels souterrains, stations de pompage et projets hydroélectriques). La simplicité des théories classiques de pression du sol est la raison principale pour leurs utilisations dans la conception des puits. Ces théories ont été développées pour les problèmes de déformation plane. Plusieurs méthodes théoriques ont été proposées pour estimer la pression axisymétrique active du sol sur les puits cylindriques, mais il n'existe toujours pas un consensus général sur la distribution radiale des pressions du sol sur les revêtements de puits. En plus, le mouvement nécessaire des murs pour atteindre les pressions calculées n'est pas complètement compris. Dans cette thèse, une investigation expérimentale a été réalisée pour étudier le profil des pressions du sol sur un mur cylindrique enfoui dans du sable sec et contraint à des déplacements radiaux. Le changement initial et progressif des pressions du sol autour des puits a été mesuré constamment pour différents déplacements de murs. Les résultats obtenus ont indiqué une réduction rapide des pressions du sol suite à l'introduction d'un mouvement minime du mur. La distribution des pressions du sol autour des puits a atteint une valeur minimale et uniforme et est devenue indépendante de tout déplacement additionnel du mur quand ce dernier est égal à $2.5 \%$ du rayon du puits. En conclusion, les méthodes de conception actuelles surestiment la pression active du sol autour des murs cylindriques, et la différence entre les valeurs de conception et les valeurs actuelles augmentent avec la profondeur. Les résultats expérimentaux ont aussi été comparés avec quelques-unes des solutions théoriques disponibles pour les conditions axisymétriques; on a constaté que pour les mouvements du mur supérieurs ou égaux à environ $1 \%$ de la hauteur du mur, les pressions mesurées se retrouvent dans le rang de pression calculé en utilisant la méthode de Hu et Cheng (2005) 
$\bullet$ 
$\bullet$ 


\section{ACKNOWLEDGEMENTS}

First and foremost, I would like to thank my supervisor Dr. M.A. Meguid whose advice, patience and encouragement made this work possible.

I would like to thank the tremendous support of the technicians John Bartczak and Marek Przykorski in building the shaft apparatus and conducting the experiments. I would also like to thank Dr. William Cook and the technicians Jorge Sayat, Ron Sheppard, and Damon Kipperchuk for their invaluable help in the experimental work.

I am deeply indebted to my parents, Leyde Valencia and Gerardo A. Tobar, for giving me the opportunity to have the most life-enriching experience in my life; without their constant support - emotional, moral and financial of course - this thesis would certainly not have been possible. Special thanks are due to my brother and buddy, Gerardo Tobar for his love and company throughout this journey.

Finally, the support and encouragement of many friends has been indispensable, and in particular I would like to acknowledge the contribution of Carolina Silva, Julian Sepulveda, and Teresa Cruz. I would like to express my sincerest appreciation to them. 


\section{NOMENCLATURE}

\begin{tabular}{|c|c|}
\hline$a$ & Shaft radius \\
\hline$c$ & Shear strength \\
\hline$D_{r}$ & Relative density \\
\hline$G$ & Shear modulus \\
\hline$g$ & Gravitational constant of the Earth \\
\hline$G_{s}$ & Specific gravity \\
\hline$h$ & Excavation depth measured from ground surface \\
\hline$H$ & Shaft wall height \\
\hline$K$ & Coefficient of lateral earth pressure on circumferential planes, $K=\sigma_{\theta} / \sigma_{v}$ \\
\hline$K_{a}$ & Coefficient of earth pressure at active conditions, $K_{a}=\tan ^{2}(45-\phi / 2)$ \\
\hline$K_{o}$ & Coefficient of earth pressure at rest, $K_{o}=1-\sin \phi$ \\
\hline$N=N_{\varphi}$ & $\tan ^{2}(45+\phi / 2)$ \\
\hline$p$ & Lateral earth pressure \\
\hline$p_{a}$ & Active earth pressure \\
\hline$p_{i}$ & Internal or support pressure (radial stress) \\
\hline$p_{i}^{c r}$ & Critical internal or support pressure \\
\hline$p_{o}$ & Vertical initial in situ stress \\
\hline$q$ & External surcharge \\
\hline$r$ & Radial distance \\
\hline$R_{p}$ & Radius of plastic zone \\
\hline
\end{tabular}




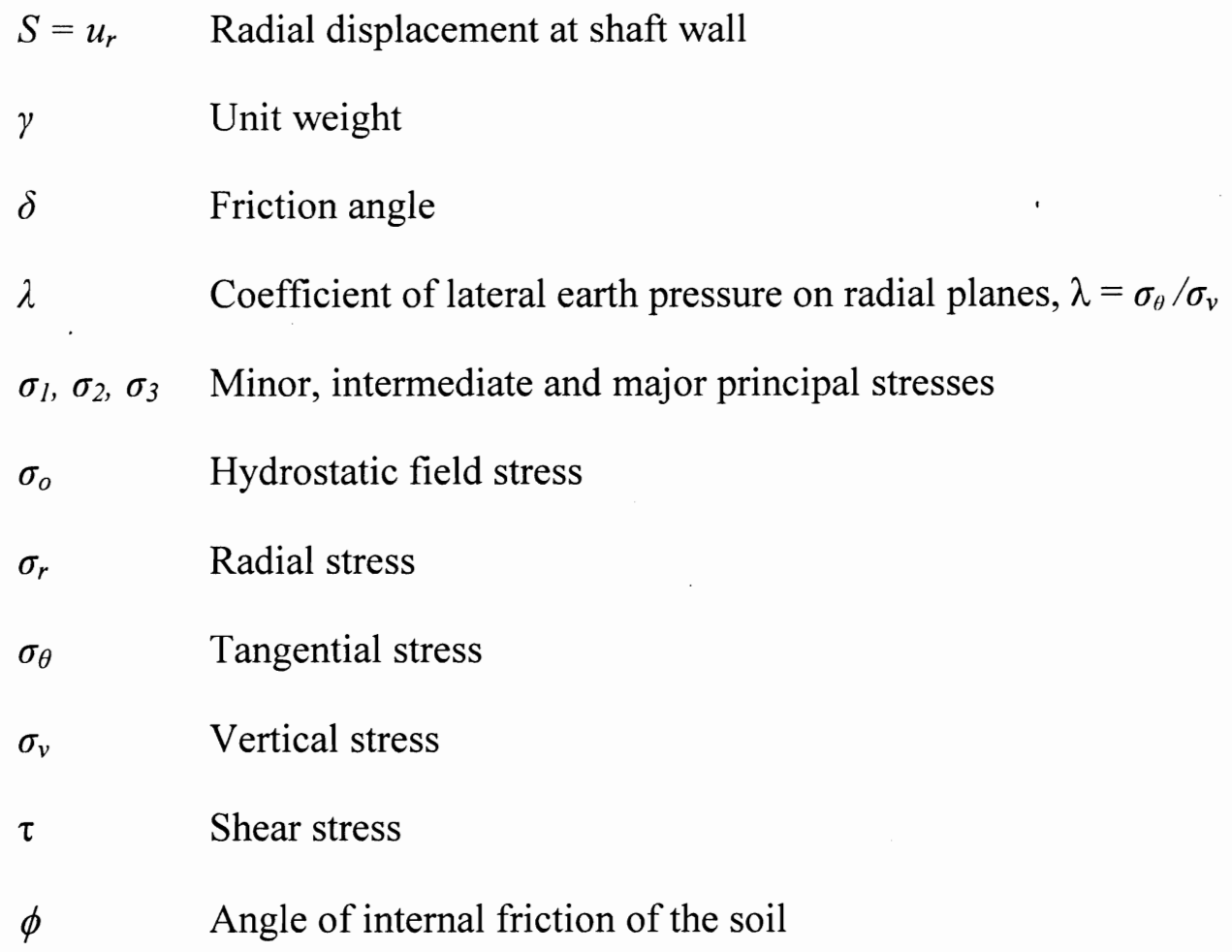




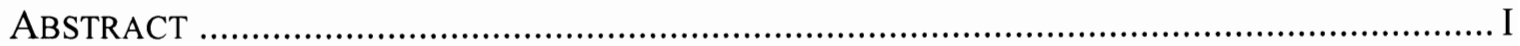

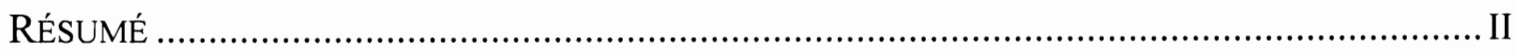

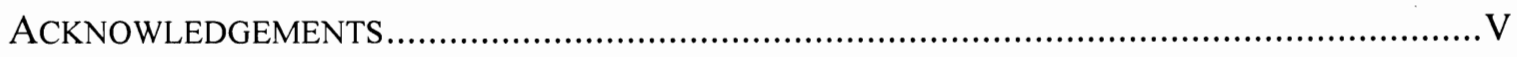

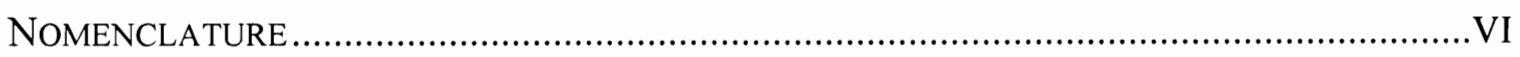

TABLE OF CONTENTS ......................................................................................... VIII

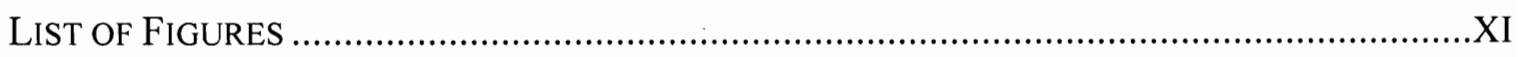

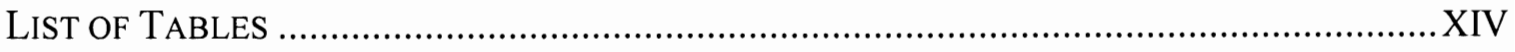

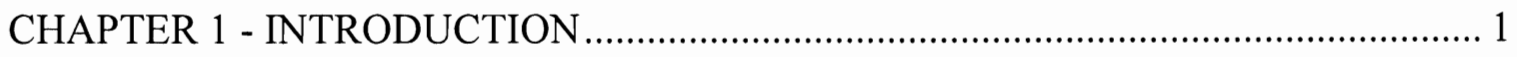

1.1 General Overview ............................................................................ 1

$1.2 \quad$ Research objectives......................................................................... 2

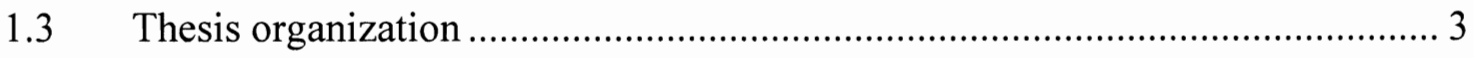

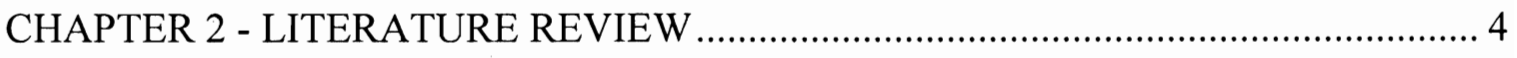

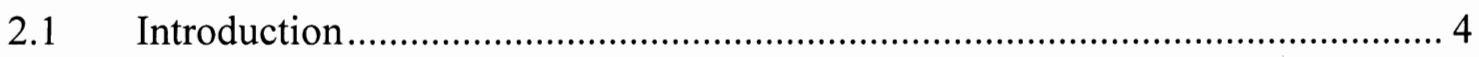

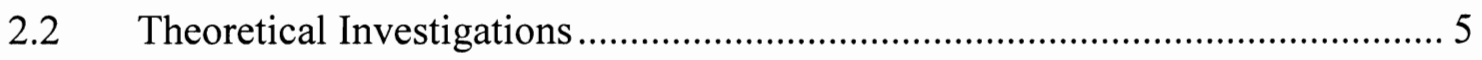

a. Solution for a thick-walled cylinder....................................................... 5

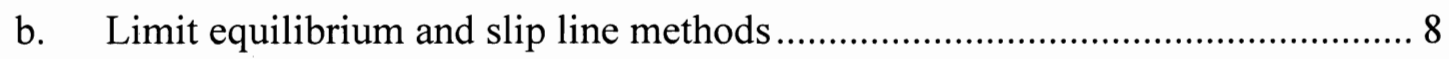

Limit equilibrium.................................................................... 9

Slip line method ........................................................................ 12

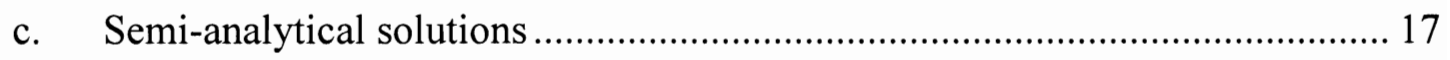

2.3 Comparison of Theoretical Solutions ....................................................... 18

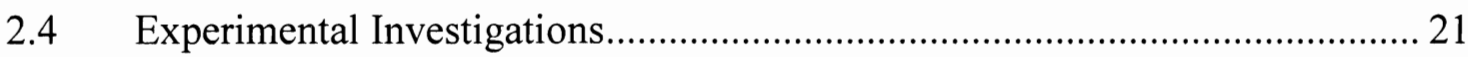

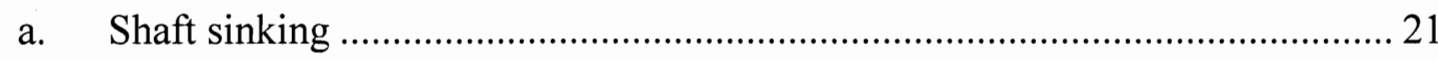


b. Temporary stabilization using fluid pressure................................................... 23

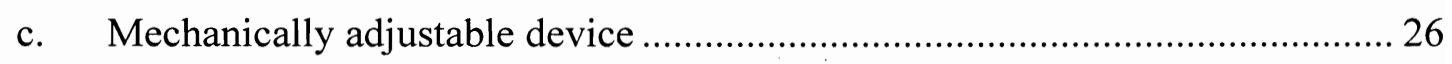

2.5 Comparison of Experimental Modeling Techniques ......................................... 32

CHAPTER 3 - EXPERIMENTAL PROGRAM............................................................. 36

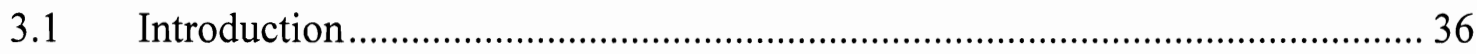

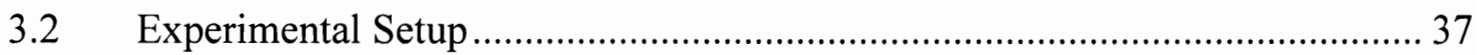

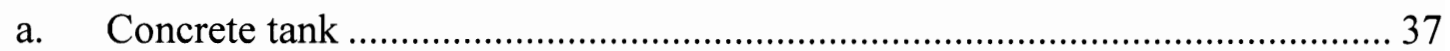

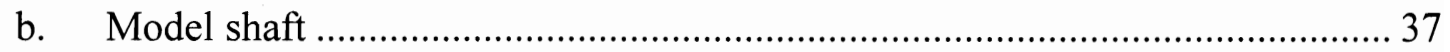

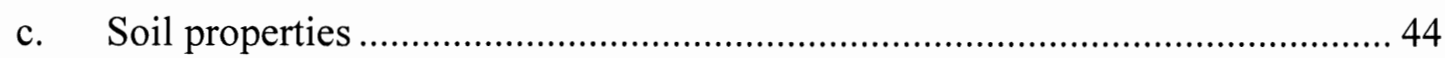

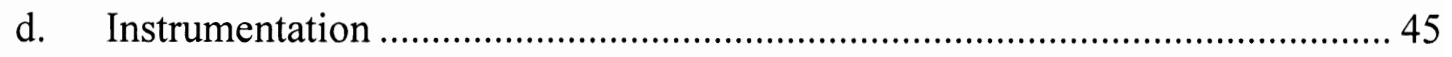

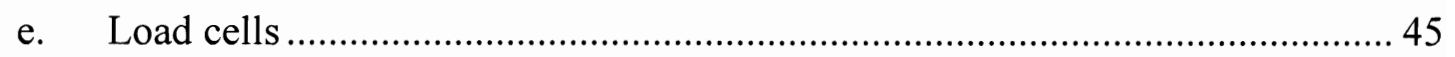

f. Linear variable displacement transducer......................................................... 46

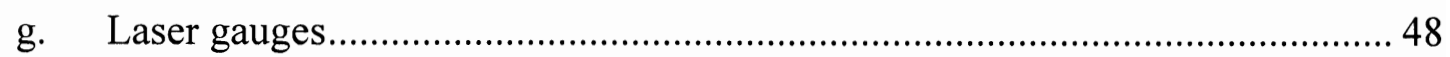

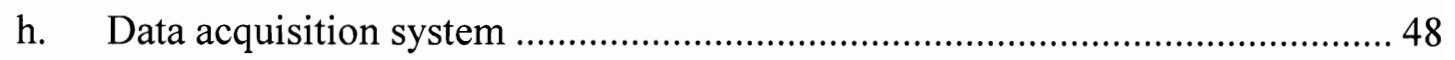

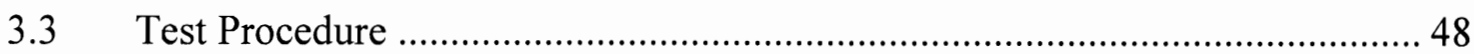

CHAPTER 4 - EXPERIMENTAL RESULTS AND ANALYSIS................................... 52

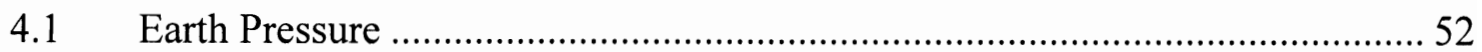

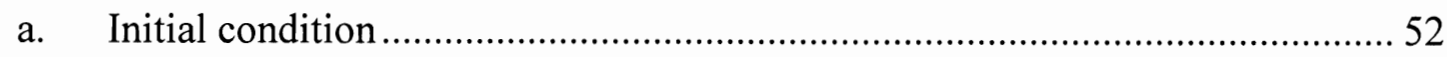

b. Earth pressure versus wall displacement ........................................................ 53

c. Normalized earth pressure versus depth and comparison with theoretical

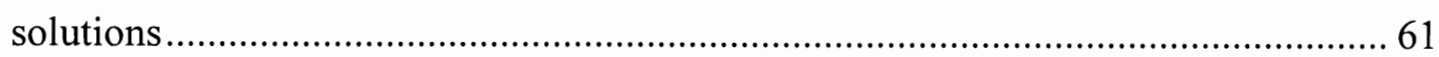

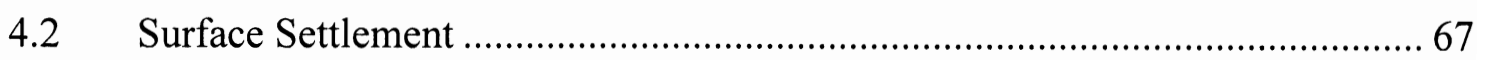

CHAPTER 5 - CONCLUSIONS AND RECOMMENDATIONS..................................... 68

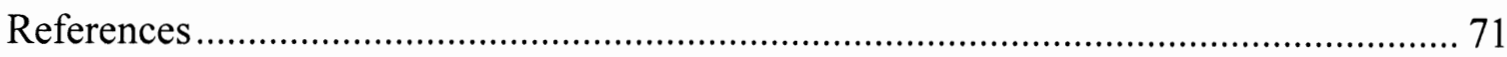

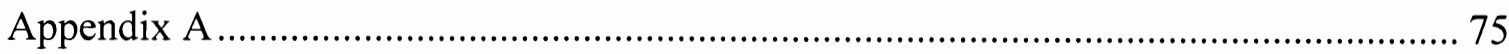




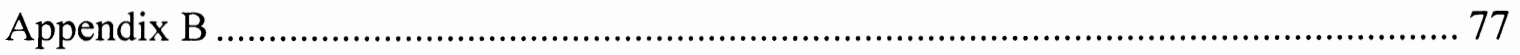

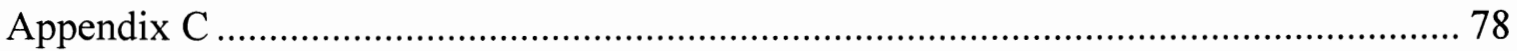

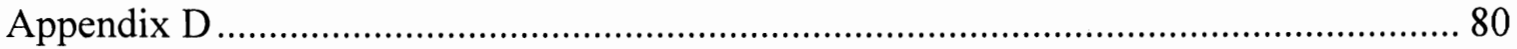

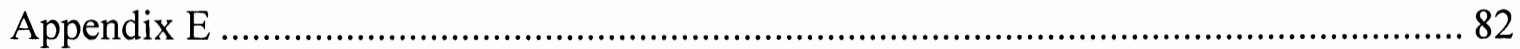

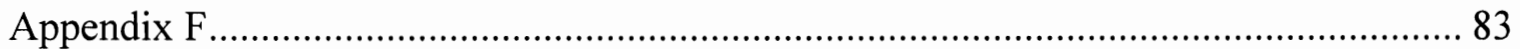




\section{LIST OF FIGURES}

Figure 1.1 Effect of wall displacement on the earth pressures acting on straight retaining walls in cohesionless soil (Adapted from the Canadian Foundation Engineering Manual, 2006). 2

Figure 2.1 Stresses acting on a soil element adjoining an axisymmetric excavation ......... 4

Figure 2.2 Schematic of the axisymmetric model used in the closed-form solution......... 6

Figure 2.3 Elastic and elastoplastic typical stress distribution around a circular hole in infinite media subject to hydrostatic stress field. [Adapted from Fara and Wright (1963)] 8

Figure 2.4 Illustration of the assumptions made by Terzaghi [Adapted from Terzaghi (1943)]

Figure 2.5 (a) Normalized support pressure versus normalized depth; (b) Normalized extent of the plastic zone versus normalized depth. $(c=0)$ [Adapted from Terzaghi (1943)]. 10

Figure 2.6 Failure surface assumed by Prater and forces acting on the sliding mass [Adapted from Prater (1977)] 11

Figure 2.7 Earth pressure distributions for cohesionless soil $(\mathrm{c}=0)$ [Based on Prater (1977)] 12

Figure 2.8 Pressure acting on a cylindrical retaining wall [Adapted from Berezantzev (1958)] 13

Figure 2.9 Earth pressure distributions using the simplified slip line solution $(c=0)$ [Based on Berezantzev (1958)] 14

Figure 2.10 Upper and lower bound axisymmetric earth pressures $(c=0)$ [Based on

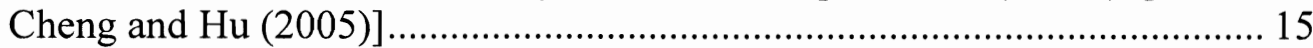

Figure 2.11 Model shaft used in the generalized solution [Adapted from Cheng and $\mathrm{Hu}$ (2007)] 16

Figure 2.12 Horizontal and vertical arching around a circular shaft [Adapted from Wong and Kaiser (1988)] 17 
Figure 2.13 Shaft design method based on Convergence-confinement concept with inclusion of gravity effect. (a) Ground reaction curves (GRC) and extent of the plastic zone due to horizontal arching; (b) Pressure distribution $\left(p_{i}\right)$ from GRC at wall displacement $u_{s}$; (c) Pressure envelope with gravity effect. [Adapted from Wong and Kaiser (1988)] ........................................................ 18

Figure 2.14 Earth pressure distribution using different theoretical methods.................... 19

Figure 2.15 Model shaft used in the sinking technique [Adapted from Walz (1973)] .... 22

Figure 2.16 Normalized earth pressure distribution versus normalized depth [Adapted form Walz (1973)]. 23

Figure 2.17 Test setup using the flexible liquid bag technique [Adapted from Lade et al. (1981)] 24

Figure 2.18 Test results for the Radial strains in the Melinex lining and lateral earth pressures versus normalized depth $\mathrm{h} / \mathrm{a}$ [adapted from Lade et al. (1981)].... 25

Figure 2.19 Overview of the test setup using the flexible air bag technique [Adapted from Konig et al. (1991)] ...................................................................... 26

Figure 2.20 Semi-cylinder shaft model [Adapted from Fujii et al. (1994)] ...................... 27

Figure 2.21 Earth pressure versus normalized depth for smooth and rough wall [Adapted from Fujii et al. (1994)] ........................................................................... 28

Figure 2.22 Active earth pressure distribution versus normalized depth for a prototype model $50 \mathrm{~m}$ deep [Adapted from Imamura et al. (1999)] ... 29

Figure 2.23 Quarter-of-cylinder model shaft [Adapted from Herten and Pulsfort (1999)]

Figure 2.24 Measured earth pressure versus depth at various wall displacement values [Adapted from Herten and Pulsfort (1999)] ...................................................... 30

Figure 2.25 Schematic of the semi-cylinder model shaft [Adapted from Chun and Shin (2006)] 31

Figure 2.26 Measured earth pressure versus depth at various wall displacement $(h / a=$ 4.3) [Adapted from Chun and Shin (2006)] 32

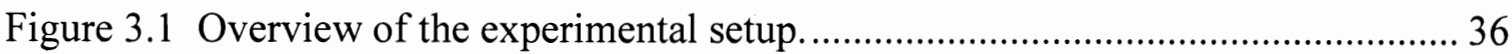

Figure 3.2 Model shaft during assemblage showing details of a typical end section...... 38

Figure 3.3 Details of the lower-end section during assemblage (above); Details of the upper-end section during assemblage (below) 40 
Figure 3.4 Details of the lower end-section showing the antirotational system for the lining segments.

Figure 3.5 Lateral cross section of the model shaft developed as it was installed in the test container.

Figure 3.6 Details of the instrumented lining segment. 46

Figure 3.7 Schematic of the model shaft showing the position of all the transducers installed

Figure 3.8 General view of the model shaft installed in the concrete tank with details of the upper and lower sections.

Figure 3.9 Schematic sketch of the experimental setup.................................................. 51

Figure 4.1 Measured initial earth pressure versus depth............................................... 53

Figure 4.2 Measured lateral load versus wall displacement, T15 ……………………... 54

Figure 4.3 Changes in lateral earth pressure at different locations along the shaft wall for a maximum wall displacement of $1 \mathrm{~mm}$....................................................... 56

Figure 4.4 Changes in lateral earth pressure at different locations along the shaft wall for a maximum wall displacement of $2 \mathrm{~mm}$

Figure 4.5 Changes in lateral earth pressure at different locations along the shaft wall for a maximum wall displacement of $3 \mathrm{~mm}$ 58

Figure 4.6 Changes in lateral earth pressure at different locations along the shaft wall for a maximum wall displacement of $4 \mathrm{~mm}$ 59

Figure 4.7 Percentage of earth pressure reduction at the three locations along the shaft 60

Figure 4.8 Comparison of measured and theoretical earth pressures along the shaft for $\mathrm{S}=$ $0.1 \%$ of the wall height 63

Figure 4.9 Comparison of measured and theoretical earth pressures along the shaft for $\mathrm{S}=$ $0.2 \%$ of the wall height 64

Figure 4.10 Comparison of measured and theoretical earth pressures along the shaft for $\mathrm{S}$ $=0.3 \%$ of the wall height

Figure 4.11 Comparison of measured and theoretical earth pressures along the shaft for $\mathrm{S}$ $=0.4 \%$ of the wall height 66

Figure 4.12. Measured surface settlement 67 


\section{LIST OF TABLES}

Table 2.1 Advantages and disadvantages of the experimental techniques used for shaft

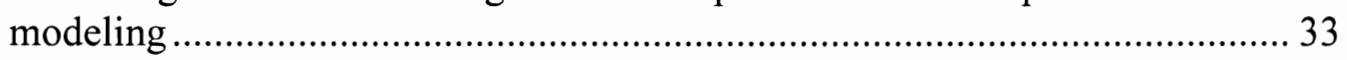

Table 2.2 Comparison of the displacement necessary to reach the active condition using different mechanically adjustable models

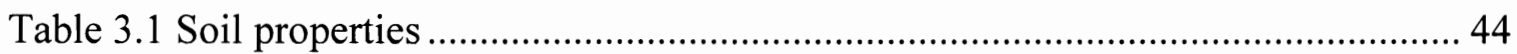




\section{CHAPTER 1}

\section{INTRODUCTION}

\section{General Overview}

Vertical shafts are generally used as temporary or permanent earth retaining structures for different engineering applications (e.g. underground tunnels, pumping stations and hydroelectric projects). Determining the earth pressure acting on a shaft lining is essential to successful shaft design, however current design codes give little guidance on this matter (e.g. Canadian Foundation Engineering Manual, 2006). The earth pressure acting on cylindrical shafts has been traditionally estimated using the classical earth pressure theories developed by Coulomb (1776) and Rankine (1856). These methods predict the lateral earth pressure on an infinitely long wall under plane strain conditions. Both theories are based on rigid plasticity methods assuming a rigid wall system. The effect of the lateral deformation of the lining on the lateral earth pressure was first investigated by Terzaghi (1920) using small-scale model tests. A retaining wall was simulated using a rigid plate that was systematically displaced while the earth pressures were measured. It was concluded that for dense sand material, a wall movement of about $0.1 \%$ of the wall height was necessary to reach the theoretical active earth pressure. Additionally, it was observed that the wall movement needed to reach the active state was the same, regardless of the displacement mode, i.e. translational or rotational displacements.

Following the work of Terzaghi (1920), more earth pressure research has been conducted (e.g. Terzaghi, 1934, 1953; Rowe, 1969; Bros, 1972; Sherif et al., 1982; Sherif et al., 1984), to determinate the magnitude of wall displacement needed to reach active earth pressures under two-dimensional condition. The effect of wall displacement on the earth pressure in cohesionless soil is shown in Figure 1.1. It can be seen that for dense 
cohesionless soil, the magnitude of the wall movement required to achieve active condition is about $0.1 \%$ of the wall height, whereas a wall movement of about $0.4 \%$ of the wall height is needed for loose material.

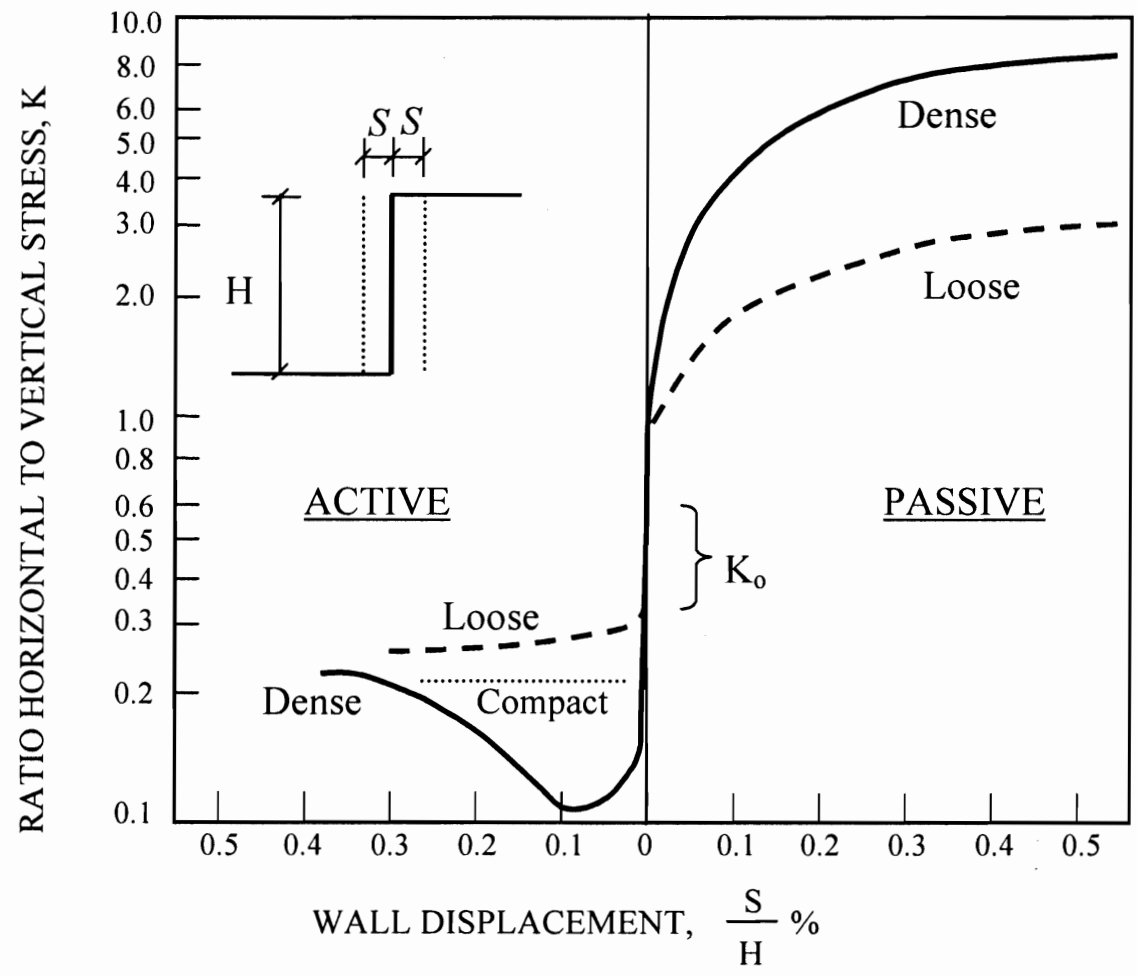

Figure 1.1 Effect of wall displacement on the earth pressures acting on straight retaining walls in cohesionless soil (Adapted from the Canadian Foundation Engineering Manual, 2006)

\section{Research objectives}

Several theoretical methods have been proposed to estimate the active earth pressure on cylindrical retaining walls; however, the results indicated significant discrepancies in the calculated pressure distribution using these methods. On the other hand, the required wall movement to reach these pressure values has not yet been well understood. The primary objective of the present study is to investigate experimentally the relationship between the earth pressure on a shaft lining and the radial wall displacement. The experimental results are then used to evaluate the applicability of some of the available theoretical methods. 
Specific objectives of this research work are:

- Review the available theoretical methods to calculate the lateral earth pressure on cylindrical shafts excavated in soft ground.

- Review different physical modeling techniques that have been used to study the ground response to shaft construction.

- Design and build an apparatus that models the full axisymmetric configuration of a cylindrical shaft and allows a uniform reduction in diameter under controlled conditions.

- Monitor the progressive changes in lateral earth pressure due to the incremental reduction of the shaft diameter.

- Compare the lateral earth pressure measured at different strain levels with the calculated pressure using some of the theoretical methods available in the literature.

- Determinate the required wall movement needed to establish active condition around the shaft.

\section{Thesis organization}

A brief description of each chapter included in the thesis is presented in below.

Chapter 2 contains the literature review, which is divided in two sections. The first section presents a review of the available theoretical methods to estimate the active earth pressure on cylindrical shafts. Emphasis is placed on studies conducted to extend the classical earth pressure theories to axisymmetric conditions. The second section presents a review of the experimental techniques used for studying the earth pressure distribution on cylindrical shafts.

A detailed description of the model shaft developed along with the experimental procedure is presented in Chapter 3. Chapter 4 contains the experimental results as well as analysis and discussion based on the experimental data. Finally, conclusions and recommendations are presented in Chapter 5. 


\section{CHAPTER 2}

\section{LITERATURE REVIEW}

\section{Introduction}

The earth pressure acting on any retaining structure is strongly dependent on the lateral deformation of the soil. Thus, theoretical methods used to predict the lateral earth pressure on a retaining structure must consider the soil deformation required to reach that final pressure. The deformation around a cylindrical wall depends on the construction technique, ground conditions, lining stiffness, and workmanship among other factors. Several authors have investigated the active earth pressure acting on rigid shafts using both theoretical and experimental methods. The reported values of earth pressure were found to be much lower than those calculated using the classical Coulomb and Rankine theories. In this chapter, a brief review of some of these investigations will be presented. The relevant studies are divided into theoretical methods and experimental modeling.

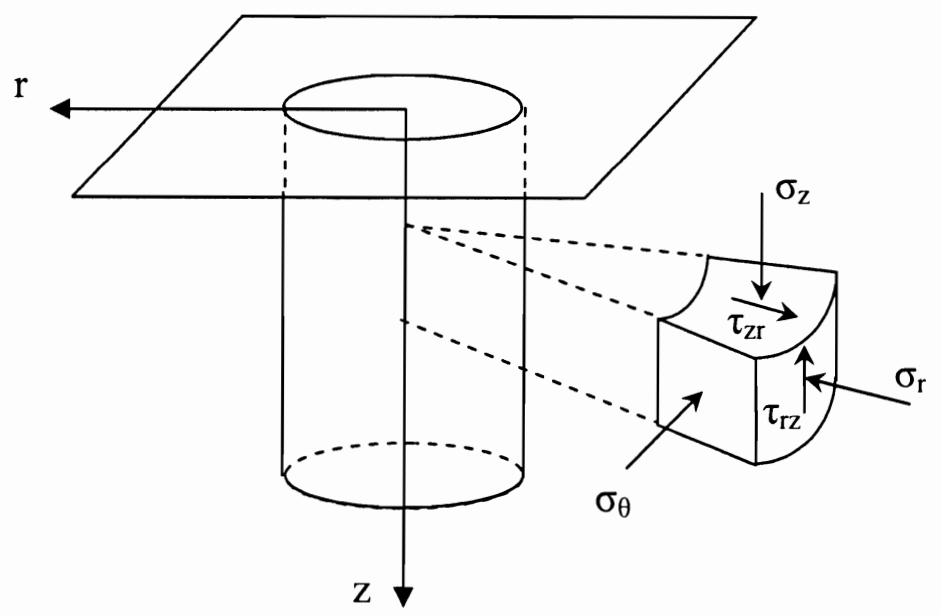

Figure 2.1 Stresses acting on a soil element adjoining an axisymmetric excavation 


\section{Theoretical Investigations}

The state of stress around a vertical axisymmetric excavation in soft ground (see Figure 2.1) has been theoretically studied by several authors. Lamé (1833) and Kirsch (1898) proposed closed-form solutions for the state of stress and displacements around a circular hole in infinite elastic medium. Fara and Wright (1963), Detournay (1986), and Carranza-Torres (2003) among others proposed elastoplastic closed form solutions for the stresses around a circular opening. Westergaard (1940), Terzaghi (1943), and Prater (1977) applied limit equilibrium to study the active earth pressure against a circular shaft in cohesionless soil. Berezantzev (1958), Cheng and $\mathrm{Hu}$ (2005), Cheng et al. (2007), Liu and Wang (2008), and Liu et al. (2009) applied slip line method to study the active/passive earth pressure against cylindrical retaining walls. Britto and Kusakabe (1982; 1983), and Pastor and Turgeman (1982) applied limit analysis to study the stability of an axisymmetric excavation in cohesive soil. Kaiser and Wong (1988) combined elastoplastic solution of a circular opening with limit equilibrium to obtain closed-form solutions for the stresses and displacements around a circular shaft taking into account the effect of gravity. A review of some of the theoretical studies related to axisymmetric active earth pressure in cohesionless soil is presented below. Emphasis is placed on the studies conducted to extend the classical earth pressure theories to axisymmetric conditions.

The methods of analysis can be divided into three main groups:
a. Solution for a thick-walled cylinder
b. Limit equilibrium and slip line methods
c. Semi-analytical solutions

\section{a. Solution for a thick-walled cylinder}

Lamé (1833) studied the state of stress of an infinitely long thick-walled cylinder subjected to a uniformly distributed internal and external pressure as shown in Figure 2.2. 
(Timoshenko, 1941). The state of stress around a circular hole of radius, $a$, in elastic medium subjected to hydrostatic stress, $\sigma_{o}$, and internal pressure, $p_{i}$, is considered to be a special case of Lamé's solution. The stresses and displacements around the circular hole are expressed by the equations:

$$
\begin{aligned}
& \sigma_{r}=\sigma_{o}-\left(\sigma_{o}-p_{i}\right)\left(\frac{a}{r}\right)^{2} \\
& \sigma_{\theta}=\sigma_{o}+\left(\sigma_{o}-p_{i}\right)\left(\frac{a}{r}\right)^{2} \\
& u_{r}=\frac{a^{2}\left(p_{o}-p_{i}\right)}{2 r G}
\end{aligned}
$$

Similar expressions were also obtained as a special case of Kirsch (1898) solution for the stresses and displacements around a circular hole in an infinite elastic plate. (Brady and Brown, 2004)

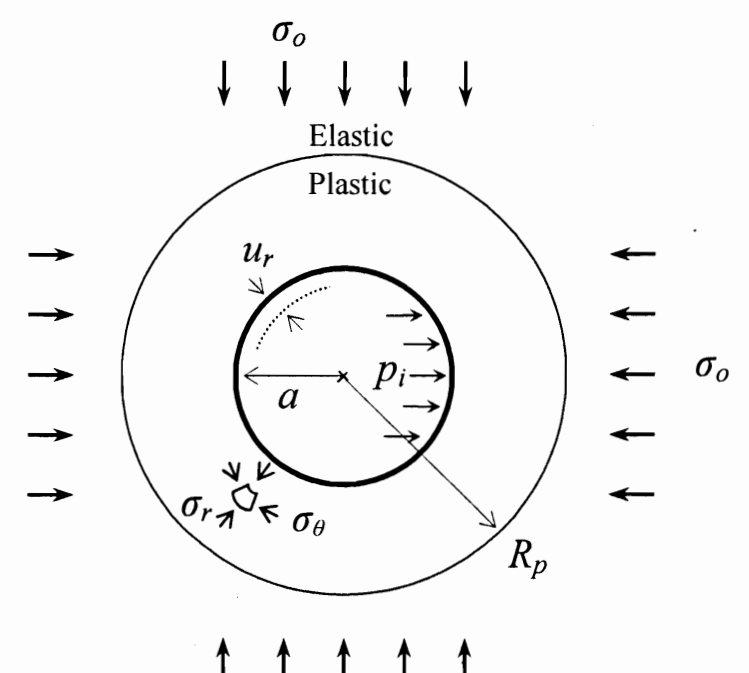

Figure 2.2 Schematic of the axisymmetric model used in the closed-form solution.

As shown in Figure 2.2 the excavation can be simulated as a reduction of the internal pressure, $p_{i}$, with the soil behaving elastically until a critical pressure $p_{i}^{c r}$ is reached. If Mohr-Coulomb criterion is assumed, the critical pressure and the radius of the 
plastic zone $\left(R_{p}\right)$ are given by equations 2.4 and 2.5 , respectively, where $N=(1+\sin \phi) /(1-\sin \phi)$ and $\sigma_{c}=2 c \sqrt{N}$

$$
\begin{aligned}
& p_{i}^{c r}=\frac{2}{N+1}\left(\sigma_{o}+\frac{\sigma_{c}}{N-1}-\frac{\sigma_{c}}{N-1}\right) \\
& R_{p}=a\left[\frac{p_{i}^{c r}+\sigma_{c} /(N-1)}{p_{i}+\sigma_{c} /(N-1)}\right]^{l /(N-l)}
\end{aligned}
$$

Thus, if $p_{i} \geq p_{i}^{c r}$, the problem is fully elastic and the stresses are given by equations 2.1 to 2.3 (Lamé solution); on the other hand, if $p_{i}<p_{i}^{c r}$ the problem has two zones: an elastic zone for $r \geq R_{p}$ and a plastic zone for $r<R_{p}$ (Figure 2.2)

The radial and tangential stresses inside the plastic zone (radius $=R_{p}$ ) are given by the following expressions:

$$
\begin{aligned}
& \sigma_{r}=p_{i}^{c r}+\frac{\sigma_{c}}{N-1}\left(\frac{r}{R_{p}}\right)^{N-1}-\frac{\sigma_{c}}{N-1} \\
& \sigma_{\theta}=N\left(p_{i}^{c r}+\frac{\sigma_{c}}{N-1}\right)\left(\frac{r}{R_{p}}\right)^{N-1}-\frac{\sigma_{c}}{N-1}
\end{aligned}
$$

Several researchers have proposed diverse solutions using different constitutive laws and failure criteria (Fara and Wright, 1963; Detournay, 1986; Carranza-Torres, 2003). As illustrated in Figure 2.3, in a purely elastic material, the radial stress decreases due to the excavation effect, while the tangential stress increases at the same rate. In an elastoplastic material the radial stress steadily decreases, whereas the tangential stress increases until the maximum strength of the material is reached. 


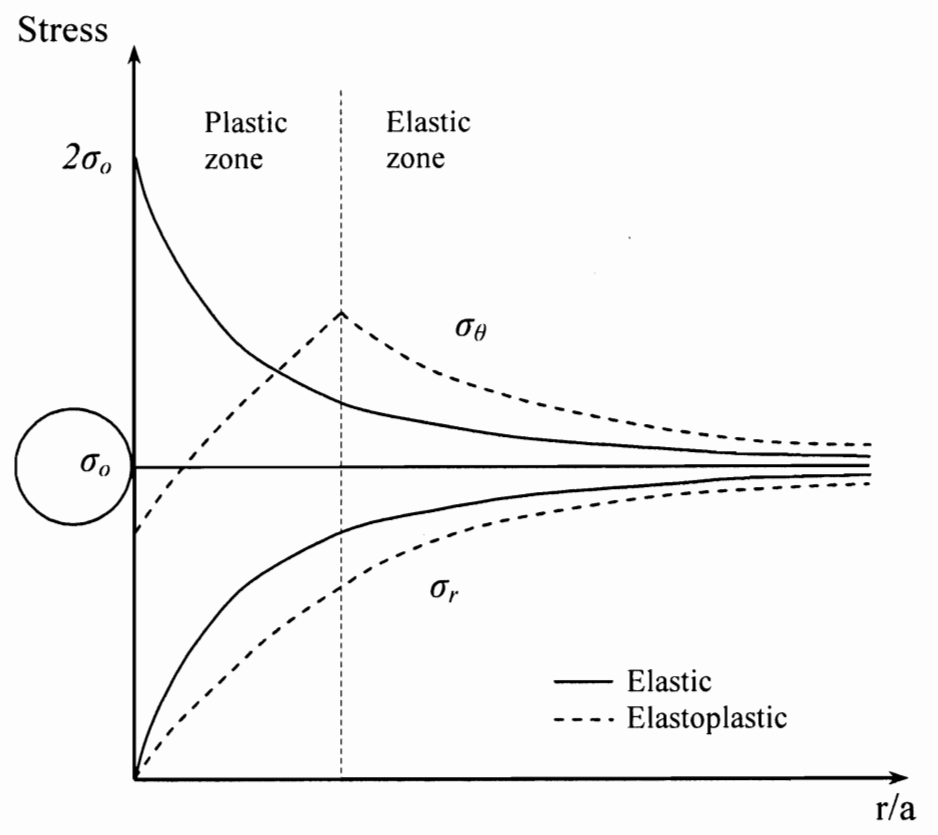

Figure 2.3 Elastic and elastoplastic typical stress distribution around a circular hole in infinite media subject to hydrostatic stress field. [Adapted from Fara and Wright (1963)]

\section{b. Limit equilibrium and slip line methods}

When Coulomb (1773) and Rankine (1857) developed their classical twodimensional earth pressure theories, they also established two simple methods of analysis: limit equilibrium and slip line method. Both methods are based on plasticity considerations, however they differ in how the solution is obtained. The limit equilibrium method assumes an arbitrary failure surface, and then simple statics is used to solve the problem. Conversely, the slip line method assumes the entire soil mass to be at the verge of failure, and the solution is obtained through a set of differential equations based on plastic equilibrium.

Several researchers have attempted to extend these simple methods to study the active earth pressure against circular shafts in cohesionless media. Westergaard (1940), Terzaghi (1943), and Prater (1977) used limit equilibrium; whereas Berezantzev (1958), Cheng and $\mathrm{Hu}$ (2005), Cheng et al. (2007), Liu and Wang (2008) Liu et al. (2009) used the slip line method of analysis. In contrast to the two classical earth pressure theories, where similar active pressure distributions are usually calculated, the distributions obtained for axisymmetric conditions differ considerably as discussed below. 


\section{Limit equilibrium}

The earliest effort to investigate the state of stress around a circular vertical opening in soil was made by Westergaard (1940) who studied the stress conditions around small unlined drilled holes, based on plastic equilibrium of a slipping soil wedge. Terzaghi (1943) extended Westergaard's theory to large lined holes, and proposed a method to calculate the minimum earth pressure exerted by a cohesionless soil on the vertical shafts. The equilibrium of the sliding soil mass was determined assuming equal principal stresses inside the elastic zone, i.e. $\sigma_{\theta}=\sigma_{v}=\sigma_{1}, \sigma_{r}=\sigma_{3}$, and Mohr-Coulomb yield criterion. Figure 2.4 summarizes Terzaghi's assumptions.
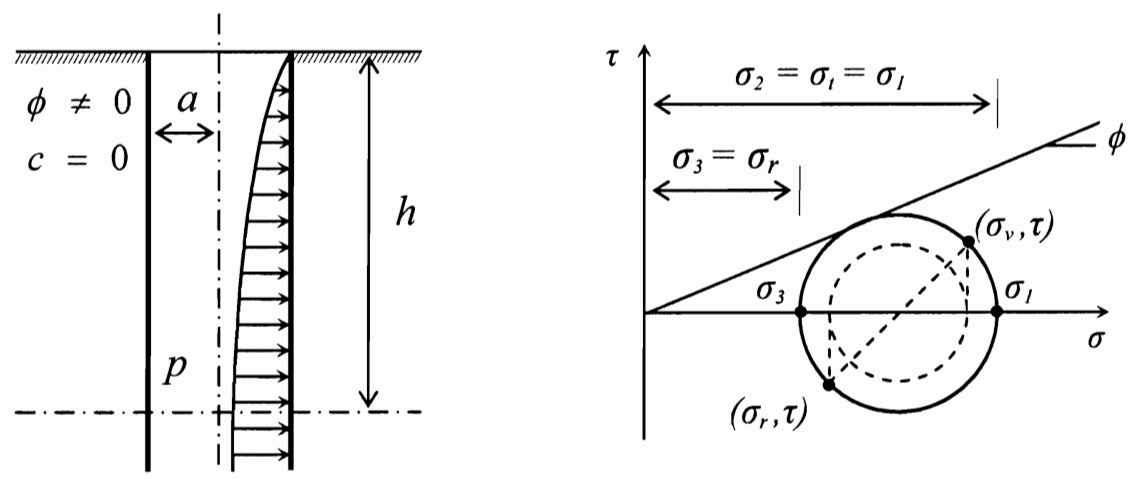

Figure 2.4 Illustration of the assumptions made by Terzaghi [Adapted from Terzaghi (1943)]

As a result, Terzaghi obtained equations 2.9 and 2.10 for the lateral earth pressure on a shaft lining, and proposed a reduction of the angle of internal friction of the sand by $5^{\circ}$ to account for the effect of the nonzero shear stresses.

$$
\begin{gathered}
m_{\sigma}=\frac{h}{a} \frac{N_{\phi}+1}{2 N_{\phi}} \frac{N_{\phi}-\left(N_{\phi}-2\right) n_{l}^{2}}{N_{\phi}+n_{l}^{N_{\phi}+1}} \\
\tan \phi^{*}=\frac{n_{l}^{2}-1}{m_{\sigma} n_{l}^{N_{\phi}}}-\frac{2 N_{\phi}}{N_{\phi}+1} \frac{a}{h} \frac{n_{l}^{N_{\phi}+1}-1}{n_{l}^{N_{\phi}}}
\end{gathered}
$$

where $m_{\sigma}=p / \gamma a=$ normalized support pressure 


$$
\begin{aligned}
& n_{1}=r / a=\text { normalized extent of the plastic zone } \\
& \phi^{*}=\phi-5^{\circ} \\
& N_{\phi}=\tan ^{2}\left(45^{\circ}+\phi / 2\right) \\
& h=\text { excavation depth } \\
& a=\text { shaft radius }
\end{aligned}
$$

Equations 2.9 and 2.10 must be solved simultaneously for any given value of the internal friction angle $(\phi)$ to obtain the normalized support pressure $\left(m_{\sigma}\right)$ and the normalized extent of the yielding zone $\left(n_{1}\right)$ as function of the excavation depth $(h)$. Figure 2.4 shows results obtained for $\phi=30^{\circ}$ and $\phi=41^{\circ}$, representing the extreme values which the angle of internal friction of a sand is likely to assume.

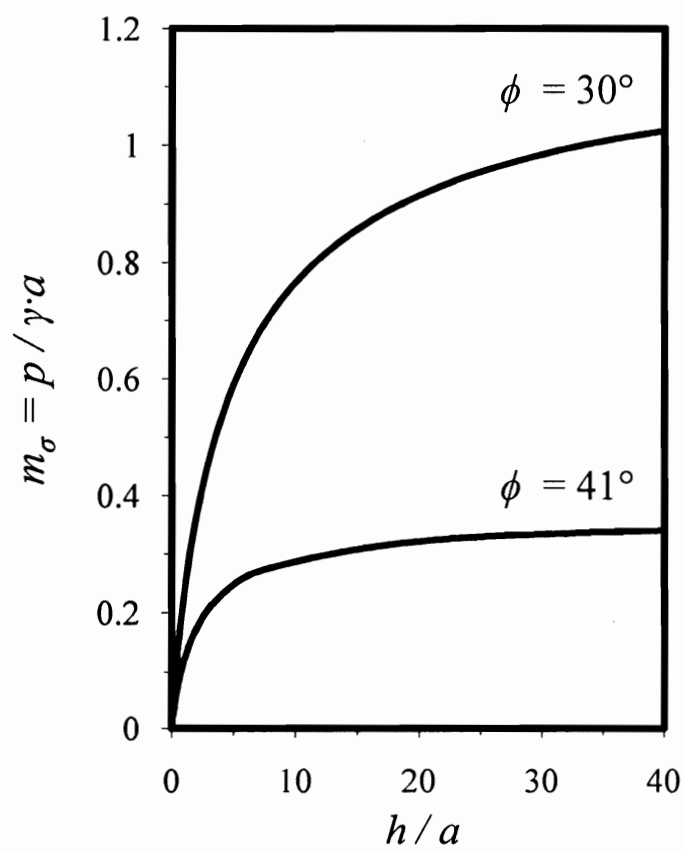

(a)

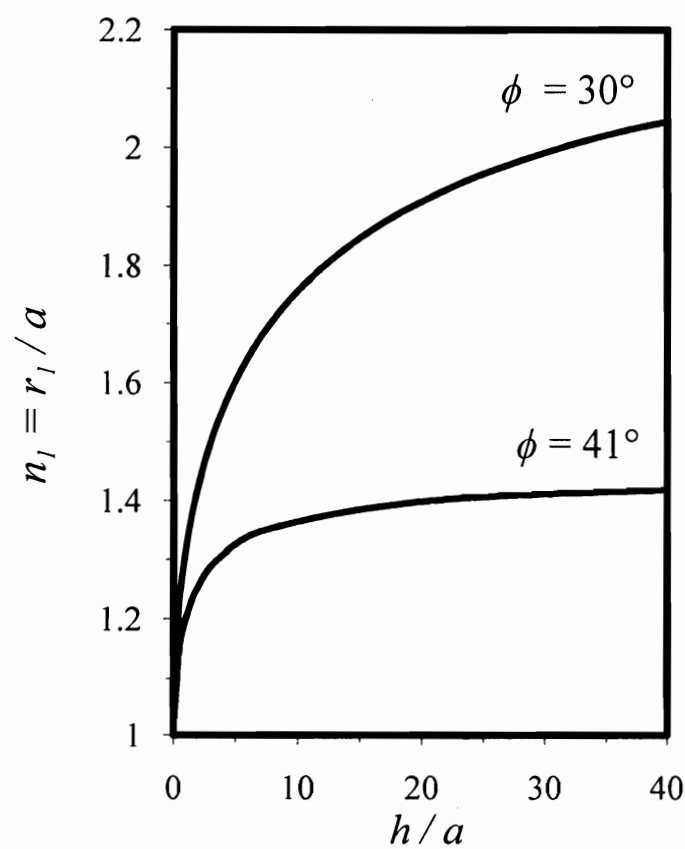

(b)

Figure 2.5 (a) Normalized support pressure versus normalized depth; (b) Normalized extent of the plastic zone versus normalized depth. $(c=0)$ [Adapted from Terzaghi (1943)]

Prater (1977) investigated the earth pressure on shafts using Coulomb wedge theory, which results in a conical sliding surface for axisymmetric conditions. A 
tangential force $T$ with a radial component $F$ in the outward direction was introduced into the analysis as shown in Figure 2.6. The force $T$ is a function of an earth pressure coefficient on radial planes, $\lambda$, which is defined by the stress ratio $\sigma_{\theta} / \sigma_{v}$. Prater argued that $\lambda$ is a decisive parameter whose value should range between $K_{a}$ and $K_{o}$ for realistic axisymmetric results, and not equal to unity as it was implicitly assumed by Terzaghi (1943).
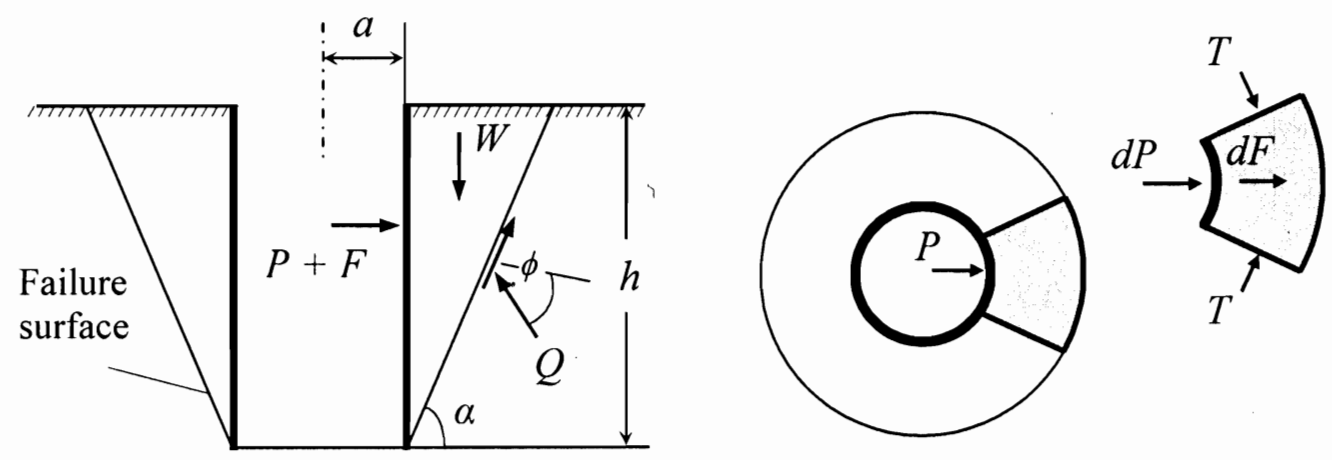

Figure 2.6 Failure surface assumed by Prater and forces acting on the sliding mass [Adapted from Prater (1977)]

As shown in Figure 2.7 for $\phi=41^{\circ}$ and $\mathrm{c}=0$, Prater's theory predicts a zero support pressure at a normalized depth $h / a$ of about 9 . However, this zero pressure did not agree with the experimental results, therefore is considered unreasonable. Prater proposed the use the maximum earth pressure value for design purposes. 


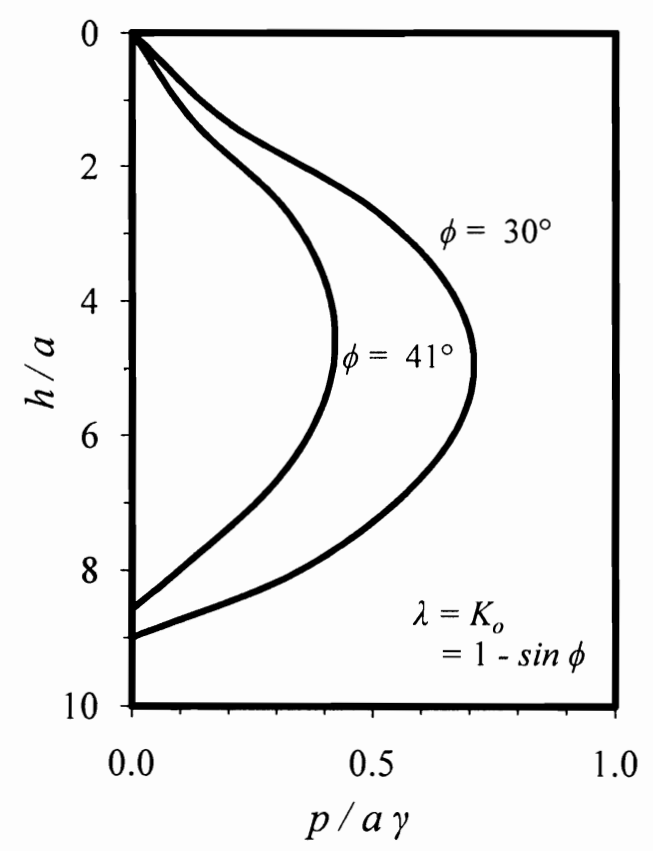

Figure 2.7 Earth pressure distributions for cohesionless soil $(c=0)$ [Based on Prater (1977)]

\section{Slip line method}

Berezantzev (1958) extended the slip line method to calculate the earth pressure acting on vertical cylindrical retaining walls, with horizontal backfill and uniform surcharge as is shown in Figure 2.8. Under axisymmetric conditions, it is necessary to equalize the intermediate stress to either the major or the minor principal stress to statically render the equilibrium equations of stress. This is known as the Kaar-von Karman hypothesis (Yu, 2006). Thus, for active conditions Berezantzev assumed that inside the plastic zone, the tangential stress equalizes the major principal stress ( $\sigma_{\theta}=\sigma_{v}=\sigma_{1}$ and $\sigma_{r}=\sigma_{3}$ ), and to simplify the calculations the slip lines were approximated to be straight lines in the $\mathrm{R}-\mathrm{Z}$ plane. 


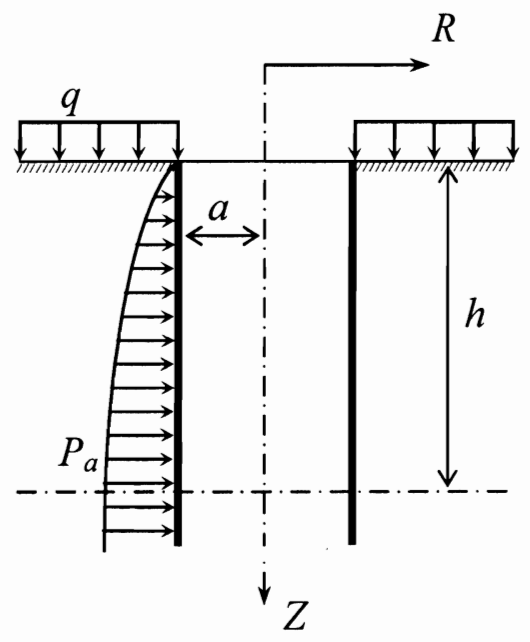

Figure 2.8 Pressure acting on a cylindrical retaining wall [Adapted from Berezantzev (1958)]

Mohr-Coulomb criterion was used as a plastic equilibrium condition, thus the stress governing equations take the form of two hyperbolic partial differential equations. To solve them, Berezantzev used Sokolovski's numerical technique based on finite difference approximation, and obtained equation 2.11 for the active earth pressure on a cylindrical retaining wall. Figure 2.9 shows the normalized pressure distribution versus normalized depth obtained for $\phi=30^{\circ}$ and $\phi=41^{\circ}$.

$$
P_{a}=a \gamma \frac{K_{a}}{\eta-1}\left[1-\left(\frac{a}{r_{b}}\right)^{\eta-1}\right]+q\left(\frac{a}{r_{b}}\right)+\cot \phi\left[\left(\frac{a}{r_{b}}\right)^{\eta} K_{a}-1\right] c
$$

where $P_{a}=$ earth pressure $\left(\mathrm{kN} / \mathrm{m}^{2}\right)$

$$
\begin{aligned}
& a=\text { shaft radius }(\mathrm{m}) \\
& c=\text { cohesion }\left(\mathrm{kN} / \mathrm{m}^{2}\right) \\
& q=\text { external surcharge }\left(\mathrm{kN} / \mathrm{m}^{2}\right) \\
& \gamma=\text { soil unit weight }\left(\mathrm{kN} / \mathrm{m}^{3}\right) \\
& h=\text { excavation depth }(\mathrm{m}) \\
& K_{a}=\tan ^{2}(45-\phi / 2) \\
& r_{b}=a+h \sqrt{K_{a}}
\end{aligned}
$$




$$
\eta=2 \tan (\phi) \tan (45+\phi / 2)
$$

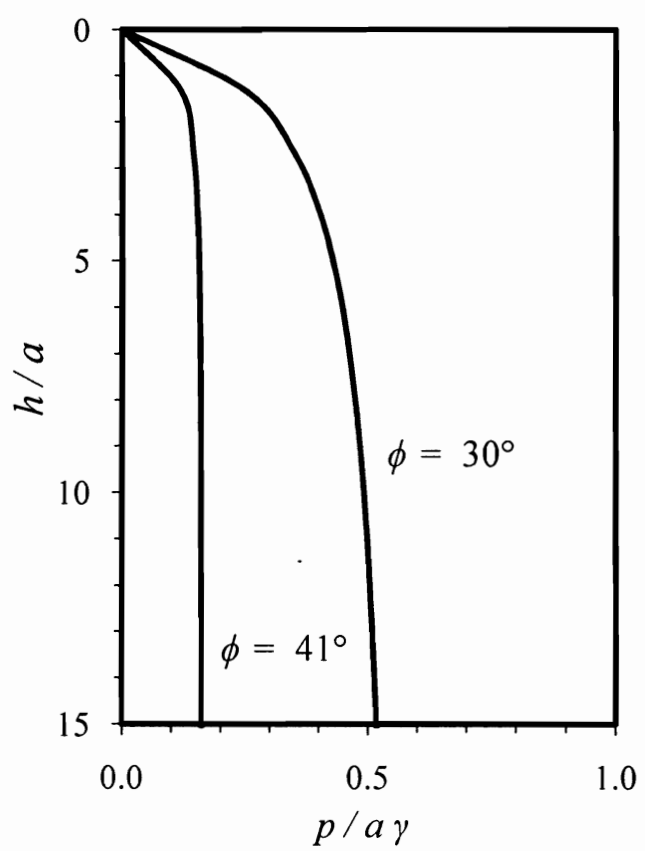

Figure 2.9 Earth pressure distributions using the simplified slip line solution $(c=0)$ [Based on Berezantzev (1958)]

Cheng and $\mathrm{Hu}$ (2005) extended Berezantzev theory by modifying the Kaar-Von Karman hypothesis that originally used a value of $\lambda$ equal to unity. A more general solution was consequently developed by considering the earth pressure coefficient in radial planes, $\lambda$, as a variable. As a result the following expression for the active earth pressure was proposed which is only valid for $0<\eta<0$ and $\phi \neq 0$.

$$
P_{a}=r_{o} \gamma \frac{\sqrt{K_{a}}}{\eta-1}\left(1-\frac{1}{r_{b}^{\eta-1}}\right)+q \frac{1}{r_{b}^{\eta}} K_{a}-\cot \phi\left[\frac{1-\lambda+\eta}{\eta}-\frac{\varepsilon}{r_{b}} K_{a}\right] c
$$

where $\quad P_{a}=$ earth pressure $\left(\mathrm{kN} / \mathrm{m}^{2}\right)$

$$
\begin{aligned}
& r_{o}=\text { shaft radius }(\mathrm{m}) \\
& c=\text { cohesion }\left(\mathrm{kN} / \mathrm{m}^{2}\right) \\
& q=\text { external surcharge }\left(\mathrm{kN} / \mathrm{m}^{2}\right) \\
& \gamma=\text { soil unit weight }\left(\mathrm{kN} / \mathrm{m}^{3}\right)
\end{aligned}
$$




$$
\begin{aligned}
& h=\text { Excavation depth }(\mathrm{m}) \\
& K_{a}=\tan ^{2}(45-\phi / 2) \\
& r_{b}=1+\frac{h}{a} \sqrt{K_{a}} \\
& \eta=\lambda \tan ^{2}(45+\phi / 2)-1 \\
& \varepsilon=\frac{1-\lambda}{\eta} \tan ^{2}(45+\phi / 2)+1
\end{aligned}
$$

It was found that the case of $\lambda$ equal to unity, as assumed by Berezantzev, produced the lowest value of the lateral pressure. Cheng and $\mathrm{Hu}$ (2005) suggested the use of $\lambda=K_{o}=1-\sin (\phi)$ for engineering applications. Therefore the upper and lower bounds of the lateral earth pressure are given by $\lambda=K_{o}$ and $\lambda=1$, respectively. Figure 2.10 shows the results obtained for $\phi=30^{\circ}$ and $\phi=41^{\circ}$.

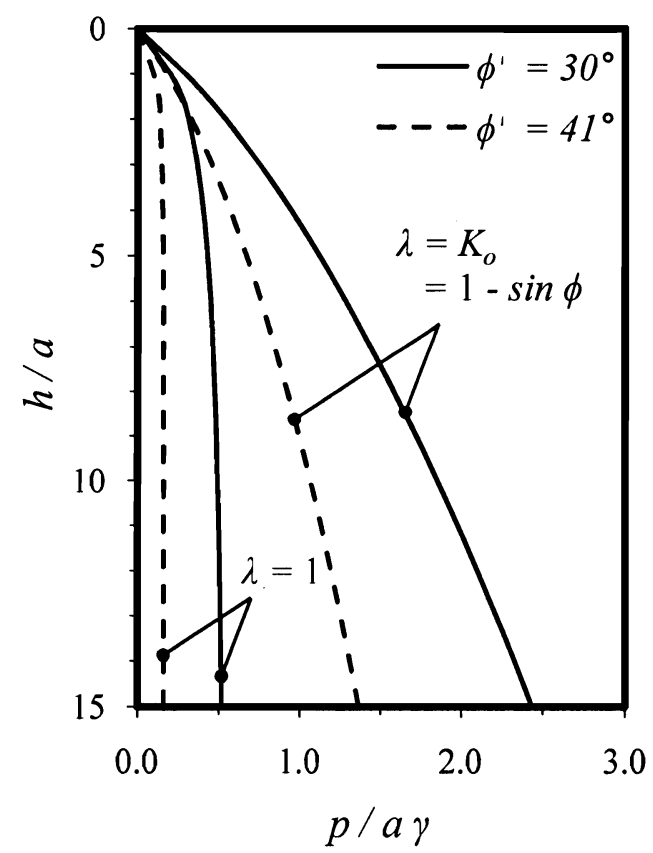

Figure 2.10 Upper and lower bound axisymmetric earth pressures $(c=0)$ [Based on Cheng and $\mathrm{Hu}$ (2005)] 
Cheng et al. (2007) and Liu and Wang (2008) further studied the active earth pressure on a circular retaining structure to derive more generalized solutions using numerical methods. The slope of the backfill, the wall friction and the coupling effects between soil weight, surcharge and cohesion were introduced into the analysis. Cheng et al. (2007) developed a rigorous solution of the characteristic equations using numerical modeling for the shaft shown in Figure 2.11. The results indicated that the pressure distribution obtained using the rigorous solution is always smaller than the one obtained using the simplified solution developed by Cheng and Hu (2005). Liu and Wang (2008) introduced the inclination of the retaining wall into the analysis and the results obtained were always larger than the values obtained using Cheng and Hu's (2005) simplified solution, but the difference was insignificant. Therefore, both investigations concluded that the analytical formula presented by Cheng and $\mathrm{Hu}$ (2005) gives a good approximation of the active pressure for the case of backfill slope angle and wall friction angle both equal to zero.

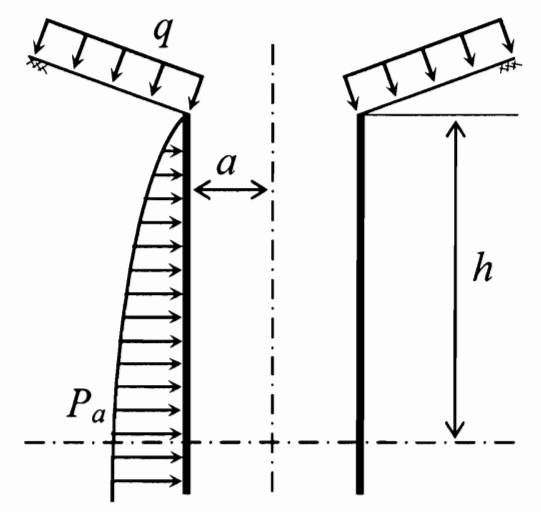

Figure 2.11 Model shaft used in the generalized solution [Adapted from Cheng and $\mathrm{Hu}(2007)]$

Liu et al. (2009) further extended Berezantzev's theory by assuming the value of the coefficient $\lambda$ to decrease linearly across the plastic zone from unity at the shaft lining to $\mathrm{K}_{\mathrm{o}}$ at the elastic-plastic interface. The results obtained are in good agreement with the results reported above. 


\section{c. Semi-analytical solutions}

The foregoing simple methods are based on plasticity considerations where the soil is assumed to be at the yielding state (e.g. Terzaghi (1943), Berezantzev (1958) and Prater (1977)). Thus, the support pressure obtained using these theories correspond to this specific limit state that is usually reached at large wall displacements. However, the amount of movement required is not quantified. To overcome these limitations, Wong and Kaiser (1988) proposed a modification of the convergence-confinement concept used in tunnel design to predict the relationship between support pressures, $p_{i}$, displacement, $u_{s}$, and the extent of the yield zone, $R$.
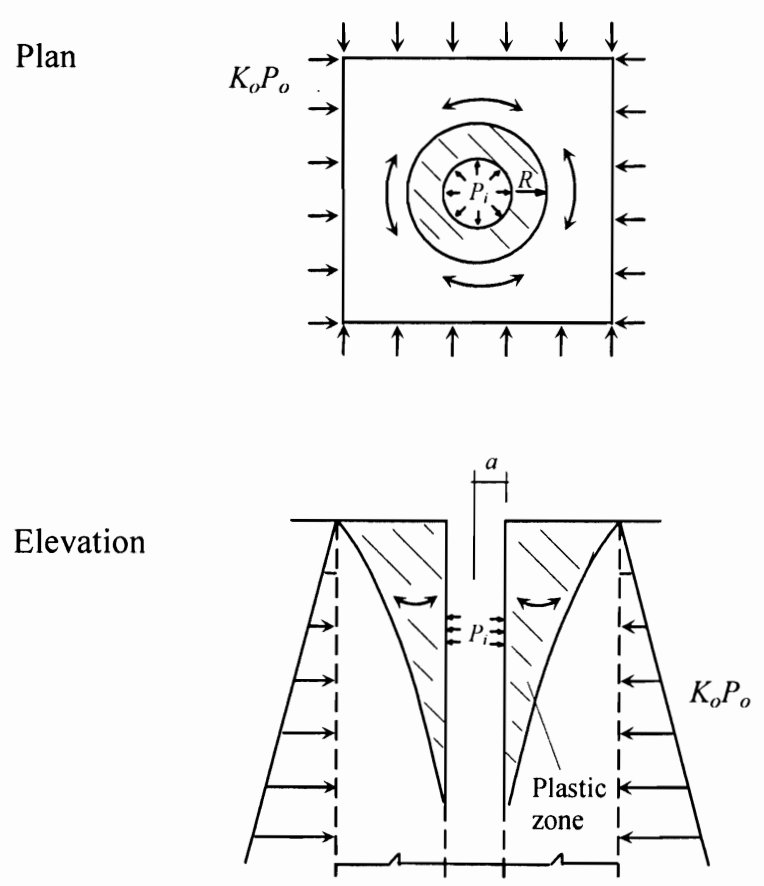

Figure 2.12 Horizontal and vertical arching around a circular shaft [Adapted from Wong and Kaiser (1988)]

The proposed method of analysis consists of separately quantifying the effects of horizontal and vertical arching, and combine them into a pressure envelop that corresponds to a given wall displacement. The horizontal arching is modeled using a twodimensional elastoplastic solution of a circular opening subjected to hydrostatic stress field, and uniform internal pressure, $p_{i}$, as illustrated in Figure 2.12. Since the excavation 
of a shaft can be simulated as a reduction of the internal pressure $p_{i}$ that causes deformation of the surrounding soil, the full relationship between the internal pressure, $p_{i}$, wall displacement, $u_{r}$, and extent of the plastic zone, $R_{p}$, can be obtained as discussed in Section 2.2.a. This relationship is shown in Figure 2.13a which is known as the ground reaction curve (GRC). For a given value of $u_{r}$, the distribution of $p_{i}$ and $R_{p}$ with depth can be obtained, as shown in Figure 2.13b.

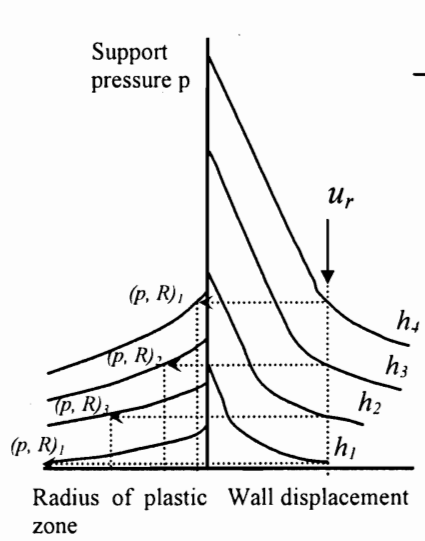

(a)

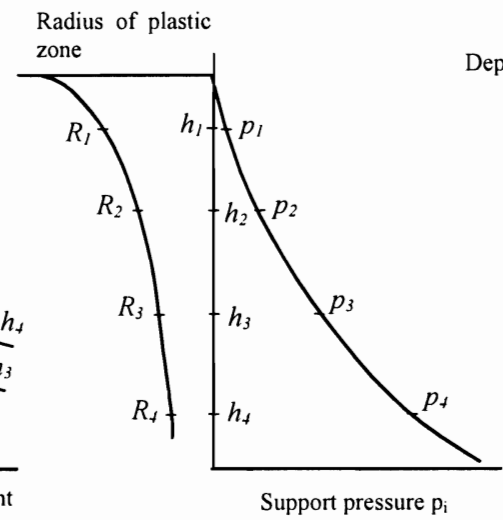

(b)

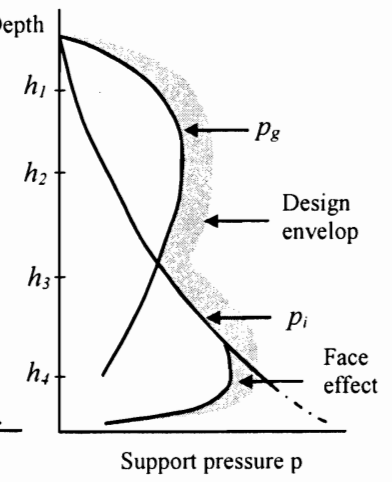

(c)

Figure 2.13 Shaft design method based on Convergence-confinement concept with inclusion of gravity effect. (a) Ground reaction curves (GRC) and extent of the plastic zone due to horizontal arching; (b) Pressure distribution $\left(p_{i}\right)$ from GRC at wall displacement $u_{s}$; (c) Pressure envelope with gravity effect. [Adapted from Wong and Kaiser (1988)]

The vertical arching induced by gravity, once horizontal arching is fully developed, is quantified using plastic equilibrium of the failed soil mass. This gives rise to a lateral support pressure, $p_{g}$, to prevent this mode of instability. Figure 2.13.c shows the earth pressure envelop that arises from combining the horizontal and vertical arching effects.

\section{Comparison of Theoretical Solutions}

Figure 2.14 shows a comparison of the calculated earth pressure distribution along a shaft of radius, $a$, and depth, $h$, using some of the above methods, namely Terzaghi (1943), Berezantzev (1958), Prater (1977) and Cheng and Hu (2005). It can be seen that although all methods predict pressures that are less than the at-rest and active values, the distribution of earth pressure considerable differs. 


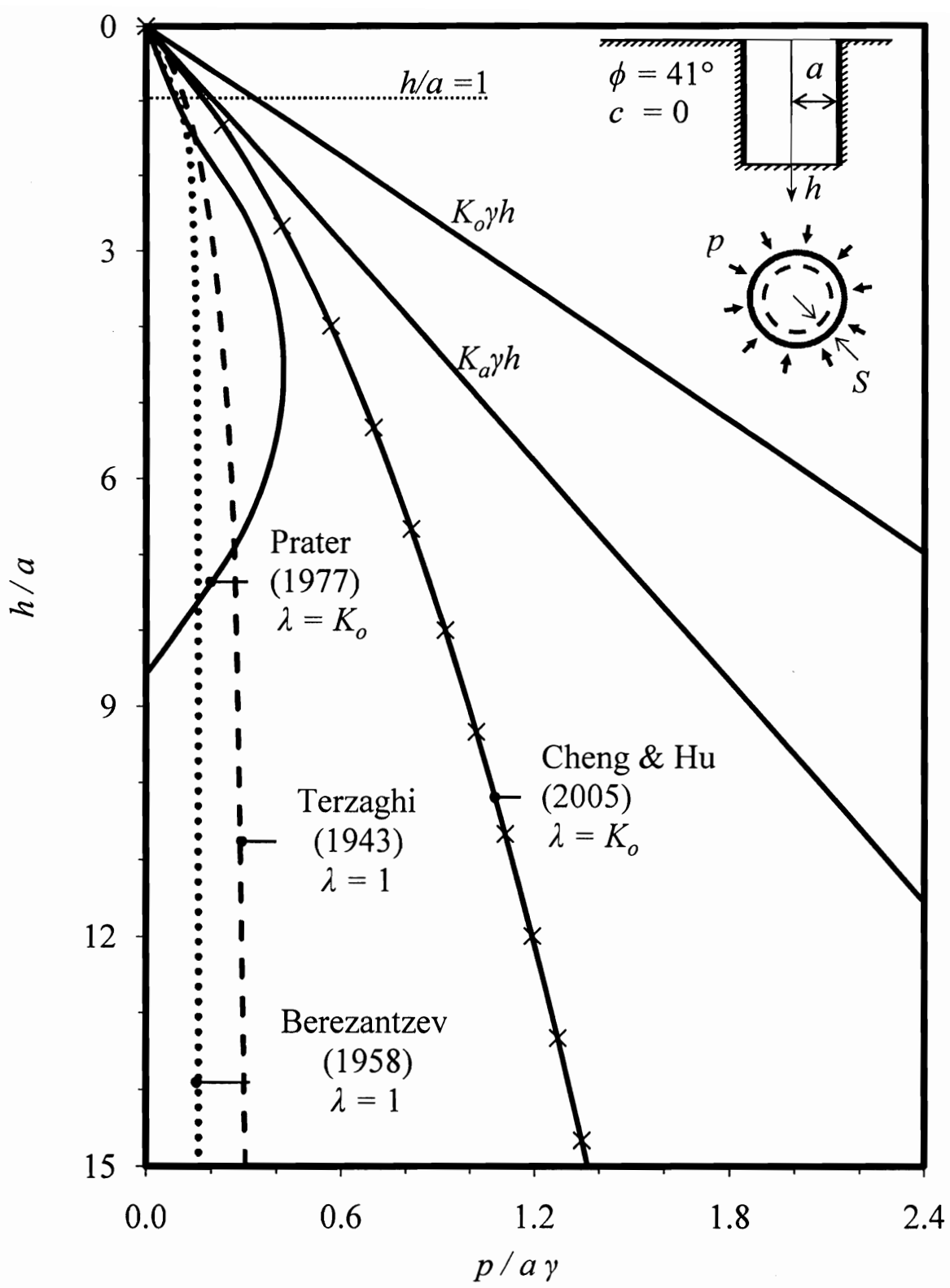

Figure 2.14 Earth pressure distribution using different theoretical methods

As it was analytically proven using Lamé equations, the excavation process causes redistribution of the horizontal stresses around the shaft cavity, i.e. the radial stress decreases while the tangential stress increases. Hence, there are two coefficients of lateral earth pressure for the active condition: One is defined as the ratio of radial stresses acting on circumferential planes, $K=\sigma_{r} / \sigma_{v}$; and the other is defined by the ratio of tangential stresses acting on radial planes, $\lambda=\sigma_{\theta} / \sigma_{v}$. Thus, during shaft construction the initial 
stresses redistribute such that the value of $K_{o}$ decreases until it reaches $K_{a}$, while the value of $\lambda$ increases; then $K_{a}<K_{o}<\lambda$. In this manner, the coefficient $\lambda$ provides a measure of the horizontal arching that has occurred in the soil adjoining the excavation. The following summarizes the observations made on the earth pressure distributions presented in Figure 2.14.

The Terzaghi (1943) and Berezantzev (1958) methods implicitly assume a value of $\lambda$ equal to unity, leading to the lowest distribution of the active earth pressure, as shown in Figure 2.14. This is consistent with the results of limit equilibrium and slip line methods. It is also observed that both distributions reach a constant earth pressure with depth.

Prater (1977) first introduced the parameter $\lambda$ arguing that its value should range between $K_{a}$ and $K_{o}$ to obtain the lower and upper bounds of the lateral earth pressure, respectively. The upper bound is consistent with the conclusions obtained by Cheng and $\mathrm{Hu}$ (2005), however Prater's distribution computes a zero value of the support pressure at some depth, which is inconsistent with experimental results as will be discussed in the next section.

Cheng and $\mathrm{Hu}$ (2005) extended Berezantzev's simplified method to introduce into the analysis any value of the parameter $\lambda$. It was concluded that for engineering purposes, the lower and upper bounds of the lateral earth pressure are given by $\lambda=1$ (Berezantzev's solution) and $\lambda=K_{o}$, respectively. Figure 2.14 shows both distributions; the earth pressure increases with depth for $\lambda=K_{o}$, whereas for $\lambda=1$ it reaches a constant value. It can also be observed that the pressure distributions calculated using Terzaghi's, Berezantzev's and Prater's methods are included into the pressure range calculated using Cheng and Hu method.

Finally, Figure 2.14 also shows that if the depth of the shaft is equal to or less than the shaft radius, the difference between the theoretical active earth pressure on a cylindrical wall and infinitely long wall is insignificant. 


\section{Experimental Investigations}

Several studies have been conducted to measure the earth pressure distribution due to the installation of a model shaft in a granular material. One of the key challenges in developing a shaft apparatus is the ability to simulate the radial deformation of the lining and the associated soil movement during construction. Researchers have developed different techniques to capture these features either during or after the installation of the lining. A description of these techniques and sample of the experimental results are given below.

The experimental techniques that have been used to perform physical modeling of shaft excavation can be grouped into three main categories:

a. Shaft sinking

b. Temporary stabilization of the excavation using fluid pressure (liquid or gas)

c. The use of mechanically adjustable lining

\section{a. Shaft sinking}

The sinking technique consists of advancing a small model caisson equipped with a cutting edge at a recess distance, $S$, from the lining surface. This recess is used to simulate the soil movement induced during excavation.

Walz (1973) investigated the lateral earth pressure against circular shafts using the above technique. The shaft lining consisted of $105 \mathrm{~mm}$ diameter and $630 \mathrm{~mm}$ deep tube composed of twelve steel rings plus a cutting edge ring equipped with a recess ranging from 0 to $5 \mathrm{~mm}$, as shown in Figure 2.15. The soil container used was a cylindrical tub of $1 \mathrm{~m}$ diameter and $1 \mathrm{~m}$ deep filled by pluvial deposition with dry sand. The pluvial deposition technique, or soil raining technique, is used to place the soil on free-fall from a reservoir located at an adjustable height above the test container such that consistent soil densities and placement conditions are obtained through an experimental program. Prior to the filling process, a hollow tube of small diameter was vertically installed across the container. This tube was attached to the cutting edge ring at the soil 
surface, and then pulled downwards using a motor to sink the model shaft, thus the cutting soil inside the shaft fell into the tube simulating the excavation process.
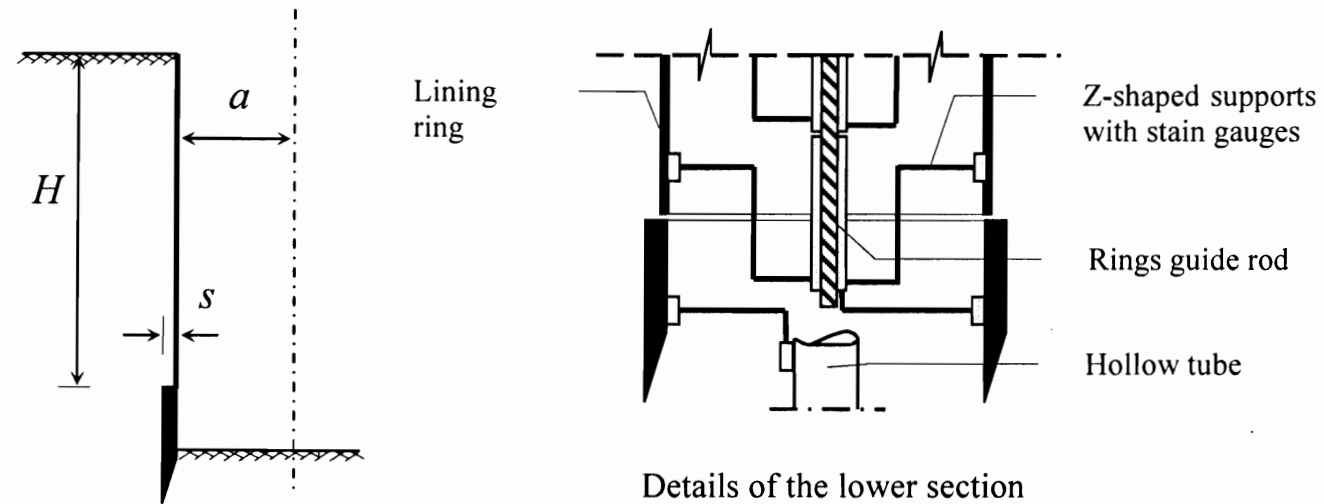

Details of the lower section

Figure 2.15 Model shaft used in the sinking technique [Adapted from Walz (1973)]

The cutting ring was also equipped with a central rod to guide the lining rings during the sinking process. Each lining ring was divided into three equal segments that were kept in position using z-shaped aluminum arms attached to a central piece as shown in Figure 2.15. These z-shaped pieces were equipped with stain gauges, and the entire system was calibrated to directly read the earth pressure acting against the lining. The normalized earth pressure distribution versus normalized depth for $S=0$ and $2 \mathrm{~mm}$ are shown in Figure 2.16. 


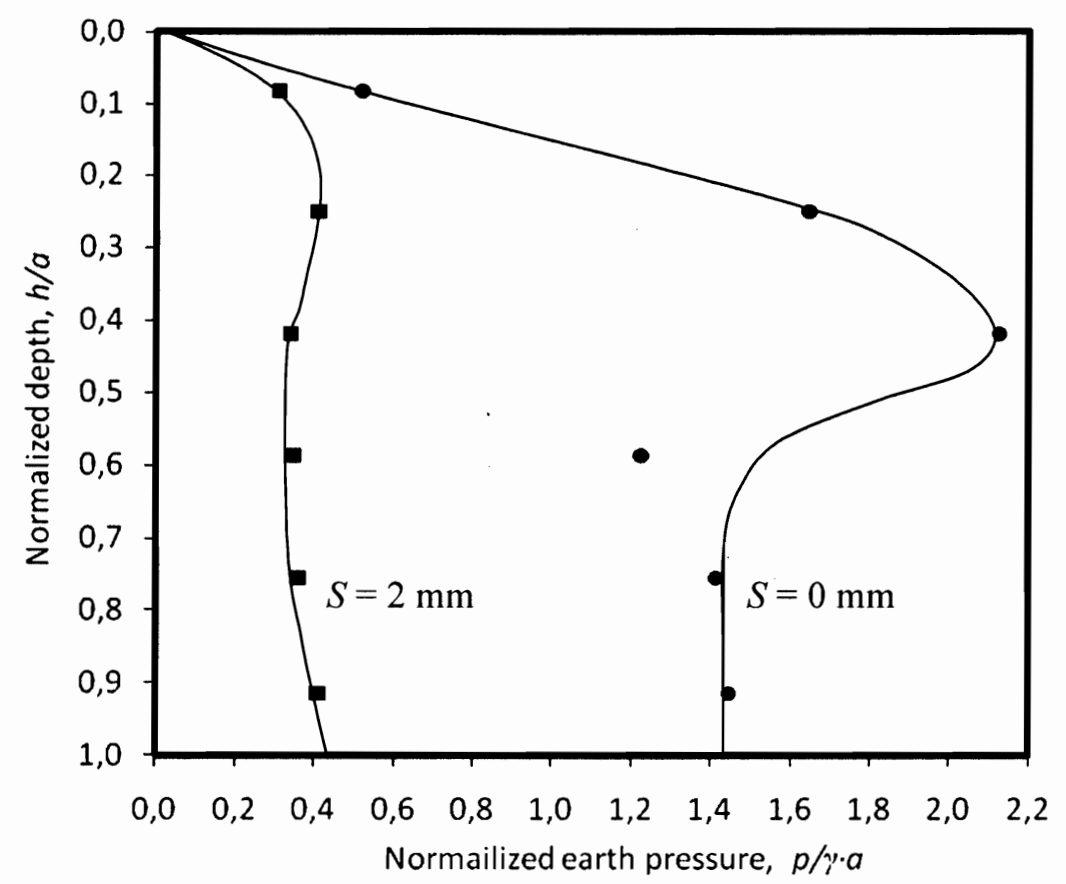

Figure 2.16 Normalized earth pressure distribution versus normalized depth [Adapted form Walz (1973)]

\section{b. Temporary stabilization using fluid pressure}

In this technique, the soil to be excavated is replaced by a flexible rubber bag filled with liquid or gas. The liquid level, or gas pressure, is lowered in stages to simulate the shaft excavation process. This technique is generally used in centrifuge testing due to restrictions in performing an actual excavation during the test.

Lade et al. (1981) conducted a series of centrifuge tests to investigate the lateral earth pressure against shafts in sand. A cylindrical tub of $850-\mathrm{mm}$ diameter and $695-\mathrm{mm}$ deep was used as the test container in which dry fine Leighton Buzzard sand $(\gamma=15.35$ $\left.15.5 \mathrm{kN} / \mathrm{m}^{3}, \phi=38.3^{\circ}\right)$ was placed through pluvial deposition. The lining shaft was formed using a $0.35-\mathrm{mm}$ thick Melinex sheet. The soil inside the shaft was replaced with two different liquids, i.e. a $\mathrm{ZnCl}_{2}$-solution with the same density as the soil outside the shaft and paraffin oil with a density of $7.65 \mathrm{kN} / \mathrm{m}^{3}$, to simulate two lateral pressures on the lining. The excavation process was simulated by removing the liquid in four stages and the liquid level was monitored. The liquid levels, in connection with data recorded 
from eight strain gauges sets installed along the lining, were used to calculate the lateral earth pressure acting on the lining shaft. Earth pressure cells and LVDT's were used to monitor the stresses in the soil around the shaft as well as the surface settlement, respectively. The test setup is shown in Figure 2.17.

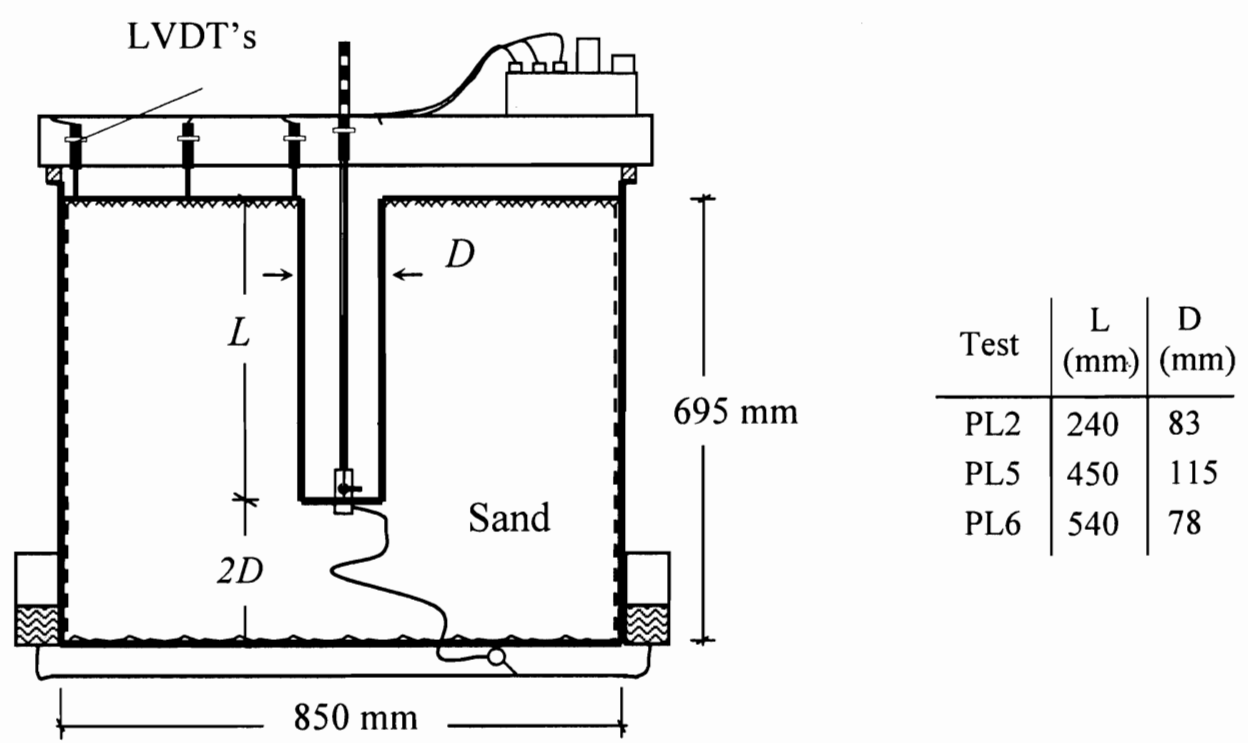

Figure 2.17 Test setup using the flexible liquid bag technique [Adapted from Lade et al. (1981)]

The radial strains in the lining and the normalized earth pressures versus normalized depth, $h / a$, are reproduced in Figure 2.18. Large inward movements at the bottom of the fully excavated shaft were recorded which produced large pressures at this depth, as shown in Figure 2.18. Before the soil 'excavation', expansion of the shaft lining was observed due to larger pressures exerted by the liquid into the shaft than the outside soil. These observations were also made by Kusakabe et al. (1985) in a series of centrifuge tests conducted to investigate the influence of axisymmetric excavation on buried pipes. 

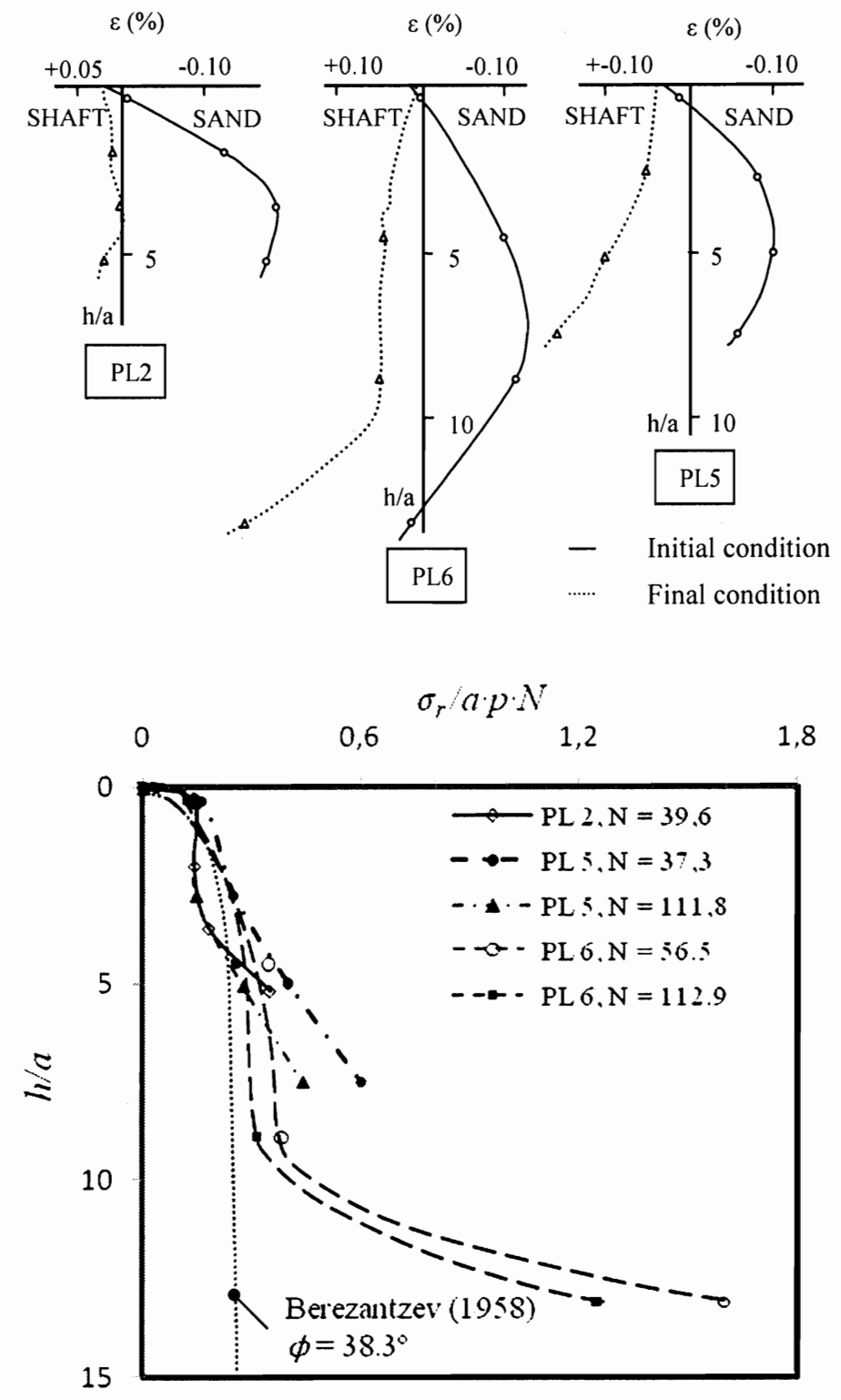

Figure 2.18 Test results for the Radial strains in the Melinex lining and lateral earth pressures versus normalized depth h/a [adapted from Lade et al. (1981)]

Konig et al. (1991) carried out a series of centrifuge test to study the effects of the shaft excavation advancement on the already installed lining. The model shaft consisted of two sections: an upper section made of a rigid tube to simulate the installed lining, and a lower section made of rubber membrane to model the unsupported area of the excavation. At the initial condition, the membrane was pressurized with air to equilibrate the pressure exerted by the soil that consist of dry sand with $\phi=36.5^{\circ}$ and $\gamma=$ 
$1.67 \mathrm{kN} / \mathrm{m}^{3}$. Hence to simulate the shaft face advance, the air pressure was reduced in small steps. The lateral movement of the rubber membrane was monitored using LVDT's embedded in the sand; the stresses in the shaft lining were monitored using strain gauges installed at different distances from the end of the lining. An overview of the test setup and detail of the unsupported excavation model can be seen in Figure 2.19.
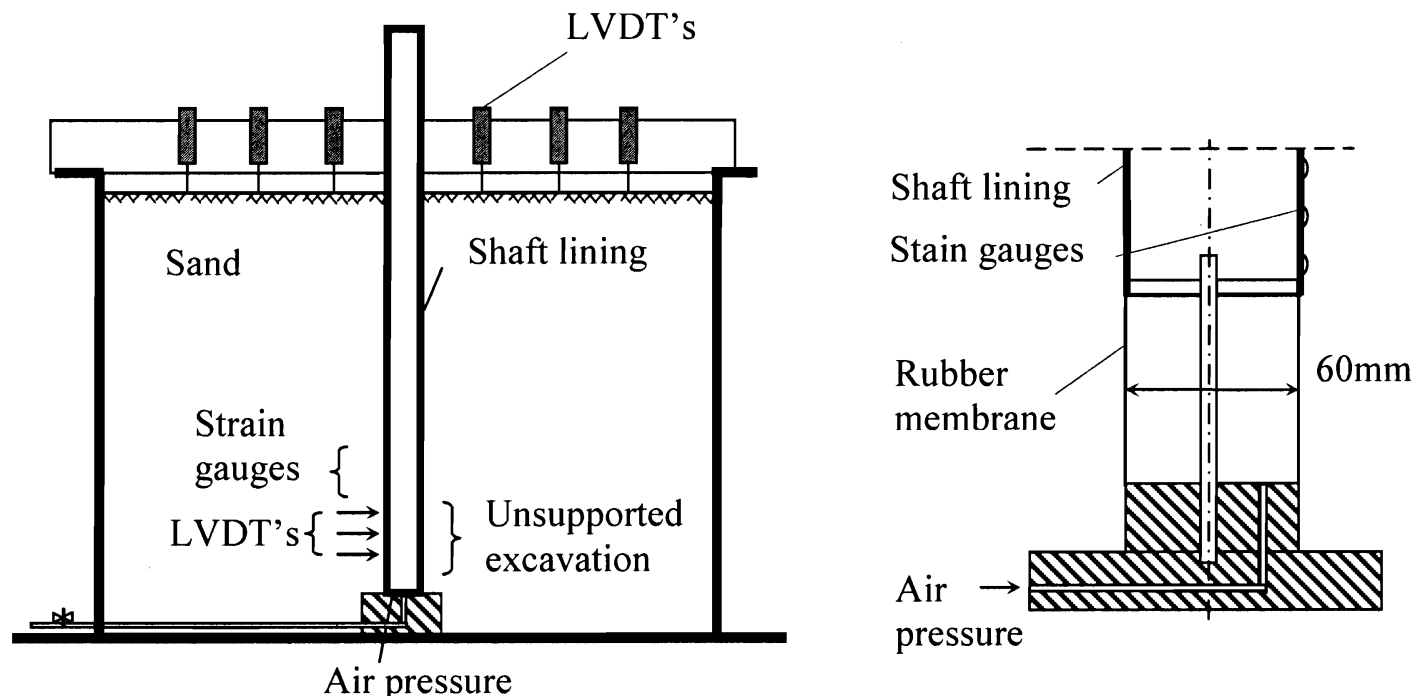

Figure 2.19 Overview of the test setup using the flexible air bag technique [Adapted from Konig et al. (1991)]

\section{c. Mechanically adjustable device}

In this technique, a mechanical mechanism is used to uniformly translate a rigid shaft lining simulating the soil displacement that may occur during the excavation process. Through this technique, it is possible to impose a homogeneous radial displacement along the entire shaft length at a controlled rate. However, a mechanism to model a shaft lining that uniformly moves inwards is not easy to achieve. Alternatively researchers have adopted simplified model shafts that either simulates an approximated prototype radial displacement of the shaft lining (Fujii et al., 1994; Imamura et al., 1999), or takes advantage of the radial symmetry to model only a portion of the problem (Herten and Pulsfort, 1999; Chun and Shin, 2006). To the best of the author's knowledge, an 
appropriated mechanism, which allow for the modeling of the full axisymmetric radial displacements of a shaft lining, has not yet been developed.

Using a mechanically adjustable shaft model, Fujii et al. (1994) conducted a series of centrifuge tests to study the effects of wall friction and soil displacements on the earth pressure distribution around rigid shafts. The lining shaft was made of an aluminum cylinder, $60 \mathrm{~mm}$ in diameter, split in two semi-cylinders; one of them was instrumented with small stress transducers and moved horizontally to simulate an approximated radial displacement of the shaft lining. The instrumented lining section was horizontally moved using a simple mechanism activated using a motor. It consisted of two disks attached to an axial rod such that as the axial rod was vertically moved, the disks slid on tampers (See Figure 2.20) moving inwards the instrumented semi-cylinder. Details of the apparatus are shown in Figure 2.20 (right).
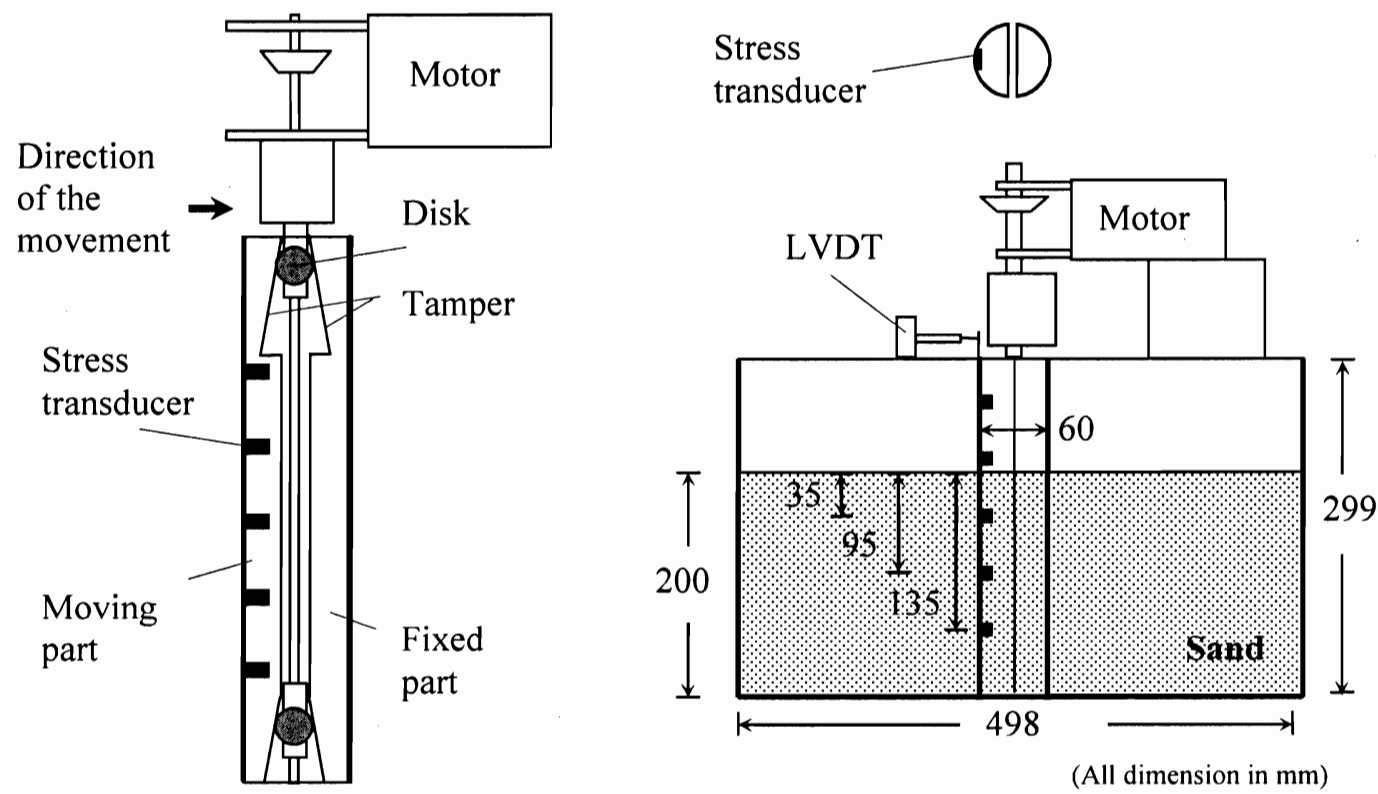

Figure 2.20 Semi-cylinder shaft model [Adapted from Fujii et al. (1994)]

The model shaft was placed into a rectangular soil container and buried with Toyoura dry sand through pluvial deposition up to $200-\mathrm{mm}$ of height, $H$. Four tests were conducted for different densities and wall friction conditions. The measured earth 
pressure versus normalized depth for dense packing $\left(\phi=42^{\circ}, \gamma=14.7 \mathrm{kN} / \mathrm{m}^{3}\right)$ and different wall friction is shown in Figure 2.21. The results showed good agreement with the theoretical values of Berezantzev (1958). Little change in the measured earth pressure was reported at displacements greater than $1 \%$ of the wall height $(6.6 \%$ of the shaft radius). The effect of wall friction was found to have a minor effect on the earth pressure distribution.

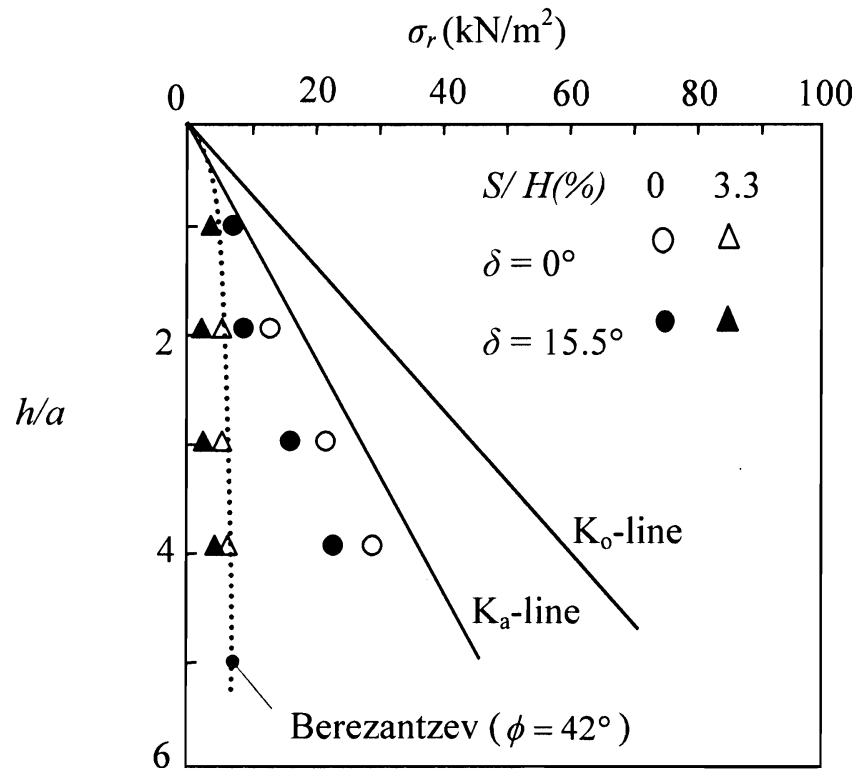

Figure 2.21 Earth pressure versus normalized depth for smooth and rough wall [Adapted from Fujii et al. (1994)]

Imamura et al. (1999) developed a model shaft similar to the one used by Fujii et al. (1994), but the instrumented semi-cylinder was moved horizontally using an external mechanism attached to a motor. The lining shaft was considered to be rigid with dimensions of $120 \mathrm{~mm}$ in diameter and $500 \mathrm{~mm}$ deep.

Air-dried Toyoura sand with $\phi=42^{\circ}$ and $\gamma=15.2 \mathrm{kN} / \mathrm{m}^{3}$ was used during the four centrifuge tests conducted to study the development of the active earth pressure around shafts and the extent of the yield zone. The results of the change in earth pressure distribution versus normalized depth at various wall displacement values are shown in Figure 2.22. It was concluded that the earth pressure decreases with increasing wall 
displacement until it coincided with Berezantzev's solution at a wall displacement that corresponds to $0.2 \%$ of the wall height (1.6\% of the shaft radius). The maximum extent of the yielding zone was found to be approximately 0.7 times the shaft diameter from the lining, and developed locally along the shaft lining.

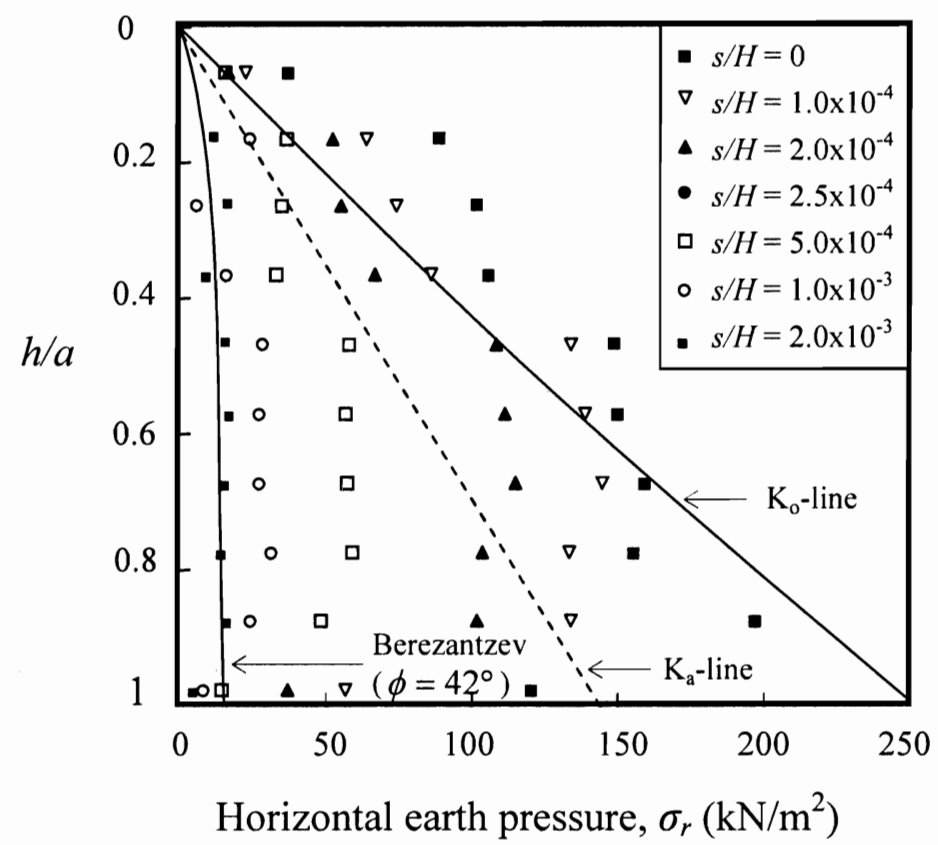

Figure 2.22 Active earth pressure distribution versus normalized depth for a prototype model $50 \mathrm{~m}$ deep [Adapted from Imamura et al. (1999)]

Herten and Pulsfort (1999) took advantage of the radial symmetry of the problem and modeled only one quadrant of the shaft. The test setup consisted of one quarter of a cylindrical shaft, $40 \mathrm{~cm}$ in diameter and $100 \mathrm{~m}$ long, that was placed along one corner of a rectangular box of $100 \times 100 \mathrm{~cm}$ in plan and $120 \mathrm{~cm}$ high. To minimize the wall friction, the walls of the box were lubricated using Teflon film and oil. The test container was filled through pluvial deposition of dry fine sand, with $\phi=41^{\circ}$ in a dense state ( $36 \%$ porosity). The shaft lining was moved horizontally using a motor to simulate radial displacement of the shaft. Details of the setup configuration can be seen in Figure 2.23 . 


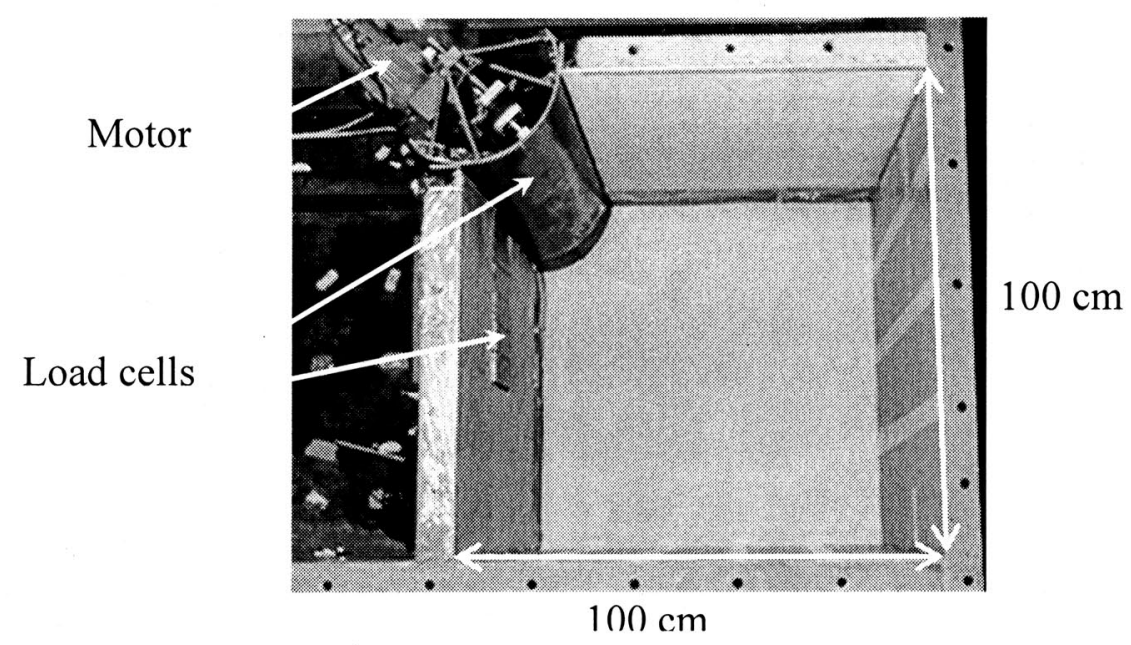

Figure 2.23 Quarter-of-cylinder model shaft [Adapted from Herten and Pulsfort (1999)]

The measured earth pressures on the shaft for one of the four tests conducted are shown in Figure 2.24. It was reported that little change in the measured lateral earth pressure occurred at wall displacements greater than $0.05 \%$ of the wall height $(0.25 \%$ of the shaft radius).

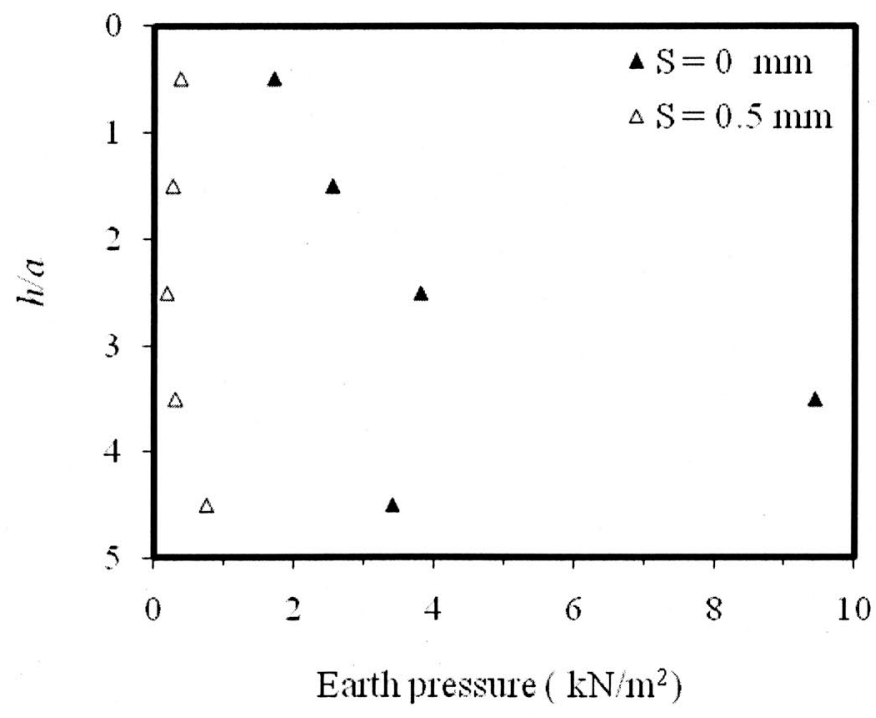

Figure 2.24 Measured earth pressure versus depth at various wall displacement values [Adapted from Herten and Pulsfort (1999)]

Chun and Shin (2006) conducted model tests to study the effects of wall displacement and shaft radius on the earth pressure distribution using a mechanically 
adjustable semi-circular shaft. The shaft lining was made from an acrylic semi-cylinder that was cut longitudinally into three equal segments, i.e. each segment extended an angle of $60^{\circ}$, to accommodate the changes in diameter during testing. Transversally, the shaft was divided into five equal segments; some of them were used as sensitive areas for installing load cells behind the lining. Figure 2.25 shows a schematic of the model shaft developed.

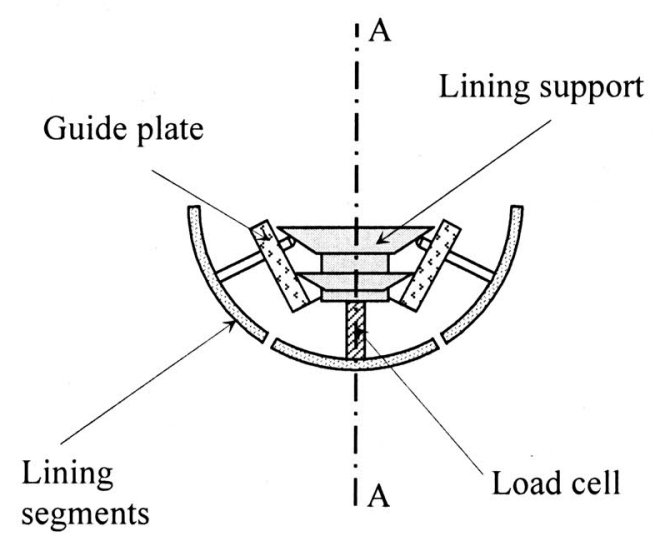

(a)

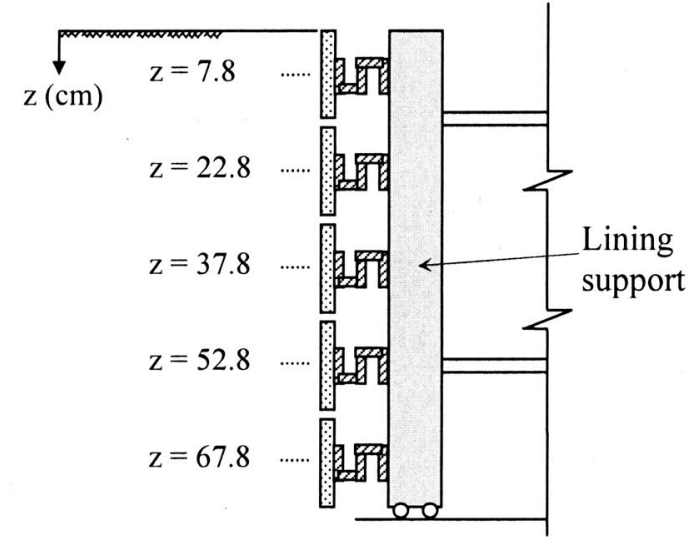

Cross section A-A

(b)

Figure 2.25 Schematic of the semi-cylinder model shaft [Adapted from Chun and Shin (2006)]

All lining segments were attached to a lining support such that the central segments served as sensitive areas for five load cells and the side segments were attached through rods to guide plates. These rods slid on the milled corners of the lining support such that the horizontal movement was transmitted to the lining segments as radial movement (Figure $2.25 \mathrm{a}$ ). The soil container used was a rectangular box, $0.7 \mathrm{~m}$ wide, 1 $\mathrm{m}$ long and $0.75 \mathrm{~m}$ deep, filled with dry sand $\left(\phi=41.6^{\circ} ; \gamma=16.4 \mathrm{kN} / \mathrm{m}^{3} ; \mathrm{D}_{\mathrm{r}}=81 \%\right)$ through pluvial deposition. Three different shaft radii, $a$, equal to $0.175,0.15$ and 0.115 $\mathrm{m}$, and constant depth, $H=0.75 \mathrm{~m}$, were tested. The reported earth pressure versus depth at various wall displacements for a smooth shaft and $h / a$ equals 4.3 are presented in Figure 2.26. The results indicated that earth pressure decreases with increasing wall movement and reached a minimum value for wall movement of 0.6 to $1.8 \%$ of the wall 
height $(0.15-0.4 \%$ of the shaft radius). It was also concluded that soil failure extended a distance of approximately one shaft radius from the outer perimeter of the shaft.

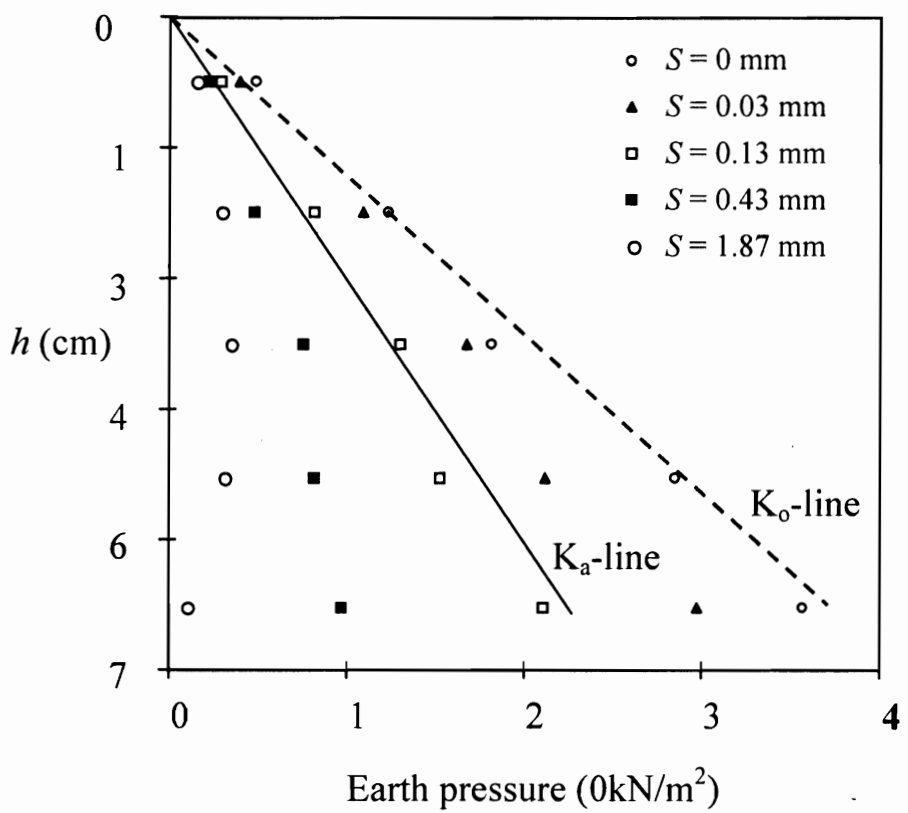

Figure 2.26 Measured earth pressure versus depth at various wall displacement $(h / a=4.3)$ [Adapted from Chun and Shin (2006)]

\section{Comparison of Experimental Modeling Techniques}

Table 2.1 summarizes some of the advantages and disadvantages of the experimental techniques used for shaft modeling as discussed in the previous section. 


\begin{tabular}{|c|c|c|}
\hline METHOD & ADVANTAGES & DISADVANTAGES \\
\hline $\begin{array}{c}\text { A. } \\
\text { SHAFT SINKING }\end{array}$ & $\begin{array}{l}\text { Suitable for modeling shafts } \\
\text { constructed using the sinking } \\
\text { technique. }\end{array}$ & $\begin{array}{l}\text { - Causes soil disturbance and } \\
\text { densification. } \\
\text { - High shear stresses can develop } \\
\text { along the shaft. } \\
\text { - Difficult to separate the effects of the } \\
\text { shear stresses along the wall and the } \\
\text { lateral earth pressure on the wall. }\end{array}$ \\
\hline $\begin{array}{c}\text { B. } \\
\text { PRESSURIZED } \\
\text { BAG }\end{array}$ & $\begin{array}{l}\text { - Can be used to simulate shaft } \\
\text { excavation schemes under } 1 \mathrm{~g} \\
\text { and centrifuge conditions. }\end{array}$ & $\begin{array}{l}\text { - Applicable for flexible shaft lining } \\
\text { models. }\end{array}$ \\
\hline Liquid bag & $\begin{array}{l}\text { - Easy to simulate the initial } \\
\text { hydrostatic state of stresses. } \\
\text { - Can simulate the excavation } \\
\text { advance process. }\end{array}$ & $\begin{array}{l}\text { - Under centrifuge conditions, the } \\
\text { liquid inside the bag may exert more } \\
\text { pressure than the soil outside. } \\
\text { - Large inward deformations may } \\
\text { occur at the bottom of the } \\
\text { unsupported excavation. }\end{array}$ \\
\hline Air bag & $\begin{array}{l}\text { - Flexibility to readjust the air } \\
\text { pressure in the bag during } \\
\text { testing. } \\
\text { - Good for modeling small } \\
\text { sections of the excavation. }\end{array}$ & $\begin{array}{l}\text { - The same pressure is imposed along } \\
\text { the model shaft based on the average } \\
\text { theoretical value. } \\
\text { - Does not simulate the excavation } \\
\text { advance with depth. }\end{array}$ \\
\hline $\begin{array}{c}\text { C. } \\
\text { MECHANICALLY } \\
\text { ADJUSTABLE } \\
\text { LINING }\end{array}$ & $\begin{array}{l}\text { - Easy to model a translation } \\
\text { displacement of the shaft } \\
\text { wall. } \\
\text { - Can be used under } 1 \mathrm{~g} \text { or } \\
\text { centrifuge conditions. } \\
\text { - Facilitate the installation of } \\
\text { pressure cells behind the } \\
\text { lining. }\end{array}$ & $\begin{array}{l}\text { - Only for rigid lining models. } \\
\text { - Generally involve an } \\
\text { oversimplification of the problem } \\
\text { geometry or the radial displacement } \\
\text { of the soil around the shaft to } \\
\text { simplify the mechanism. } \\
\text { - Does not simulate the excavation } \\
\text { advance. }\end{array}$ \\
\hline
\end{tabular}

Table 2.1 Advantages and disadvantages of the experimental techniques used for shaft modeling 
The mechanically adjustable lining technique was mainly used to investigate the relationship between the earth pressure on the shaft wall and the wall displacement. As discussed earlier, to simplify the mechanism of the shaft apparatus, the physical models have generally involved approximation of either the prototype radial displacement around the shaft, or the problem geometry. The experimental results obtained using the different mechanically adjustable models are summarized in Table 2.2 It can be seen that no agreement was reached among researchers as to the required wall movement to reach the active condition of cohesionless soils around shafts. 


\begin{tabular}{|c|c|c|c|}
\hline PROTOTYPE & MODEL & $\begin{array}{l}\text { WALL MOVEMENT (S) } \\
\text { TO REACH ACTIVE CONDITION }\end{array}$ & SOIL \\
\hline$\uparrow 1$ & $\begin{array}{c}\text { Semi-cylinder } \\
\text { (non-segmented) }\end{array}$ & $\begin{array}{l}\text { - Fujii et al. (1994) } \\
\qquad \begin{aligned} S^{*} \geq 1 \% H^{* *} \\
\text { or } \\
$\[ \geq 6.6 \% a^{* * *} \]$\end{aligned} \\
\text { - Imamura et al. (1999) } \\
\qquad \begin{aligned} S & =0.2 \% H \\
& \text { or } \\
S & =1.6 \% a\end{aligned}\end{array}$ & Dense sand \\
\hline & $\begin{array}{l}\text { Quarter cylinder } \\
\text { (non-segmented) }\end{array}$ & $\begin{array}{l}\text { - Herten and Pulsfort (1999) } \\
\qquad \begin{aligned} S & =0.05 \% H \\
& \text { or } \\
S & =0.25 \% a\end{aligned}\end{array}$ & Dense sand \\
\hline & $\begin{array}{l}\text { Semi-cylinder } \\
\text { (Segmented) }\end{array}$ & $\begin{array}{l}\text { Chun and Shin (2006) } \\
\begin{aligned} & 0.6 \% H<S<1.8 \% H \\
& \text { or }\end{aligned} \\
0.15 \% a<S<0.4 \% a\end{array}$ & Dense sand \\
\hline
\end{tabular}

Table 2.2 Comparison of the displacement necessary to reach the active condition using different mechanically adjustable models 


\section{CHAPTER 3}

\section{EXPERIMENTAL PROGRAM}

\section{Introduction}

An experimental program was conducted under $1 \mathrm{~g}$ conditions to study the development of the active earth pressure on cylindrical walls in dry sand. A model shaft that reproduced the full axisymmetric configuration was developed using mechanically adjustable lining segments. The initial and progressive changes in earth pressure along the shaft were measured for different radial wall displacement. The shaft was $150 \mathrm{~mm}$ in diameter and $1025 \mathrm{~mm}$ long, and was placed into a cylindrical concrete tank to contain the soil as shown in Figure 3.1. Details of the model shaft developed and the experimental procedure are discussed in this chapter.

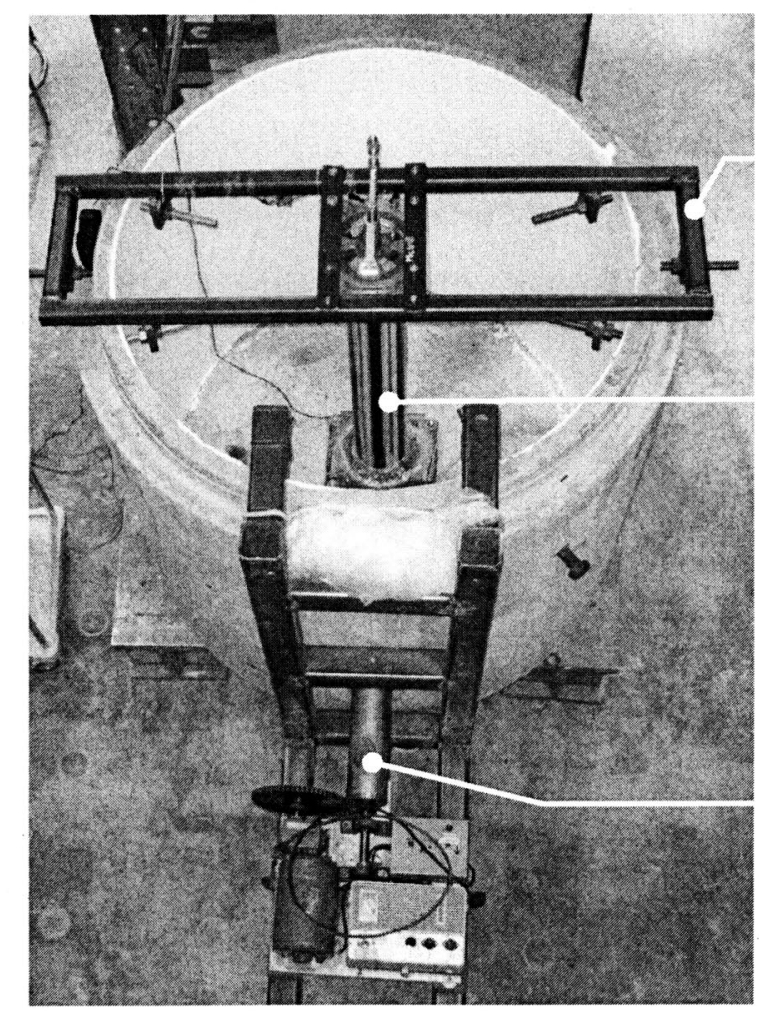

Steel frame

Shaft model

Sand auger system

Figure 3.1 Overview of the experimental setup. 


\section{Experimental Setup}

\section{a. Concrete tank}

The test container selected is a cylindrical concrete tank, as it provides the axisymmetric geometry and the rigidity needed to contain the large volume of sand used in the experiment. The inner dimensions of the concrete tank are $1220 \mathrm{~mm}$ diameter, $1070 \mathrm{~mm}$ in depth, with a wall thickness of $127 \mathrm{~mm}$. The interior of the tank was smoothened and painted to eliminate friction and create a sliding boundary for the sand. In addition the tank diameter was chosen to ensure a minimum distance of seven times the shaft diameter from the outer perimeter of the shaft to the tank wall. Based on the literature review, this was considered necessary to minimize the effect of the rigid boundaries on the measured earth pressures along the shaft. To facilitate the removal of the sand after each test, the tank was equipped with a circular hole (150 $\mathrm{mm}$ in diameter) located at the base, on one side of the tank. A sand auger powered by an AC motor was used after the completion of the tests to accelerate the sand removal process. This system was supported using a steel frame located outside the tank and hooked to the tank wall, as shown in Figure 3.1. The above system facilitated test repetition within a reasonable time frame.

\section{b. Model shaft}

The model shaft developed is a mechanically controlled lining that modeled the full axisymmetric configuration of the shaft. It consisted mainly of 6 curved steel segments cut longitudinally from a rigid steel tube, $6 \mathrm{~mm}$ of wall thickness. The segments were machined at both ends to fit into segment holders which were attached using steel hinges to hexagonal nuts as shown in Figure 3.2. These nuts pass through a central threaded rod extended through the shaft axis. The central rod consisted of right hand and left hand threaded rods joined by a collar. The basic mechanism that contracts the diameter of the apparatus is quite simple; when the axial rod is rotated, the nuts move vertically pulling the segment holders radially inwards. This process leads to an inward movement of the lining segments and consequently the shaft diameter decreases 
uniformly. The details of the model shaft are shown in Figure 3.2. A brief review of the apparatus components and other important details of the mechanism follow.

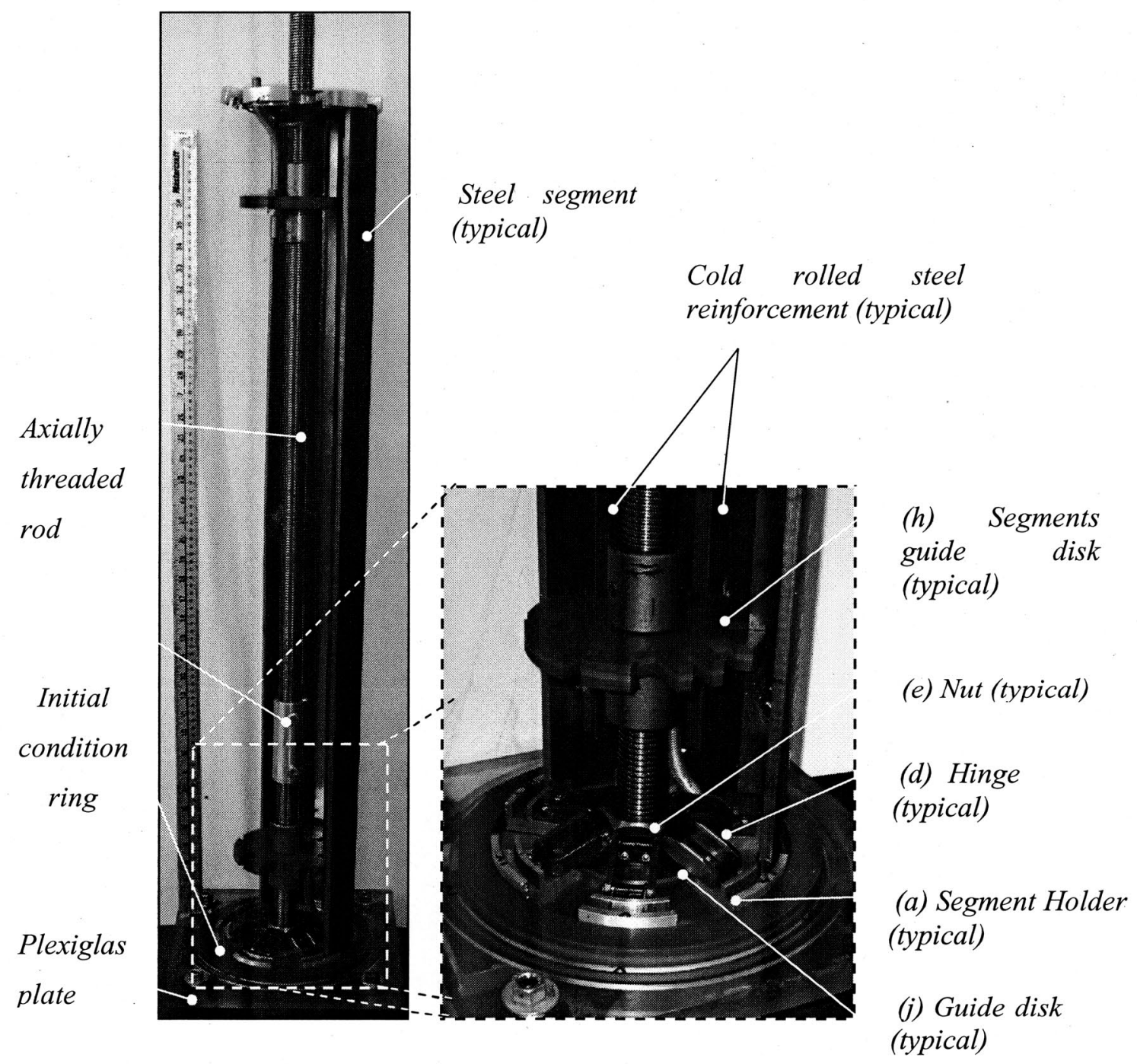

Figure 3.2 Model shaft during assemblage showing details of a typical end section.

The model shaft consisted of a typical section that is symmetrically repeated at both extremes of the apparatus connected through an axially threaded rod as shown in the general view in Figure 3.2. Each end section consisted of: six segment holders (a), six hinges $(d)$, one hexagonal nut $(e)$, one segments guide disk $(h)$, guide disk $(j)$, one antirotational rod $(i)$, one initial condition ring $(k)$ and one Plexiglas plate $(l)$. A brief description of the apparatus components and their role follows. 
- Steel segments (a): Six curved steel segments, 680-mm wide and 1035-mm length, compose the shaft lining. They were cut from a steel pipe with a 4 "outer diameter and $1 / 4$ " wall thickness. To avoid inward bulging of the lining shaft, the segments were reinforced using cold rolled steel strips along the inner part of each segment, as can be observed in Figures 3.2 and 3.3. These steel strips, in conjunction with the segment guide disks $(h)$, were used further to prevent radial rotation of the lining during diameter changes as explained below.

- Segment holder (b): The elevation/cross-section view of the segment holder had the shape of a rotated letter $\mathrm{F}$ (Figure 3.3). It was a key element for the diameter change mechanism performing three important functions: To keep the steel segments in vertical position, and to move and guide them during diameter changes keeping the cylindrical shape of the shaft model. There were six segment holders at each end of the apparatus installed such that each lining segment rested on two segment holders as shown in Figure 3.3 .

- Shims (c): Shims bent from gauge steel strips were used to cover the spaces between the lining segments. They were placed on the outer surface of the lining overlapping the steel segments such that one of the edges of each shim was fixed to one of the lining segments, whereas the other edge was free to slide over the lining segment. This compensated for the difference in circumference between the initial and final shaft diameter.

- Hinges (d) and nut (e): At each end of the apparatus, six segment holders were attached using steel hinges to hexagonal nuts as shown in Figure 3.4. The nuts passed through the axially threaded rod and were allowed to move only vertically. 
(c) Six shims

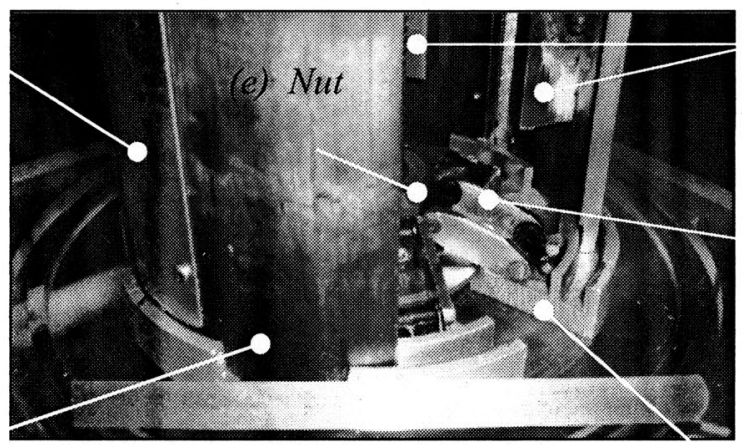

Cold rolled steel

reinforcement

(Typical)

(d) Six hinges

(Typical)

(a) Six steel segments

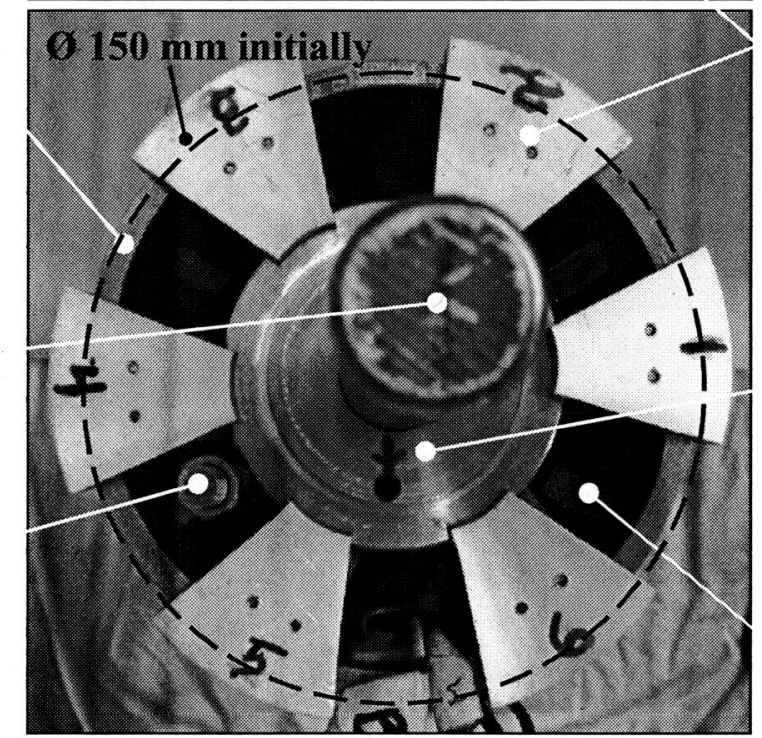

(b) Six Segment

holders (Typical) threaded rod

(i) Antirotational rod (Typical)
(j) Guide disk (Typical)
holders (Typical)

(Typical)

Cold rolled steel reinforcement (Typical)

Figure 3.3 Details of the lower-end section during assemblage (above); Details of the upperend section during assemblage (below)

- Axial threaded rod $(f)$ : It consisted of right hand and left hand threaded steel rods joined by a collar $(g)$. This combination of threaded rods was required to simultaneously move the nuts in opposite directions when the axial rod was rotated. The axial rod was only allowed to rotate around itself; its vertical movement was restricted by confining collars located on the Plexiglas plates.

- Segments guide disks (h): This piece restricted the horizontal path followed by the lining segment during diameter reduction of the apparatus keeping them from sliding out of the segment holders. Therefore, the disks were manufactured such that the steel reinforcing strips inside the lining segments fit perfectly into the slots in the segment guide disk as shown in Figure 3.4. Two holding collars fixed the segment guide disk 
vertically, while an antirotational rod (i) kept it from rotating (Figure 3.3 and 3.4). The guide disks facilitated the assembly of the apparatus, and provided a mechanical limit for the mechanism avoiding a system overload.

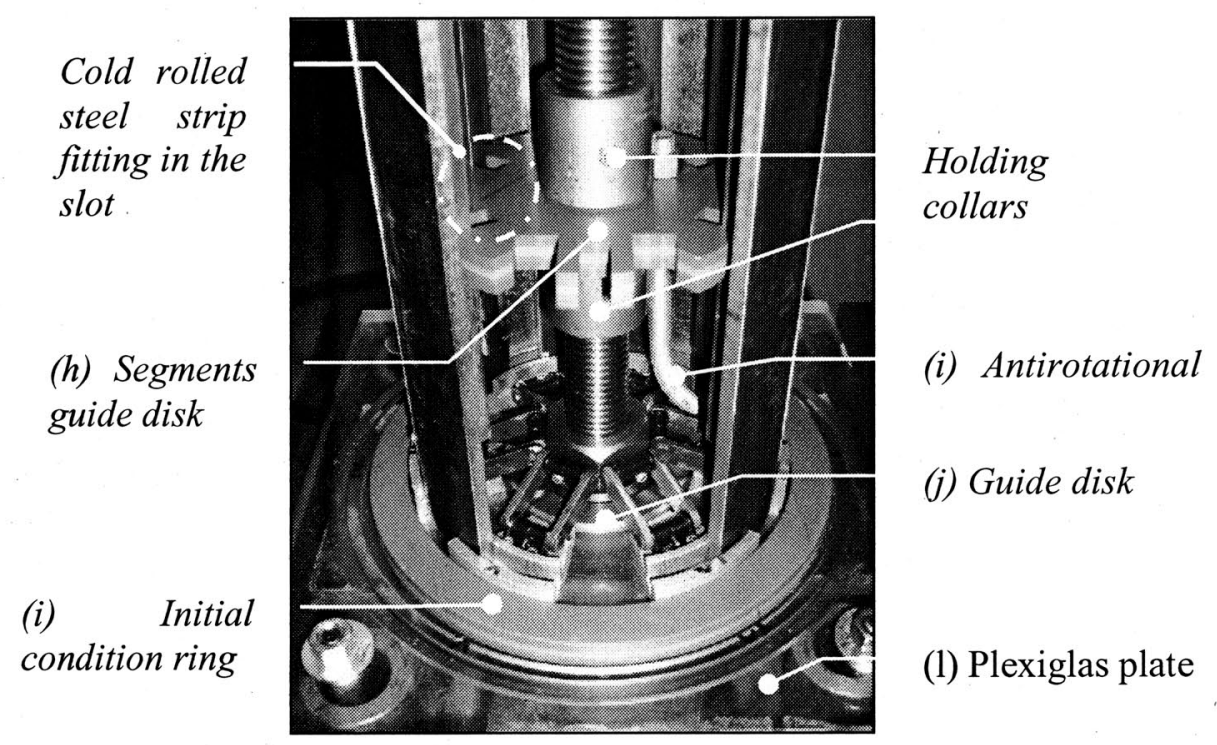

Figure 3.4 Details of the lower end-section showing the antirotational system for the lining segments.

- Guide disks (j): These pieces were located next to the nuts to establish setting their initial position during assembly. They also permitted the top and bottom hinges to be assembled at the same initial angle with the horizontal. Consequently, the same horizontal displacement rate was obtained along the lining segments. The guide disks had the shape of a solid hat; where the "brim" was used as a horizontal guide for the segment holders; and the "crown" thickness was such that the guide disks and the holder segments were in full contact with the Plexiglas plate, as shown in Figure 3.4.

- Initial condition setting rings ( $k$ ): It was used to set the initial position of the segment holders during assemblage. The inner diameter of the ring was such that the initial diameter of the lining shaft was $150 \mathrm{~mm}$. (Figures 3.4 and 3.5) 
- Plexiglas plates (l): At each end of the shaft, a square Plexiglas plate of 2500-mm side and 20-mm thick was used to provide a flat and smooth surface for the segment holders to slide horizontally. To ensure full contact between the Plexiglas plate and the segment holders, the guide disks were screwed to the Plexiglas plates. And leveling screws were installed at the corner of the plates as shown in Figure 3.5.

- Bungee cords $(m)$ : The segmented model shaft required vertical and radial confinement to operate properly. The Plexiglas plates provided the vertical confinement, whereas bungee cords were used to ensure the radial confinement. The bungee cords were placed at both ends of the model shaft. (Figure 3.5)

The model shaft was placed into the concrete tank on a leveling base plate anchored to the concrete floor. To keep the model shaft in vertical position, it was fixed through leveling screws to an upper support installed atop the concrete tank. Further details of the model shaft apparatus installed into the concrete tank are shown in Figure 3.5 ; and the components discussed above are also detailed. 


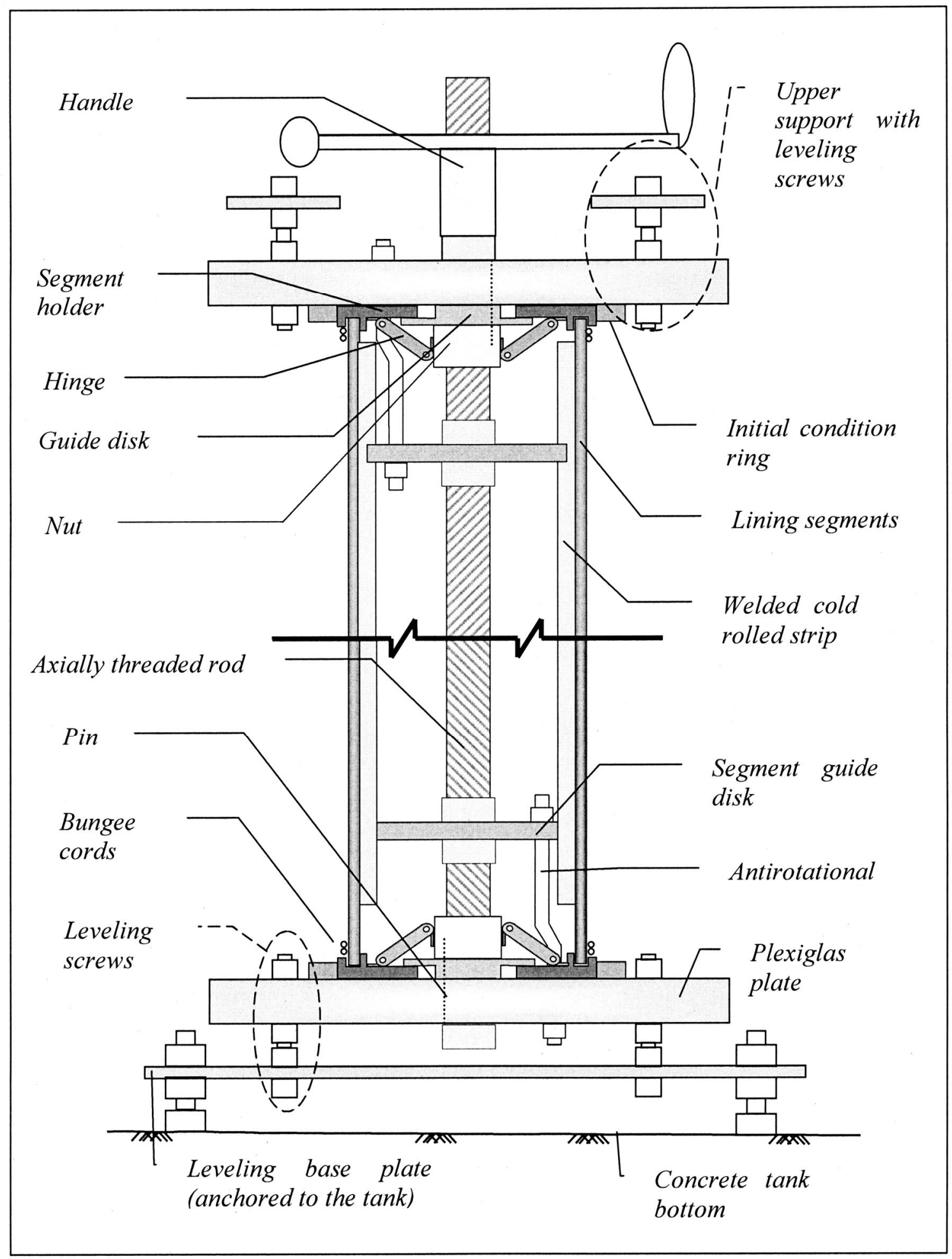

Figure 3.5 Lateral cross section of the model shaft developed as it was installed in the test container. 


\section{c. Soil properties}

Quartz industrial 2075 coarse sand material was selected for this study. Sieve analysis was performed on different selected samples according to the standards outlined by ASTM D6913-04e1. The particle-size distribution indicated a coarse grained material $\left(D_{10}=0.75 \mathrm{~mm} ; D_{60}=1.75 \mathrm{~mm}\right)$ with no fines. More details about the test are provided in Appendix A. The specific gravity of the sand was determined according to ASTM D854-06 (See Appendix B), and was found to be 2.65 .

During the sand placement, density cups were placed at different layers inside the tank. The average unit weight across the tank was found to be $14.7 \mathrm{kN} / \mathrm{m}^{3}$. The internal friction angle $(\phi)$ was determined according to the direct shear test procedure outlined by ASTM D3080-04 which was found to be $41^{\circ}$. Further details are provided in Appendix C .The soil properties are summarized in Table 3.

\begin{tabular}{|l|c|}
\hline \multicolumn{1}{|c|}{ PROPERTY } & VALUE \\
\hline Specific gravity & 2.65 \\
\hline Coefficient of uniformity $\left(C_{u}\right)$ & 3.6 \\
\hline Coefficient of curvature $\left(C_{c}\right)$ & 0.82 \\
\hline Minimum dry unit weight $\left(\gamma_{\min }\right)$ & $14.2 \mathrm{kN} / \mathrm{m}^{3}$ \\
\hline Maximum dry unit weight $\left(\gamma_{\max }\right)$ & $16.4 \mathrm{kN} / \mathrm{m}^{3}$ \\
\hline Experimental unit weight $\left(\gamma_{d}\right)$ & $14.7 \mathrm{kN} / \mathrm{m}^{3}$ \\
\hline Unified soil classification & $\mathrm{SP}$ \\
\hline Internal friction angle $(\phi)$ & $41^{\circ}$ \\
\hline Cohesion $(c)$ & 0 \\
\hline
\end{tabular}

Table 3.1 Soil properties 


\section{d. Instrumentation}

To measure the earth pressure, wall movement and surface settlement during the test, load cells, displacement transducers, and laser gauge sensors, respectively, were used in the experiments. All of the transducers were connected to a Model 5100 data acquisition system and controlled through a desktop computer. Each transducer is briefly reviewed in the following sections.

\section{e. Load cells}

To monitor the lateral earth pressure on the shaft, three load cells were installed behind one of the lining segments at three locations along the shaft. The load cells were equipped with sensitive circular areas of $25.4 \mathrm{~mm}$ (one inch) in diameter with the same curvature of the lining shaft. The centers of these sensitive areas were located at $84 \mathrm{~mm}$, $240 \mathrm{~mm}, 490 \mathrm{~mm}$ below the sand surface. Figure 3.6 shows details of the instrumented lining segment. The maximum capacity of the load cells was $5.9 \mathrm{~N}$. Thin plastic film was used to cover the sensitive areas of the load cells to avoid the sand particles blocking their movement. Further details of the load cell are provided in Appendix D. 


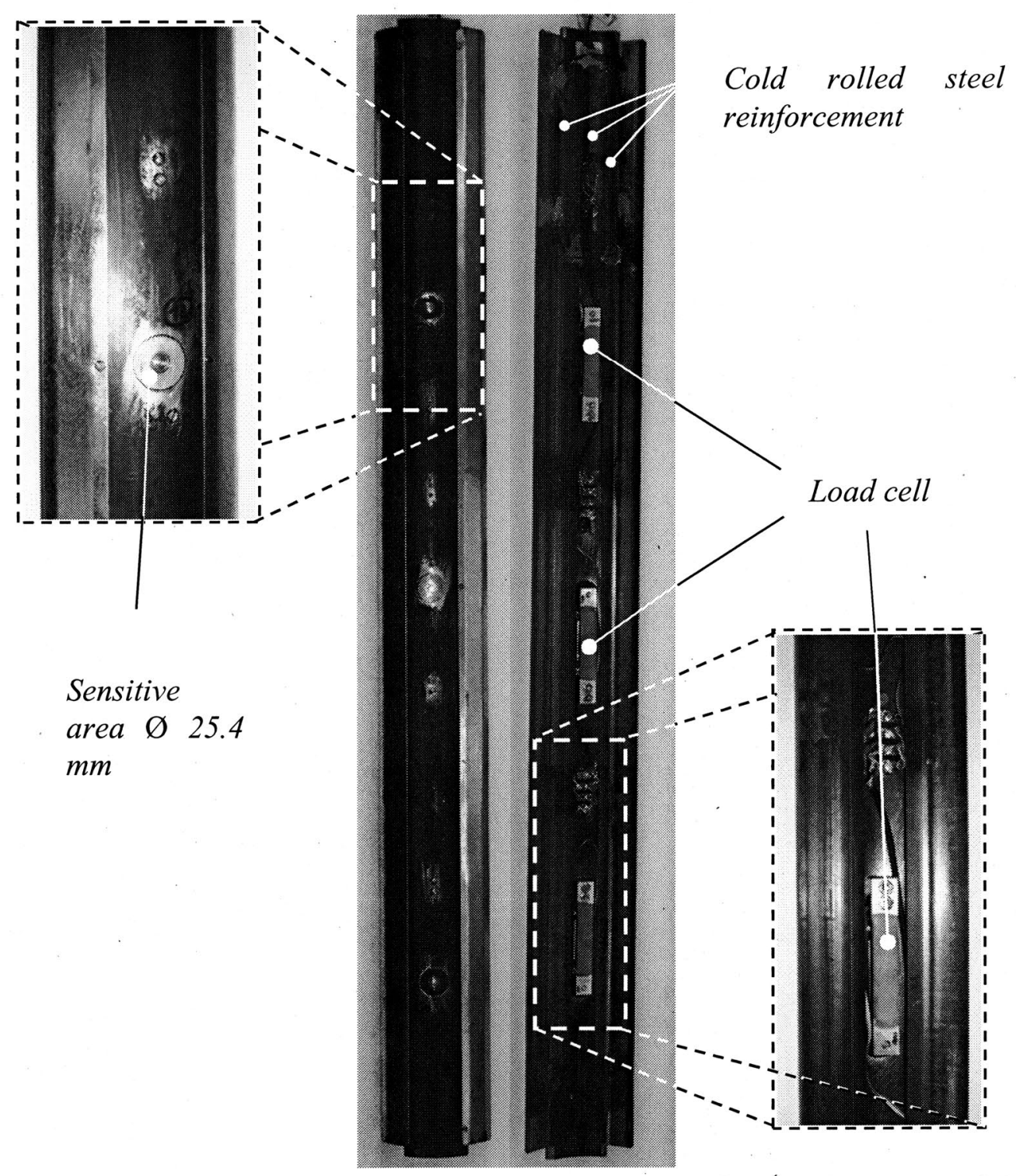

Figure 3.6 Details of the instrumented lining segment.

\section{f. Linear variable displacement transducer}

To monitor the reduction in radius of the model shaft during testing, two linear variable displacement transducers (LVDT) were installed in front of the instrumented lining segment as shown in Figure 3.7. They were protected from contact with the surrounding soil to ensure proper performance, th lower LVDT was covered using a rigid Plexiglas cap able to support the weight of sand (see details in Figure 3.8), whereas the upper LVDT was protected using a small plastic tube attached to a spring. 


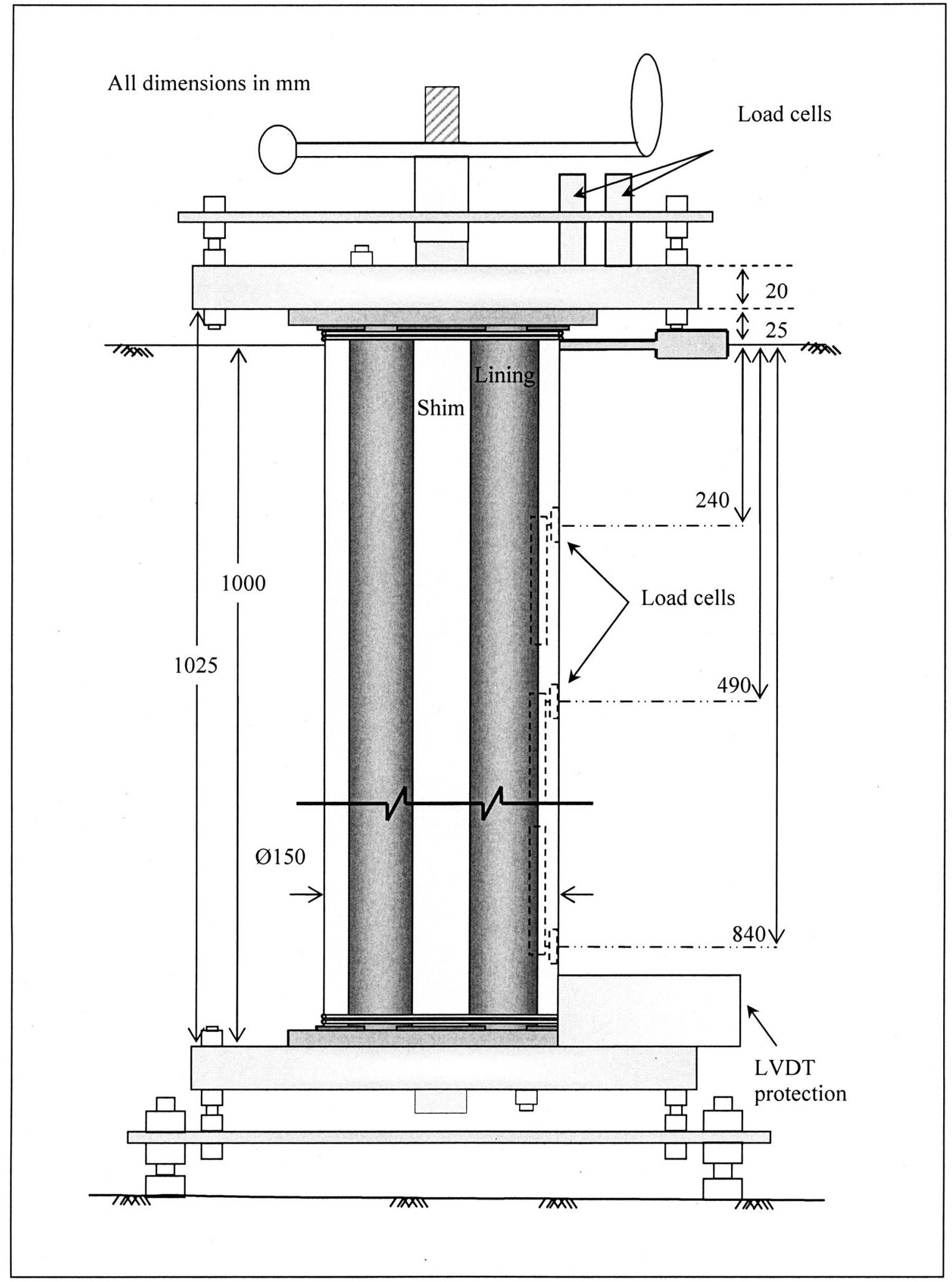

Figure 3.7 Schematic of the model shaft showing the position of all the transducers installed 


\section{g. Laser gauges}

The surface settlement was monitored using L-Gage type laser sensors at two locations, 1.3 and $8.2 \mathrm{~cm}$ radially measured from the lining shaft. They were installed on the upper Plexiglas plate. A light-emitting diode on the laser box indicated when the target was within the sensing distance, i.e. 45 to $60 \mathrm{~mm}$ measured from the sensor lens; therefore the laser sensors were used to monitor the sand level, such that the lower sensing bound coincided with the desired sand height. Preliminary tests of the sensors showed that the laser signal was unstable on the sand due to the translucence of the sand grains. Therefore, a thin layer of painted sand was placed over the surface area, where the lasers were reflected to obtain a steady signal for the entire displacement range. Further details of the laser gauging sensors are provided in Appendix E.

\section{h. Data acquisition system}

All of the transducers were connected via nine-pin connectors to a Model 5100 scanner box, equipped with two stain gauge cards and two high voltage cards. The load cells were connected to the strain gauge card, whereas the LVDT's and the laser sensors were connected to the high voltage cards. The data acquisition system was activated using the Strain Smart 4.3 software package installed on a desktop computer.

\section{Test Procedure}

The first step was preparation of the tank and shaft for the sand placement and to ensure cleanness and readiness of the exposed surfaces and the installed transducers. All of the gaps that may allow obstruction of the mechanism with sand grains were covered. Thin plastic film was used to protect the sensitive areas of the load cells and the lower section of the mechanism, whereas regular adhesive tape was used on the interface shimlining segment. It should be noted that at the edge where the shim was required to slide over the lining segment, oil was applied to the lining segment. This guaranteed free movement of the tape over the lining while keeping the sand out of the system. A schematic sketch of the test setup is shown in Figure 3.9. 


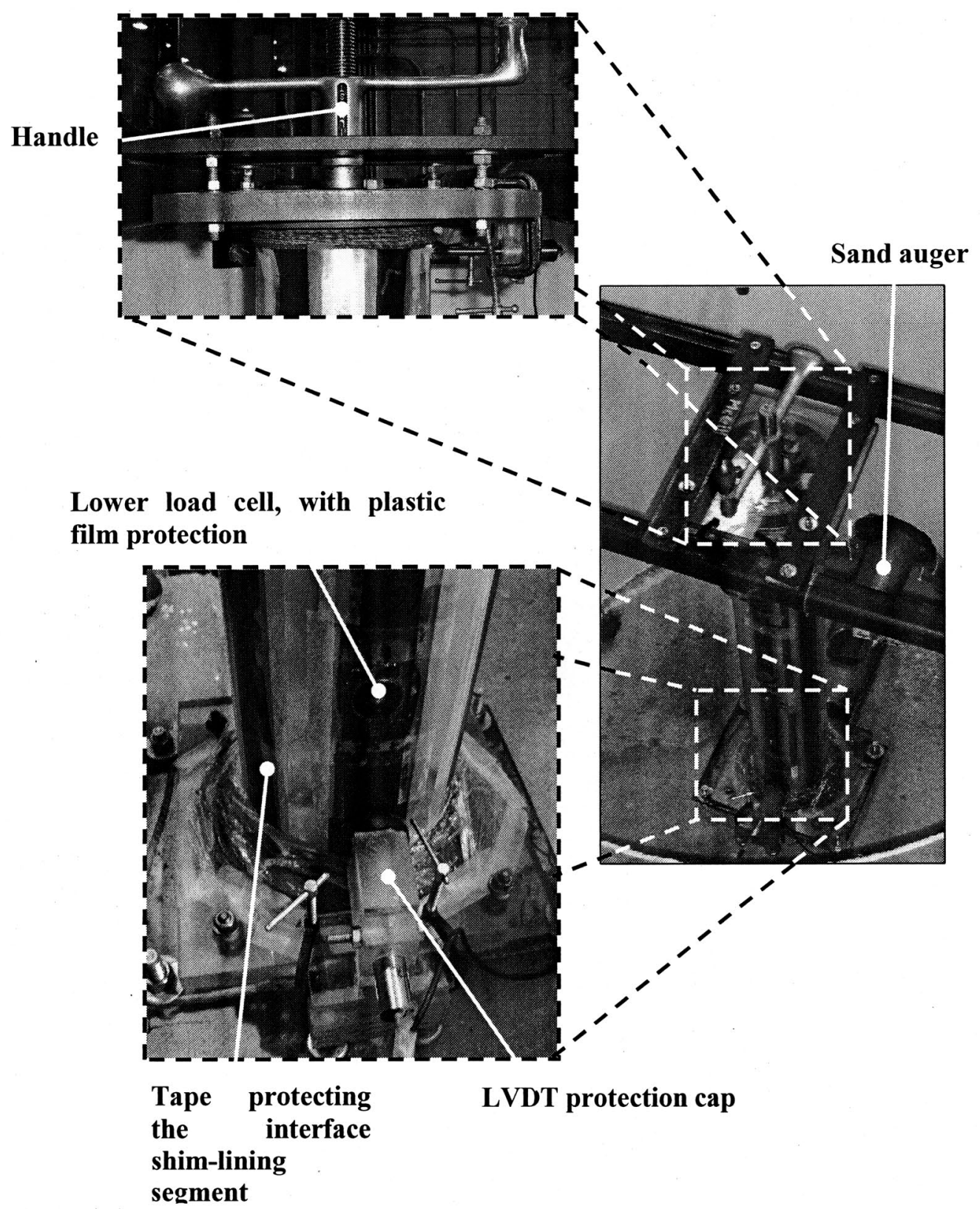

Figure 3.8 General view of the model shaft installed in the concrete tank with details of the upper and lower sections

Once the entire system was ready, the concrete tank was filled with industrial 2075 coarse sand through pluvial deposition up to one meter height from the base of the model shaft. A hopper, with a spreading hose attached, was used as a sand reservoir. It was lifted and positioned over the concrete tank using a 10-ton crane. To place each sand layer, the hopper was positioned vertically such that the initial distance between the 
spreading hose and the beginning of the new layer was approximately $500 \mathrm{~mm}$. This condition was kept during the placement of each layer. Density cups were placed at the beginning of each of the three layers required to fill the concrete tank. The average unit weight across the tank was found to be $14.7 \mathrm{kN} / \mathrm{m}^{3}$. Once the sand reached one meter approximately on the lining shaft, the sand surface was leveled even by using a ruler. Then the sand height was checked and more sand was added as required. The height was checked using the laser sensors to ensure consistent initial conditions for each test. The next step was to enhance surface reflection below the laser sensors using a thin layer of colored sand manually rained.

After the initial readings were recorded; the shaft diameter was slowly decreased by rotating the precalibrated handle installed at the top of the shaft and monitoring the readings of the displacement transducers using the data acquisition system until the LVDT's registered the desired wall movement when the experiment was terminated. Then the concrete tank was emptied using the sand auger system, and the apparatus handle rotated backward to increase the diameter for the next test. A total of twelve tests were conducted and the readings were recorded for each wall movement increment $(1,2$, 3 and $4 \mathrm{~mm}$ ). The experiments were repeated three times to ensure their reproducibility and the above procedure was followed for each test. 

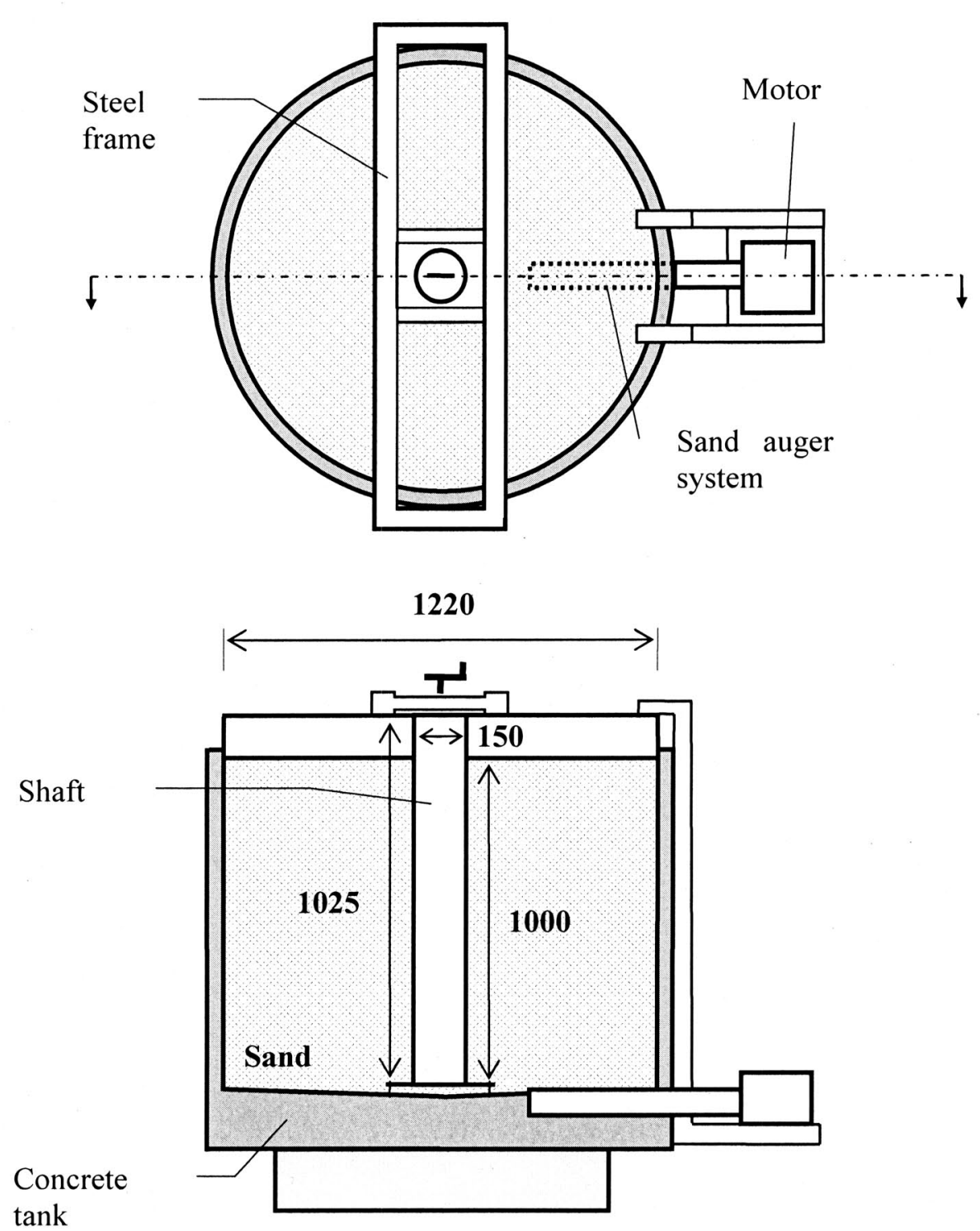

Cross-Section A-A

(Units: $\mathrm{mm}$ )

Figure 3.9 Schematic sketch of the experimental setup 


\section{ChAPTER 4}

\section{EXPERIMENTAL RESULTS AND ANALYSIS}

This chapter presents the results of the experimental program, with emphasis on the measured active earth pressure along the shaft wall. The corresponding surface settlements are also presented.

\section{Earth Pressure}

The reported earth pressures are based on the load cell readings at selected locations along the shaft. First, the initial pressures on the wall will be presented along with the measured earth pressure versus the wall movement. Emphasis will be placed on the change in earth pressure before and after a predefined wall movement is introduced. Then the experimental results will be compared with some of the available theoretical methods, presented in Chapter 2.

\section{a. Initial condition}

The initial pressure acting laterally on the cylindrical wall is presented in Figure 4.1. The calculated at rest pressure is also presented for comparison purposes. It can be seen that the measured earth pressure generally increased with depth. The increasing trend was found to be consistent with the calculated at-rest earth pressure distribution except near the foot of the shaft where smaller pressure was measured. This could be attributed to the arching effects that resulted from the initial compression of the lower sand layers around the shaft. Herten and Pulsfort (1999) and Imamura et al. (1999) observed similar results. 


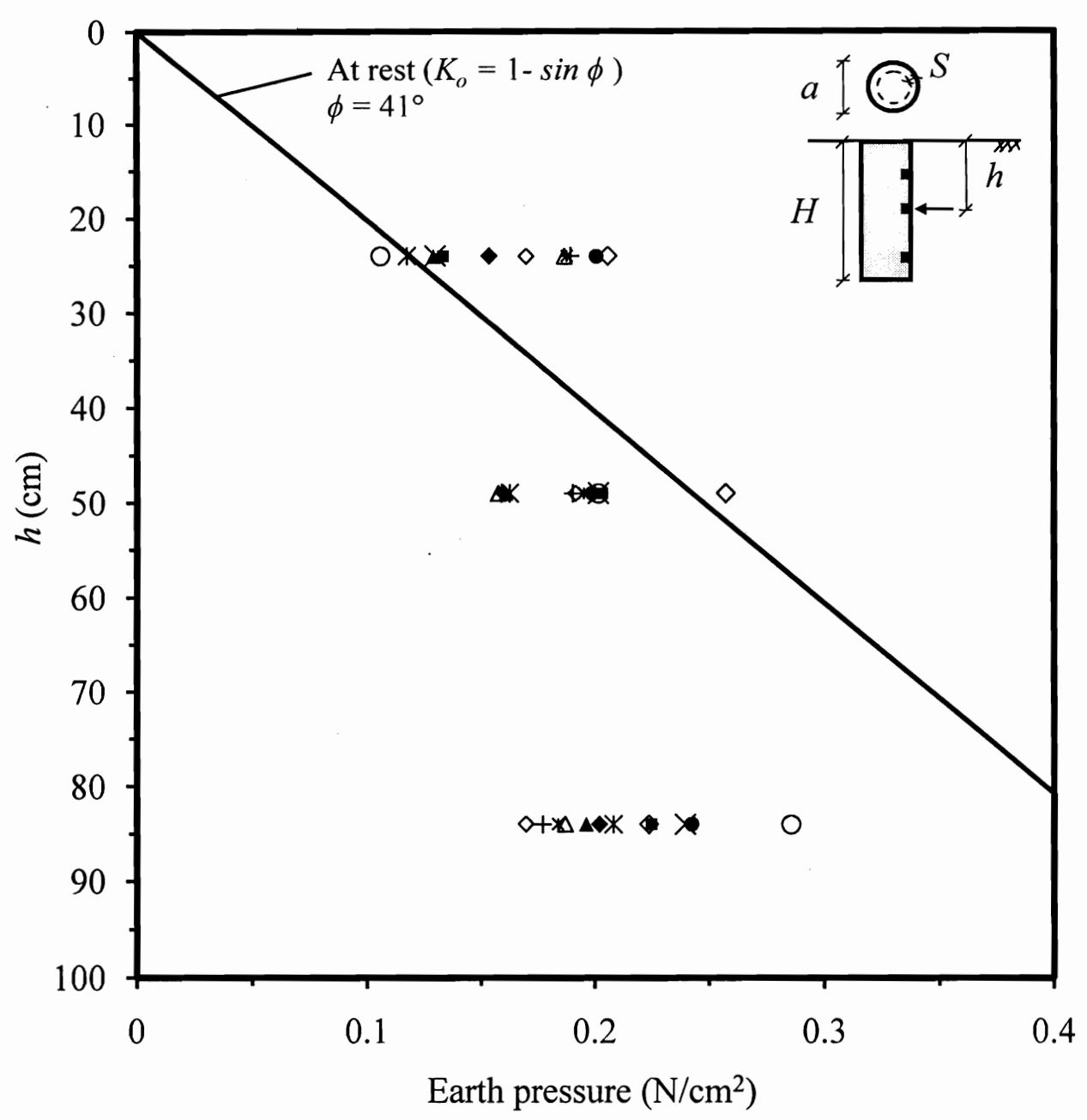

Figure 4.1 Measured initial earth pressure versus depth

\section{b. Earth pressure versus wall displacement}

Figure 4.2 shows the measured lateral loads at the three investigated locations for one of the tests performed. The measured lateral load, $p(\mathrm{~N})$, is plotted on the vertical axis, whereas the measured axisymmetric wall displacement, $S(\mathrm{~mm})$ is plotted on the horizontal axis. A consistent reduction of lateral pressure on the load cells as the horizontal wall movement increases can be observed. Identical trend is observed for the remaining test; these results are provided in Appendix F. 


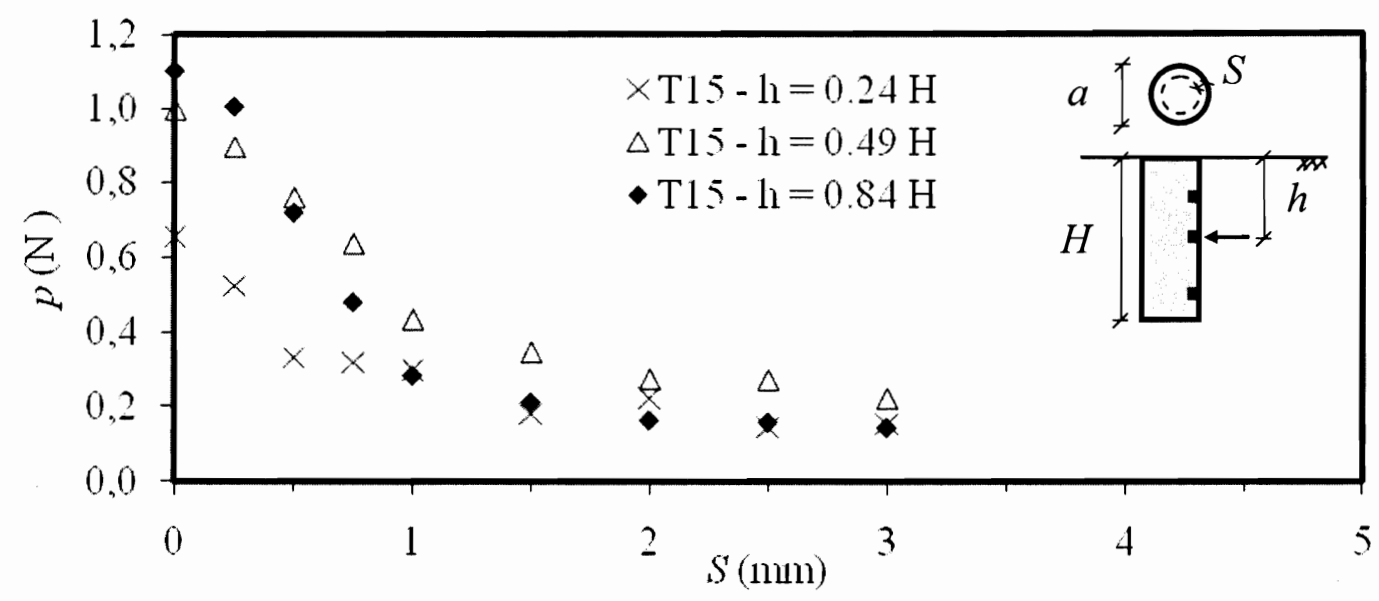

Figure 4.2 Measured lateral load versus wall displacement, T15

To analyze the effect of the wall displacement on the lateral earth pressure distribution, the measured pressures, $p$, are normalized with respect to the initial pressure, $p_{o}$. Figures 4.3 through 4.6 summarize the normalized earth pressure at the locations of the load cells $(0.24 H, 0.49 H$ and $0.84 H)$ for different maximum wall movements. All tests revealed the same pattern in the development of the active earth pressure. First, there was a large reduction in the lateral earth pressure for wall movements up to approximately $1 \mathrm{~mm}$ as is shown in Figure 4.3. The pressure decreased from $100 \%$ of the initial pressure for $S=0$ to about $60 \%$ at $0.24 \mathrm{H}$ and $0.49 \mathrm{H}$, and to about $30 \%$ at $0.84 \mathrm{H}$ below the surface. For values of $S$ between one and two millimeters, the rate of reduction was less significant as shown in Figure 4.4; the initial earth pressure decreased to $30 \%$ at $0.24 \mathrm{H}$ and $0.49 \mathrm{H}$, and to $15 \%$ at $0.84 \mathrm{H}$. Finally, additional displacement produced almost no change and the pressure reached a constant value of approximately $20 \%$ of the initial pressure at $0.24 \mathrm{H}$ and $0.49 \mathrm{H}$, and approximately $10 \%$ at $0.84 \mathrm{H}$ as shown in Figures 4.5 and 4.6.

The above conclusions can be visualized in Figure 4.7 that summarizes the percentages of pressure reduction at the three locations. Figure 4.7 also shows that the reduction in pressure was rapid especially near the bottom of the shaft. For wall movements of $0.25 \mathrm{~mm}$, the measured earth pressure decreased by about $30 \%$ more at the lower sensor $(h / a=11.2)$ compared to the other sensors. However at wall movements 
equal to or greater than $2 \mathrm{~mm}$, the reduction in earth pressure along the shaft lining was uniform with an average reduction of about $80 \%$ of the initial pressure. Therefore, it was concluded that the axisymmetric active earth pressure fully developed at wall displacements between 2 and $3 \mathrm{~mm}$ (about $2.5 \%$ to $4 \%$ of the shaft radius). 

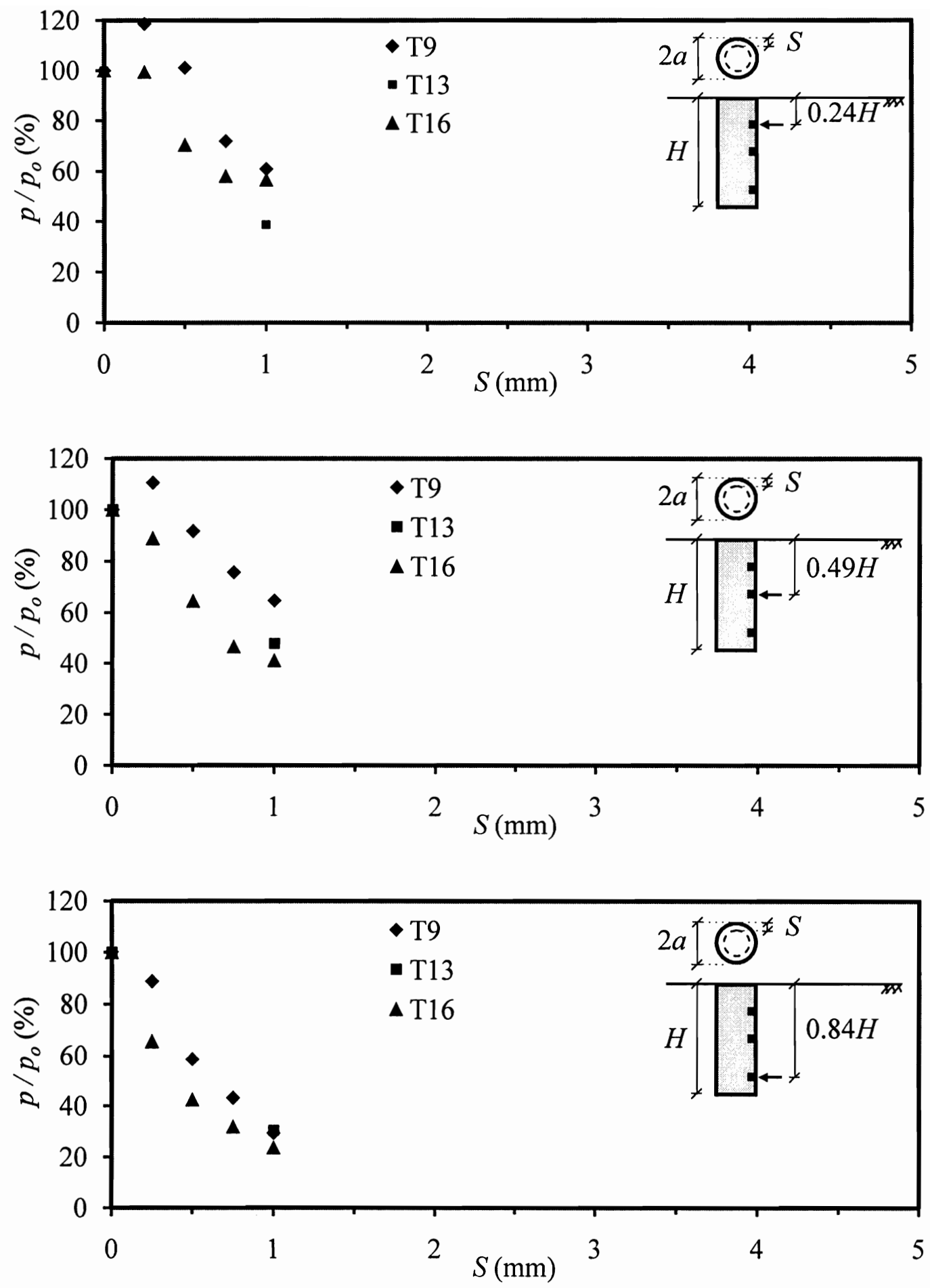

Figure 4.3 Changes in lateral earth pressure at different locations along the shaft wall for a maximum wall displacement of $1 \mathrm{~mm}$. 

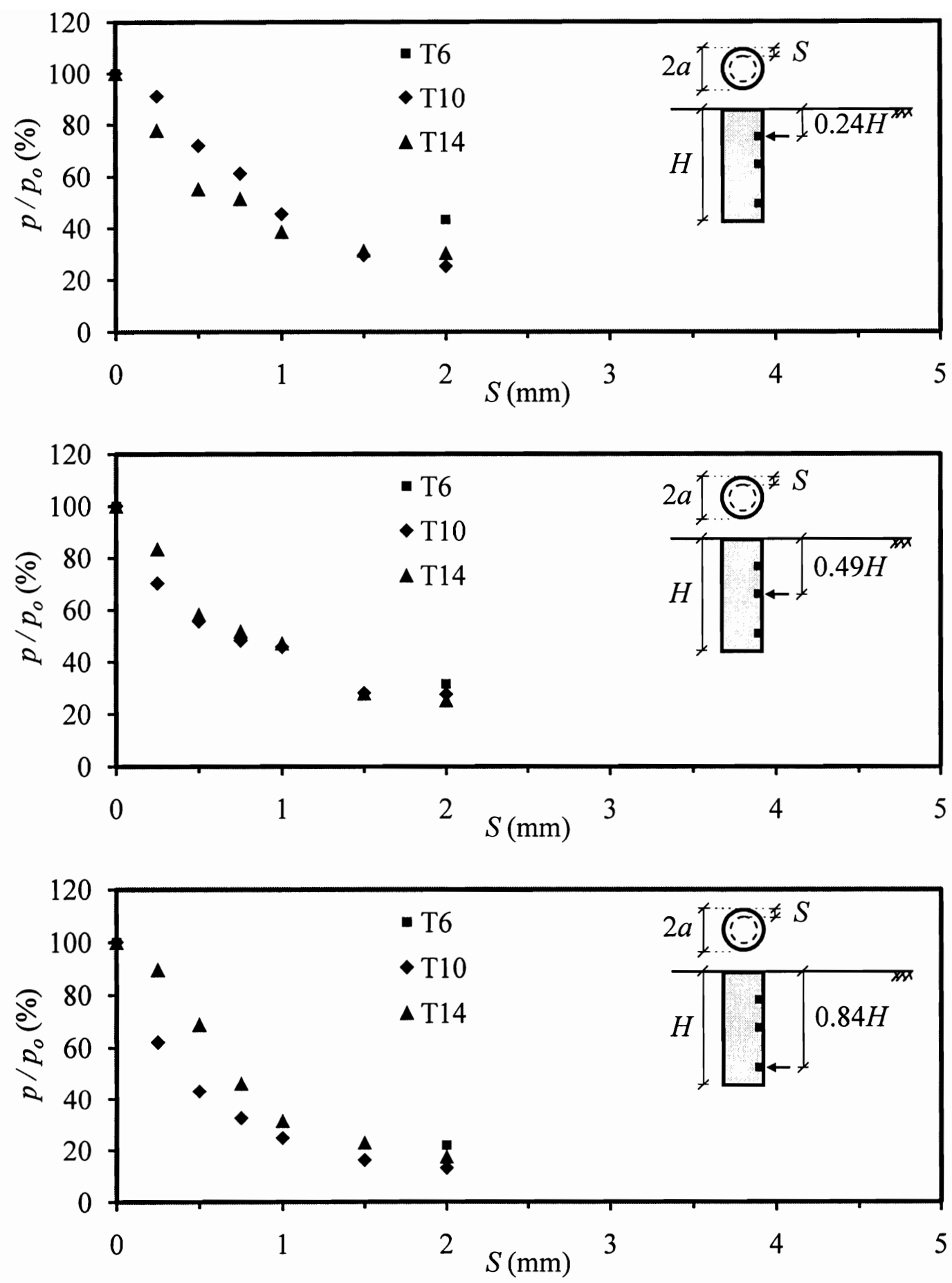

Figure 4.4 Changes in lateral earth pressure at different locations along the shaft wall for a maximum wall displacement of $2 \mathrm{~mm}$ 

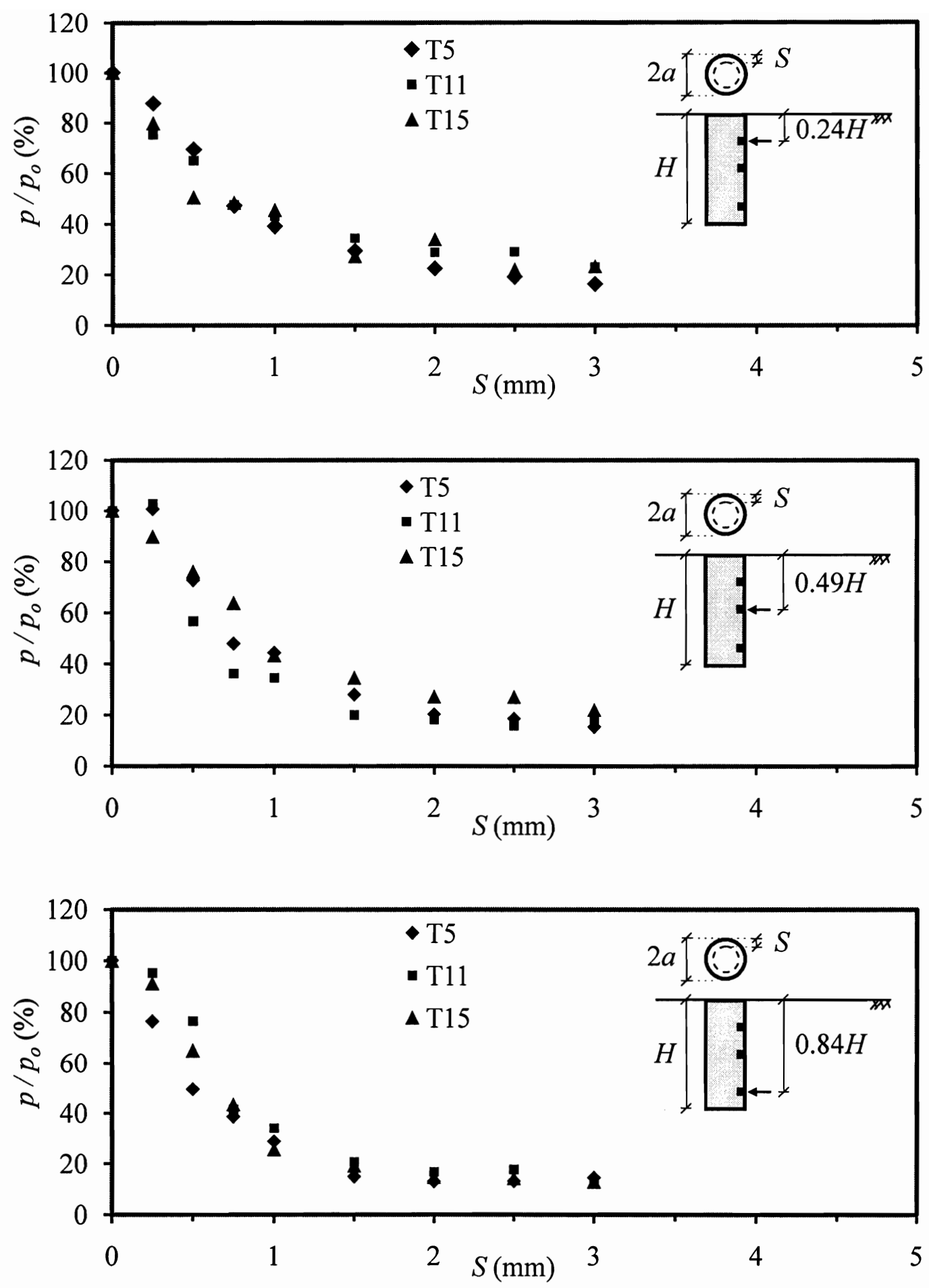

Figure 4.5 Changes in lateral earth pressure at different locations along the shaft wall for a maximum wall displacement of $3 \mathrm{~mm}$ 

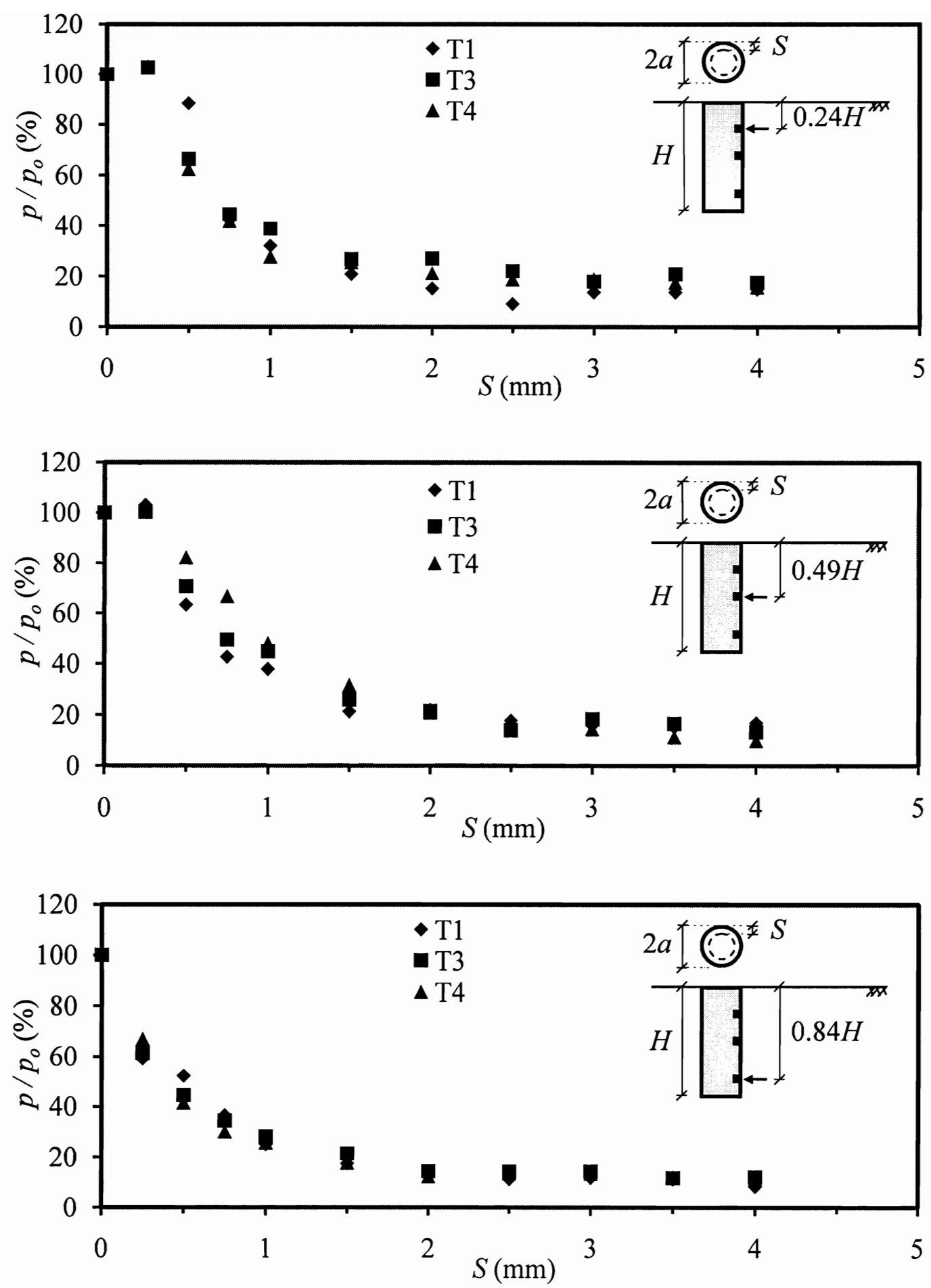

Figure 4.6 Changes in lateral earth pressure at different locations along the shaft wall for a maximum wall displacement of $4 \mathrm{~mm}$ 

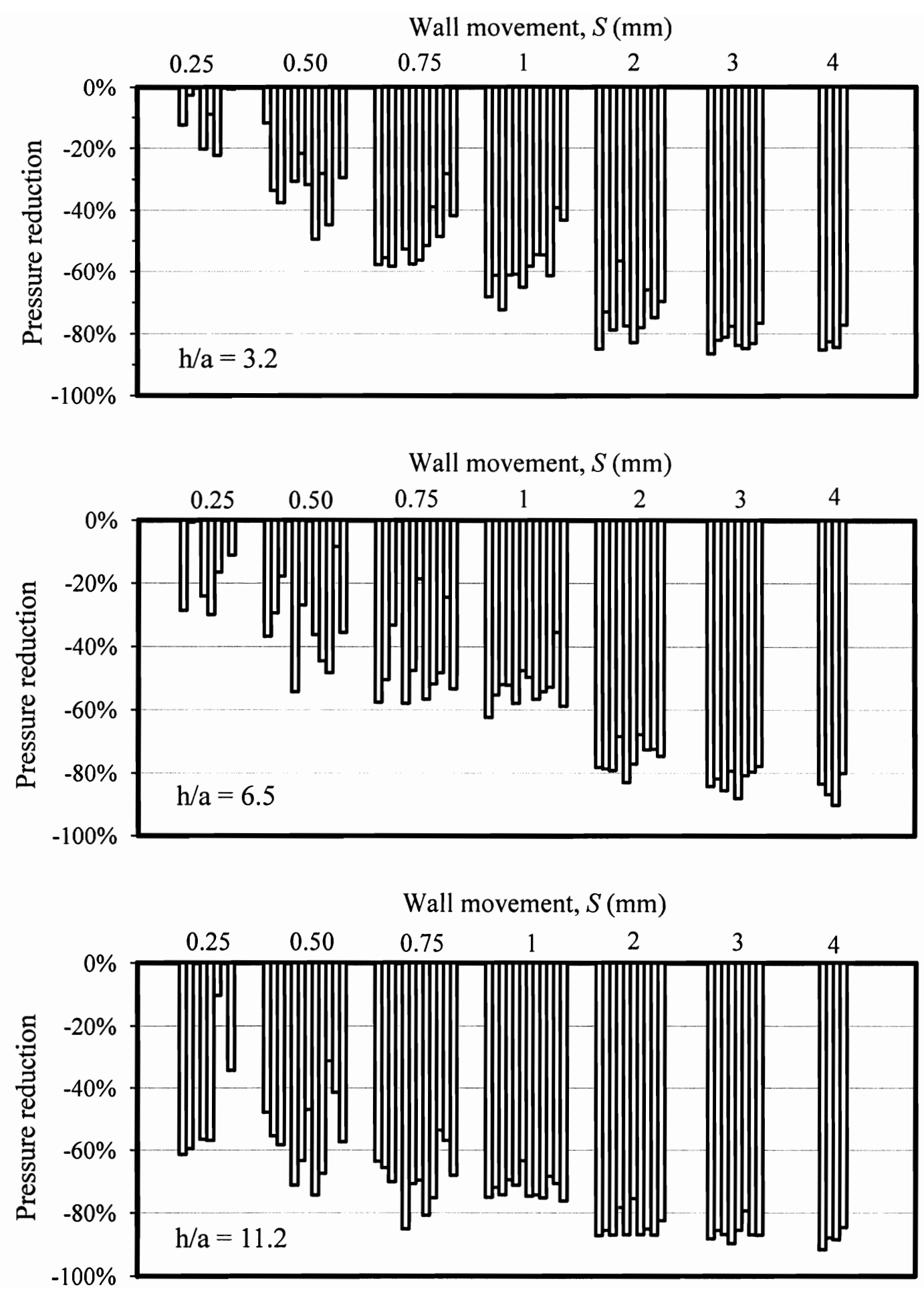

Figure 4.7 Percentage of earth pressure reduction at the three locations along the shaft 


\section{c. Normalized earth pressure versus depth and comparison with theoretical solutions}

The earth pressures distribution normalized with respect to the shaft radius, $a$, and the unit weight of the soil, $\gamma$, versus the shaft length normalized with respect to the shaft radius, $a$, are plotted in Figures 4.8 to 4.11 for wall movements $S=0.1,0.2,0.3$ and 0.4 percent of the wall height $(H)$, respectively. It can be seen in Figure 4.8 that for $S=$ $0.1 \%$ of the wall height, the measured lateral pressure followed similar pattern to the initial earth pressure where it increased from the surface up to the mid- height of the shaft $(h / a \approx 7)$ and decreased below this level. However, the overall magnitudes of the pressure values have decreased by about $60 \%$ as discussed in the previous section. For $S=0.2 \%$ of the wall height, the distribution became more uniform with depth as shown in Figure 4.9. Additional increase in $S$ to $0.3 \%$ and $0.4 \%$ of the wall height did not causes significant changes in earth pressure distribution from those shown in Figures 4.10 and 4.11.

To evaluate the performance of some of the available theoretical methods discussed in Chapter 2, the experimental results are compared with four different solutions, namely Terzaghi (1943), Berezantzev (1958), Prater (1977) and Cheng \& $\mathrm{Hu}$ (2005) as summarized in Figures 4.8 to 4.11.

It was found that Terzaghi (1943) and Berezantzev (1958) solutions provide reasonable estimates for the earth pressure acting on the shaft if enough soil movement is allowed, as shown in Figures 4.10 and 4.11. This is consistent with the results of limit equilibrium and slip line methods on which these theories are based.

By comparing the experimental results with Prater's (1977) solution, it has been found that Prater's solution is only acceptable when the soil surrounding the shaft fully yields. However, as the solution computes a zero value of earth pressure at a normalized depth $h / a$ of about $9\left(\phi=41^{\circ}\right.$ and $\left.\mathrm{c}=0\right)$, which is inconsistent with experimental results, Prater suggested the use of the maximum earth pressure value for design purposes.

Cheng and $\mathrm{Hu}$ (2005) proposed bounds for the earth pressure distribution based on slip line analysis using different values of the parameter $\lambda$. The upper bound is 
derived using $\lambda=K_{o}$, whereas the lower bound is derived using $\lambda=1$ which reduces the solution to the one proposed by Berezantzev (1958). As shown in Figures 4.8 and 4.9, the calculated pressure distribution for $\lambda=K_{o}$ agrees well with the experimental results for the upper half of the shaft when small movements are induced. However, the predicted distribution is not uniform with depth as measured. It can be observed that the earth pressures measured for wall movements greater than $0.1 \%$ of the wall height agree well with the range of pressures predicted using Cheng and $\mathrm{Hu}$ (2005).

The above comparison highlights the importance of the relationship between the soil movement around the shaft and the expected earth pressure distribution as it has been shown to have significant implication on the selected method of analysis. 


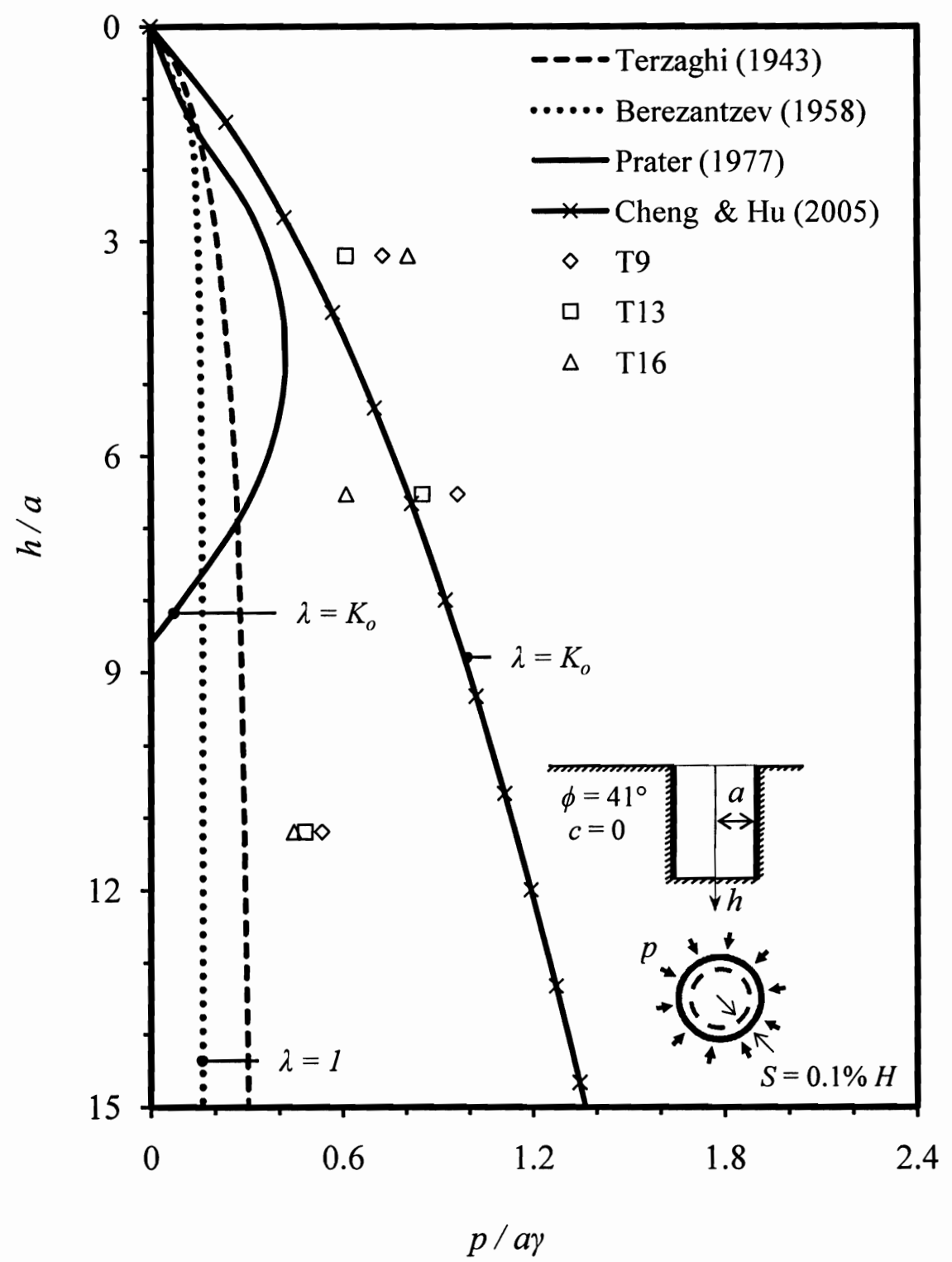

Figure 4.8 Comparison of measured and theoretical earth pressures along the shaft for $S=$ $0.1 \%$ of the wall height 


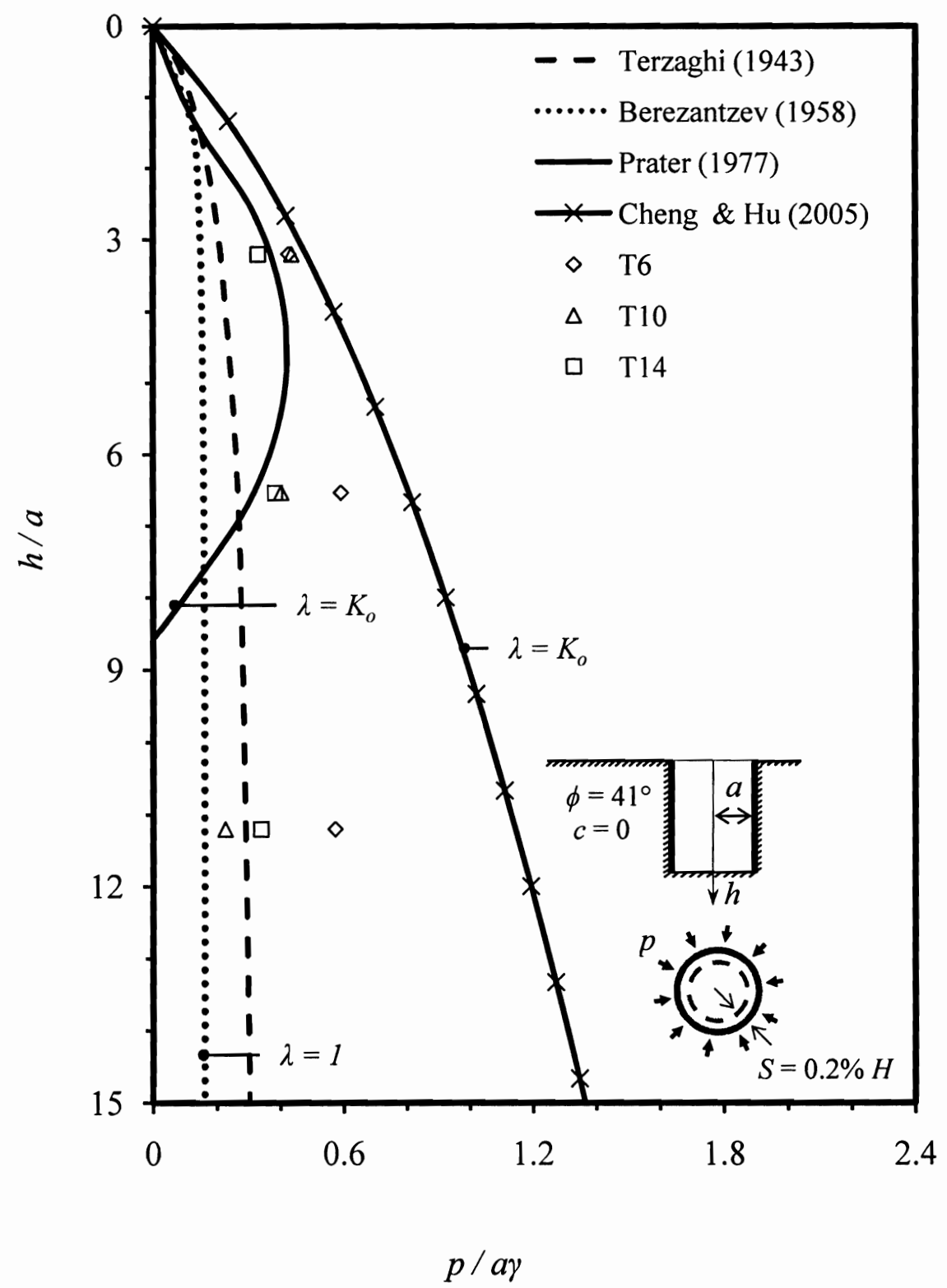

Figure 4.9 Comparison of measured and theoretical earth pressures along the shaft for $\mathrm{S}=$ $0.2 \%$ of the wall height 


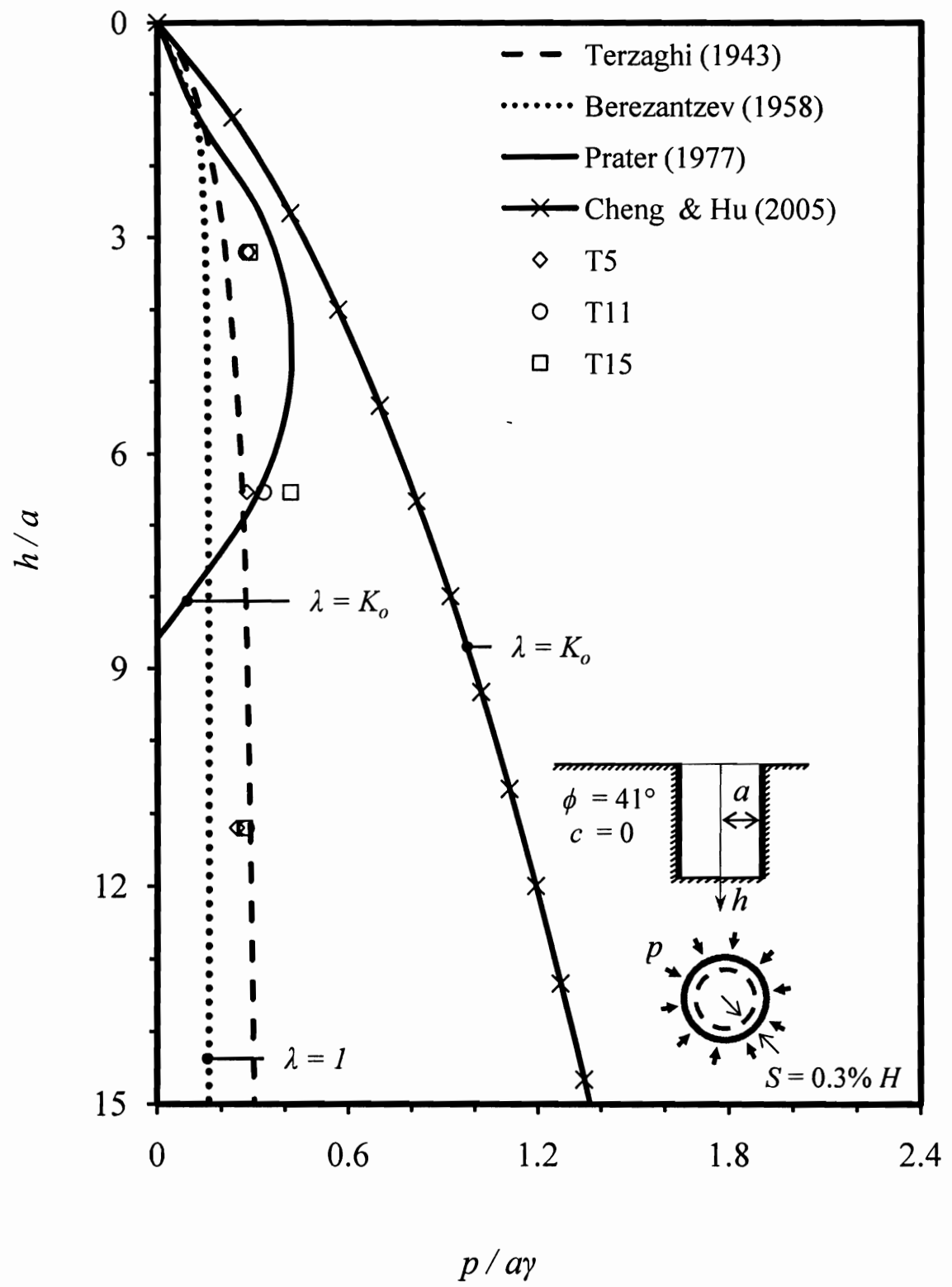

Figure 4.10 Comparison of measured and theoretical earth pressures along the shaft for $S=$ $0.3 \%$ of the wall height 


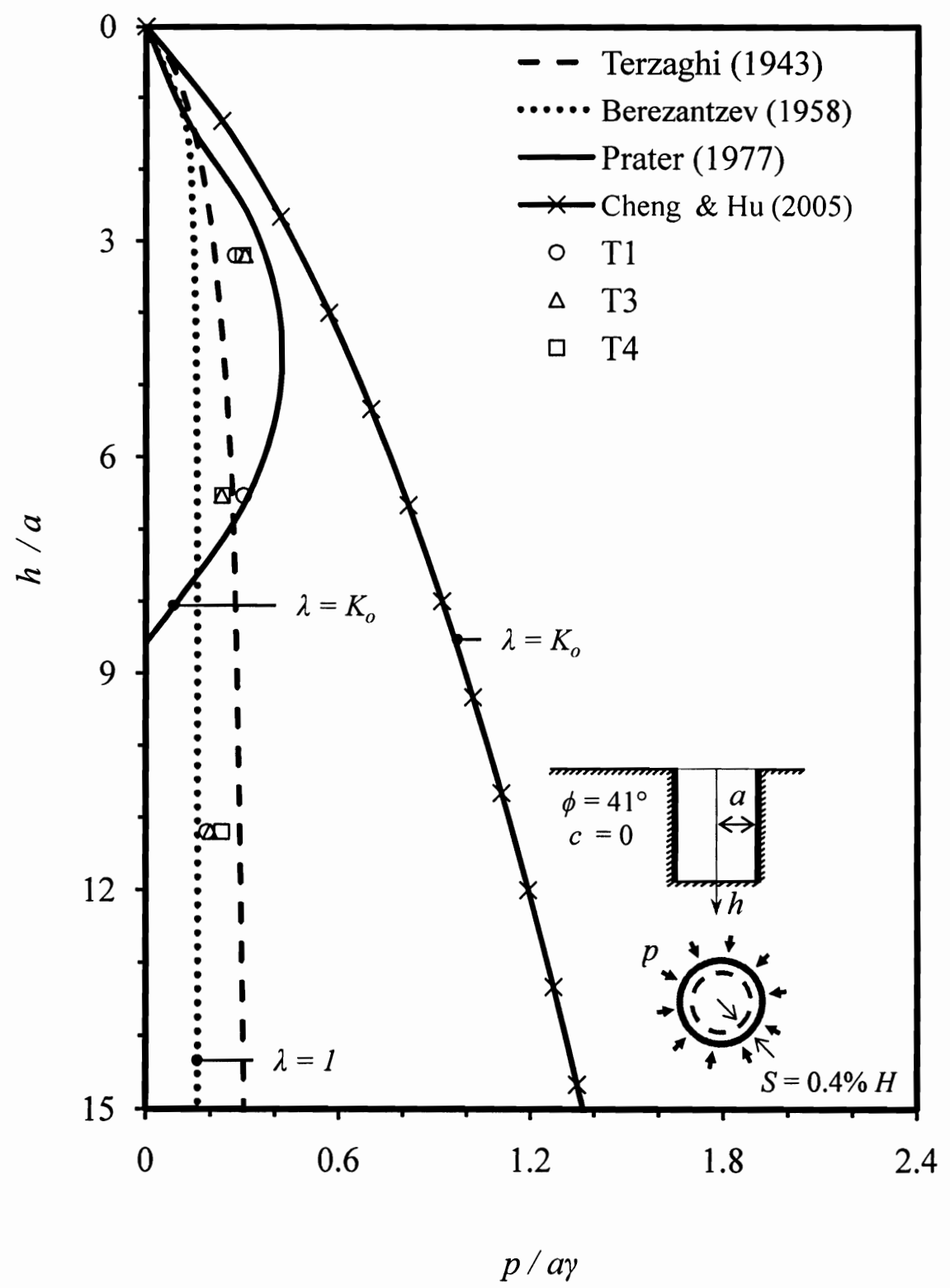

Figure 4.11 Comparison of measured and theoretical earth pressures along the shaft for $S=$ $0.4 \%$ of the wall height 


\section{Surface Settlement}

The surface settlement was measured at two locations in the close vicinity of the lining and the results are summarized in Figure 4.12. The surface settlement continued to increase as the wall movement increased. For $r / a=1.2$, a maximum settlement of about 8 $\mathrm{mm}$ was measured, whereas a settlement of about $5 \mathrm{~mm}$ was measured for $r / a=2.1$. This indicates a decreasing settlement with distance from the shaft. It was also observed, based on the experimental results, that the magnitude of the maximum surface settlement near the shaft circumference $(r / a=1.2)$ was approximately twice the wall movement.

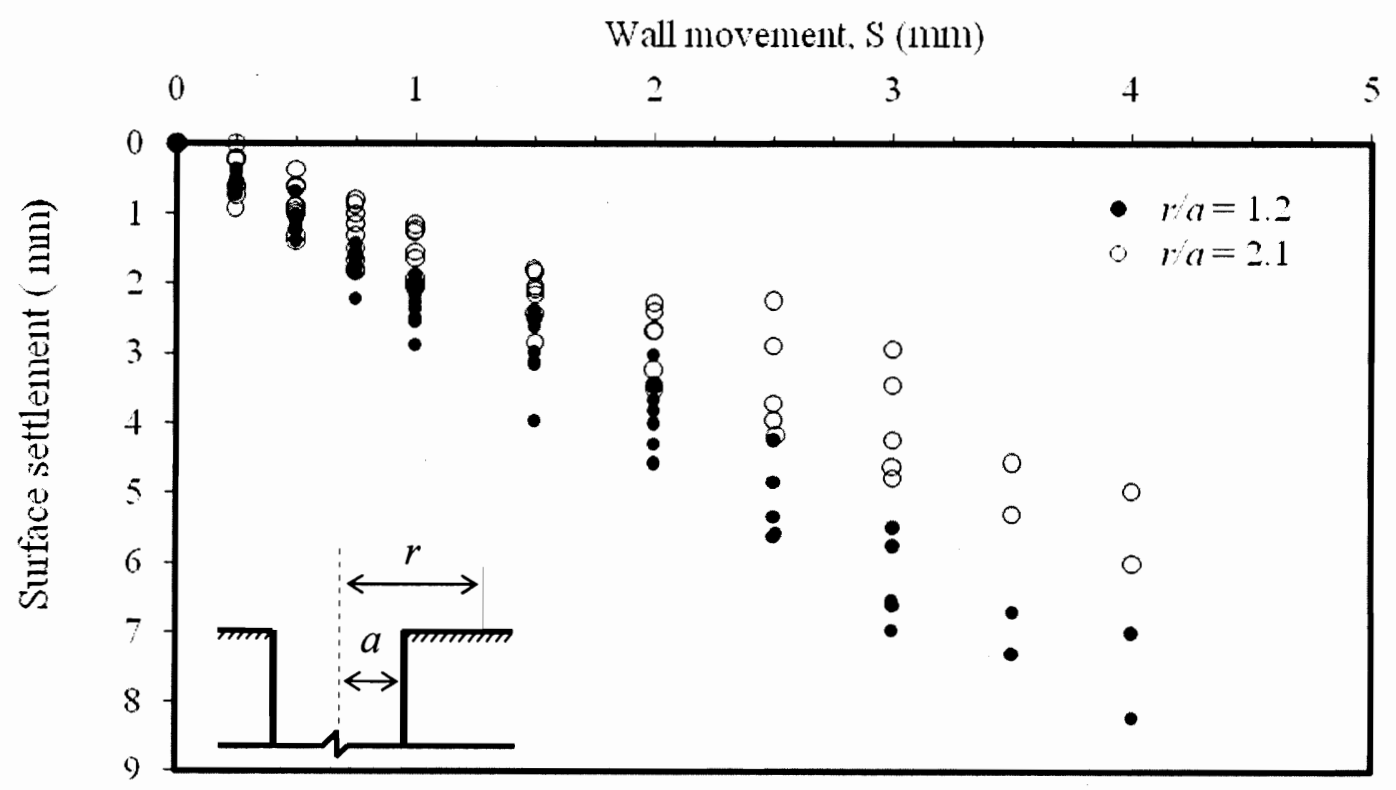

Figure 4.12. Measured surface settlement 


\section{CHAPTER 5}

\section{CONCLUSIONS AND RECOMMENDATIONS}

An experimental study was performed to investigate the earth pressures on cylindrical walls, considering the wall displacement effects. A model shaft was developed to satisfy the full axisymmetric configuration of the shaft, and to allow the continuous measurement of the earth pressure acting on the shaft during the radial wall displacements. The results were compared with some of the theoretical distributions.

Based on this study, the following conclusions can be drawn:

- For shafts of depth equal to or less than one shaft radius, the difference in the theoretical active earth pressure acting on cylindrical walls and on infinitely long walls is negligible. For shafts deeper than one shaft radius, the classical earth pressure theories overestimate the values of the axisymmetric active pressure, and the pressure difference increases with depth.

- The axisymmetric active pressure distribution does not increase linearly with depth. As the soil movement increases, the pressure distribution reduces until a constant value independent of the depth is reached at ultimate state.

- Cheng and $\mathrm{Hu}$ (2005) proposed a simple formula that estimates the lateral earth pressure on the shaft using any value of the coefficient of earth pressure on radial planes, $\lambda=\sigma_{\theta} / \sigma_{v}$. In this manner, the lateral earth pressure on the shaft can be calculated considering the effects of the horizontal arching. For engineering purposes, it was recommended that $\lambda=1$ and $\lambda=K_{o}$ should be used to obtain the lower and upper bounds of the pressure distribution, respectively.

- For shafts in cohesionless soil, horizontal backfill and no surcharge, it was observed that the pressure range calculated using Cheng and $\mathrm{Hu}$ (2005) solution 
includes the pressure distributions estimated using the other theories (i.e. Terzaghi, 1943; Berezantzev, 1958; and Prater, 1977).

- By comparing the experimental data with the range of pressures predicted using the Cheng and $\mathrm{Hu}(2005)$ method; it was observed that at wall movements greater than or equal to about $0.1 \%$ of the wall height, the measured pressures fell into the predicted pressure range using $\lambda=1$ and $\lambda=K_{o}$, as was recommended.

- For shafts in cohesionless soils, no agreement has been reached among researchers as to the magnitude of wall movement required to reach the active condition. Based on this study, the wall movement needed to establish active condition is approximately $0.2 \%$ of the wall height; the reduction in pressure can reach about $80 \%$ of the initial value, in contrast to a reduction of about $40 \%$ predicted using the classical earth pressure theories.

- These conclusions are based on limited number of $1 \mathrm{~g}$ tests. Field verification is, therefore, needed to confirm the above findings.

It is clear from the foregoing presentation that more research is needed to establish an overall accepted design methodology for cylindrical retaining structures, as it exists today for plane retaining structures. On the other hand, some of the theoretical studies on the earth pressure on cylindrical walls include the effects of the horizontal arching, and therefore they are a step ahead of the classical earth pressure theories.

Based on this thesis, the following recommendations for further research can be made:

- Model tests should be conducted using various types of soils, density conditions, and shaft geometries with the purpose of establishing the radial displacement needed to reach the axisymmetric active condition, as well as to understand the effect of the shaft aspect ratio on the wall displacement. The relationship among the coefficient of earth pressure on radial planes $(\lambda)$, the wall displacement and the 
lateral earth pressure on the shaft should be investigated experimentally. This would contribute to develop a more rational design methodology for shafts.

- Create a database including information from experimental investigations, theoretical values and field measurements to develop correlations between the theoretical and measured data. This will contribute to the evaluation of the applicability of the theoretical methods, as well as to introduce correction factors to account for the essential design parameters. 


\section{References}

ASTM. (2007) "ASTM D854 (Standard Test Methods for Specific Gravity of Soil Solids by Water Pycnometer)"

ASTM. (2007) "ASTM D3980-04 (Standard Test Method for Direct Shear Test of Soils under Consolidated Drained Conditions)"

ASTM. (2007) "ASTM D6913-04e1 (Standard Test Methods for Particle-size Distribution (Gradation) of Soils Using Sieve Analysis)"

Berezantzev, V.G. (1958) "Earth pressure on the cylindrical retaining walls," Conference on earth pressure problems. Brussels, pp 21-27.

Brady, B.H.G., \& Brown E.T. (2004) Rock mechanics for underground mining, Springer.

Britto, A. M., and Kusakabe, O. (1982) "Stability of unsupported excavations in soft clay." Geotechnique, Vol. 32, No. 3, pp 261-270.

Britto, A. M., and Kusakabe, O. (1983) "On the stability of unsupported excavations" Cambridge University, Engineering Department, (Technical Report)

Bros, B (1972) "The influence of model retaining wall displacements on active and passive earth pressure in sand." Proc. 5th European Conf. on Soil Mech. and Found. Eng, Vol. 1., pp 241-249

Canadian Foundation Engineering Manual, (2006), Fourth edition, Canadian Geotechnical Society, 488p

Carranza-Torres, C. (2003) "Dimensionless graphical representation of the exact elastoplastic solution of a circular tunnel in a Mohr-Coulomb material subject to uniform farfield stress." Rock Mechanics and Rock Engineering, Vol. 36, No. 3, pp 237-253.

Cheng, Y. M., and Hu, Y.Y. (2005) "Active earth pressure on circular shaft lining obtained by simplified slip line solution with general tangential stress coefficient." Chinese Journal of Geotechnical Engineering, Vol. 27, No. 1, pp 110-115. 
Cheng, Y. M., Hu, Y.Y and Wei W. B. (2007) "General axisymmetric active earth pressure by method of characteristics - Theory and numerical formulation." International Journal of Geomechanics, Vol. 7, No. 1, pp 1-15.

Chun, B, and Shin, Y. (2006) "Active earth pressure acting on the cylindrical retaining wall of a shaft," South Korea Ground and Environmental Engineering Journal, Vol. 7, No. 4, pp 15-24.

Detournay, E. (1986) "Elastoplastic model of a deep tunnel with variable dilatancy." Rock Mechanics and Rock Engineering, Vol. 19, No. 2, pp 99-108.

Fara, H. D., and Wright F. D. (1963) "Plastic and Elastic Stresses around a Circular Shaft in a Hydrostatic Stress Field" Transactions of the society of mining engineers of American institute of mining (AIME), Vol. 226, No. Sep, pp 319-320.

Fujii, T., Hagiwara, T., Ueno, K. and Taguchi, A. (1994) "Experiment and analysis of earth pressure on an axisymmetric shaft in sand." Proceedings of the 1994 International Conference on Centrifuge, Singapore, p 791-796.

Herten, M., and Pulsfort, M. (1999) "Determination of spatial earth pressure on circular shaft constructions," Granular Matter, Vol. 2, No. 1, pp 1-7.

Imamura, S., Nomoto, T., Fujii, T., and Hagiwara, T. (1999) "Earth pressures acting on a deep shaft and the movements of adjacent ground in sand," In: O. Kusakabe, K. Fujita, and Y. Miyazaki, Eds., Proceedings of the international symposium on geotechnical aspects of underground construction in soft ground. Tokyo, Japan: Balkema, Rotterdam, pp 647-652.

Konig, D., Guettler, U., and Jessberger, H. L. (1991) "Stress redistributions during tunnel and shaft constructions," Proceedings of the International Conference Centrifuge 1991, Boulder, Colorado, pp 129-135.

Kusakabe, O., Tsutomu, K., Akira O., Nobuo, T., and Nobuaki, N. (1985) "Centrifuge model test on the influence of axisymmetric excavation on buried pipes.," Proceedings of the 3rd international conference of ground movements and structures: Pentech Press, London, England, pp 113-128.

Lade, P. V., Jessberger, H. L., Makowski, E., and P. Jordan (1981) "Modeling of deep shafts in centrifuge test" Proceedings of the International Conference on Soil Mechanics and Foundation Engineering, Stockholm, Sweden, Vol. 1, pp 683-691. 
Liu, F. Q., and Wang, J. H. (2008) "A generalized slip line solution to the active earth pressure on circular retaining walls," Computers and Geotechnics, Vol. 35, No. 2, pp $155-164$.

Liu, F. Q., Wang, J. H., and Zhang, L. L. (2009) "Axi-symmetric active earth pressure obtained by the slip line method with a general tangential stress coefficient," Computers and Geotechnics, Vol. 36, No. 1-2, pp 352-358.

Pastor, J., and Turgeman, S. (1982) "Limit analysis in axisymmetrical problems: numerical determination of complete statical solutions," International Journal of Mechanical Sciences, Vol. 24, No. 2, pp 95-117.

Prater, E. G. (1977) "Examination of some theories of earth pressure on shaft linings," Canadian Geotechnical Journal, Vol. 14, No. 1, pp 91-106.

Rowe, P. W. (1969) "Progressive failure and strength of sand mass," Seventh International Conference on Soil Mechanics and Foundation Engineering, Vol. 1., pp. 341-349

Sherif, M. A., Fang, Y.S. and Sherif, R (1984) " $K_{a}$ and $K_{0}$ behind rotating and nonyielding walls," Journal of Geotechnical Engineering, Vol. 110, No. 1, pp 41-56.

Sherif, M.A., Ishibashi,I., and Lee, C.D. (1982) "Earth pressures against rigid retaining walls," American Society of Civil Engineers, Journal of the Geotechnical Engineering Division, Vol. 180, No. GT5, pp 679-695.

Timoshenko, S (1941) Strength of materials, New York: D Van Nostrand Company, Inc.

Terzaghi, K. (1920) "Old earth-pressure theories and new test results," Engineering News-Record, Vol. 85, No. 13, pp 632-637.

Terzaghi, K. (1934) "Large retaining-wall tests," Engineering News-Record, Vol. 112, pp. 5-23.

Terzaghi, K. (1943) Theoretical soil mechanics, New York: Jhon Wiley \& sons Inc.

Terzaghi, K. (1953) "Anchored bulkheads," American Society of Civil Engineers Proceedings, ASCE, Vol. 79, No. Separate 262, p 39.

Walz, B. (1973) "Left bracket apparatus for measuring the three-dimensional active soil pressure on a round model caisson right bracket," Baumaschine und Bautechnik, Vol. 20, No. 9, pp 339-344. 
Westergaard, H. M. (1940) "Plastic state of stress around deep well," Boston Society of Civil Engineers Journal, Vol. 27, No. 1, pp 1-5.

Wong, R. C. K., and Kaiser P. K. (1988) "Behaviour of vertical shafts: reevaluation of model test and evaluation of field measurements." Canadian Geotechnical Journal, Vol. 25, No. 2, pp 338-352.

Yu, H.S (2006) "Slip line analysis," Plasticity and Geotechnics: Springer, New York, pp 293-330. 


\section{Appendix A \\ PARTICLE-SIZE DISTRIBUTION}

This appendix present the results of the sieve analysis performed on the soil according to the standards outlined by ASTM D6913-04e1 (Standard Test Methods for Particle-Size Distribution (Gradation) of Soils Using Sieve Analysis).

Quartz industrial 2075 coarse sand material was selected for this study. Three samples of about $500 \mathrm{~g}$ were randomly obtained from the sand bags. The samples were run through a stack of sieves prepared as indicated in the ASTM procedure, and shook for 10 minutes using a mechanical shaker. The average result of the grain size versus percent passing on each sieve for the three samples is plotted in Figure A.1. The computed soil properties are listed in Table A.1.

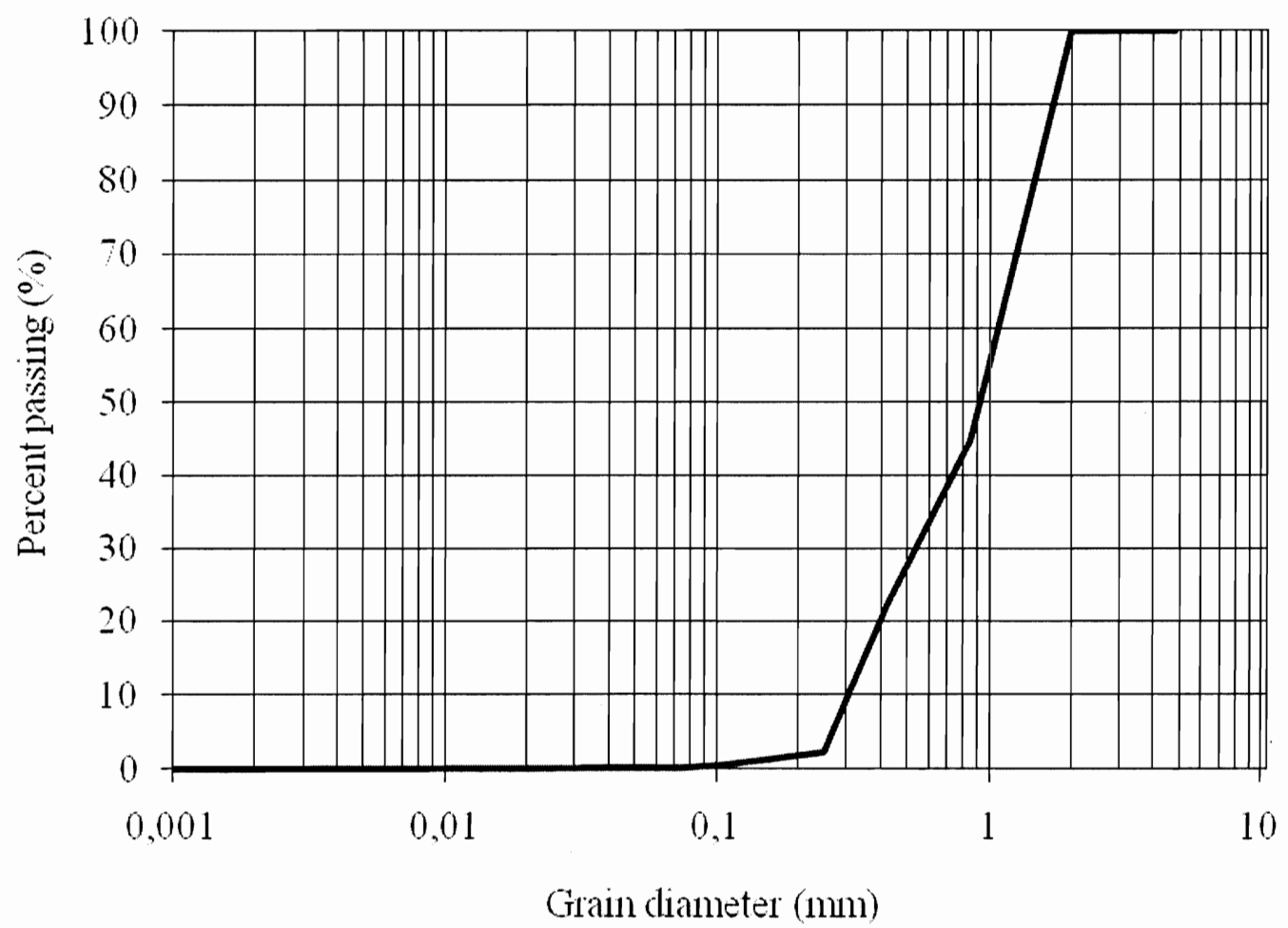

Figure A.1 Particle-size distribution 


\begin{tabular}{|c|c|}
\hline PROPERTY & VALUE \\
\hline $\mathrm{D}_{10}(\mathrm{~mm})$ & 0.31 \\
\hline $\mathrm{D}_{30}(\mathrm{~mm})$ & 0.57 \\
\hline $\mathrm{D}_{60}(\mathrm{~mm})$ & 1.17 \\
\hline Coefficient of uniformity $\left(\mathrm{C}_{\mathrm{u}}\right)$ & 3.6 \\
\hline Coefficient of curvature $\left(\mathrm{C}_{\mathrm{c}}\right)$ & 0.82 \\
\hline Unified soil classification & $\mathrm{SP}$ \\
\hline
\end{tabular}

Table A.1 Soil properties 


\section{Appendix B SPECIFIC GRAVITY}

Specific gravity of the testing soil was performed according to the procedure outlined by ASTM D854-06 (Standard Test Methods for Specific Gravity of Soil Solids by Water Pycnometer).

The test was performed on three random samples of about $100 \mathrm{~g}$ each of Quartz industrial 2075 coarse sand. The average of the calculated specific gravity for the three samples was found to be 2.65 . 


\section{Appendix C}

\section{DIRECT SHEAR TEST}

This appendix present the results of the direct shear test conducted on the testing soil according to the standards outlined by ASTM D3980-04 (Standard Test Method for Direct Shear Test of Soils under Consolidated Drained Conditions).

The direct shear machine used was powered by a motor to impose a rate of shear of $0.05 \mathrm{in} / \mathrm{min}$. Three different normal loads were imposed, and corresponded to 13.6, 27.3 and $40.9 \mathrm{kPa}$, on three different sand samples in loose condition. The calculated shear stress versus horizontal displacement is plotted in Figure C.1 for the three specimens tested which had an average density of $14.2 \mathrm{kN} / \mathrm{m}^{3}\left(\gamma_{\min }\right)$. The normal stress versus shear stress is plotted in Figure C.2. The measured internal friction angle was about $41^{\circ}$ and the cohesion was zero. Additionally, a maximum soil density of 16.4 $\mathrm{kN} / \mathrm{m}^{3}\left(\gamma_{\max }\right)$ was measured using the shear box.

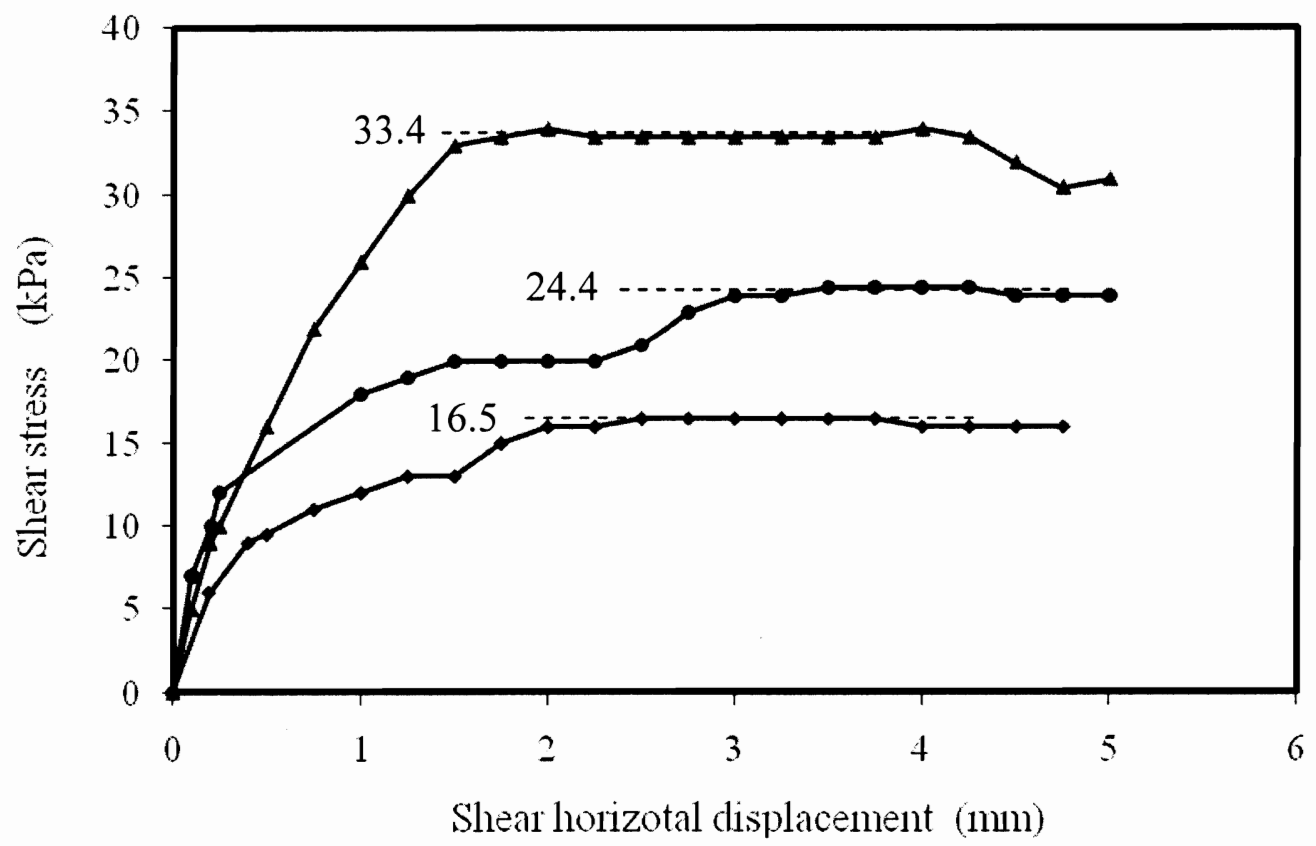

Figure C.1. Shear stress versus horizontal displacement 


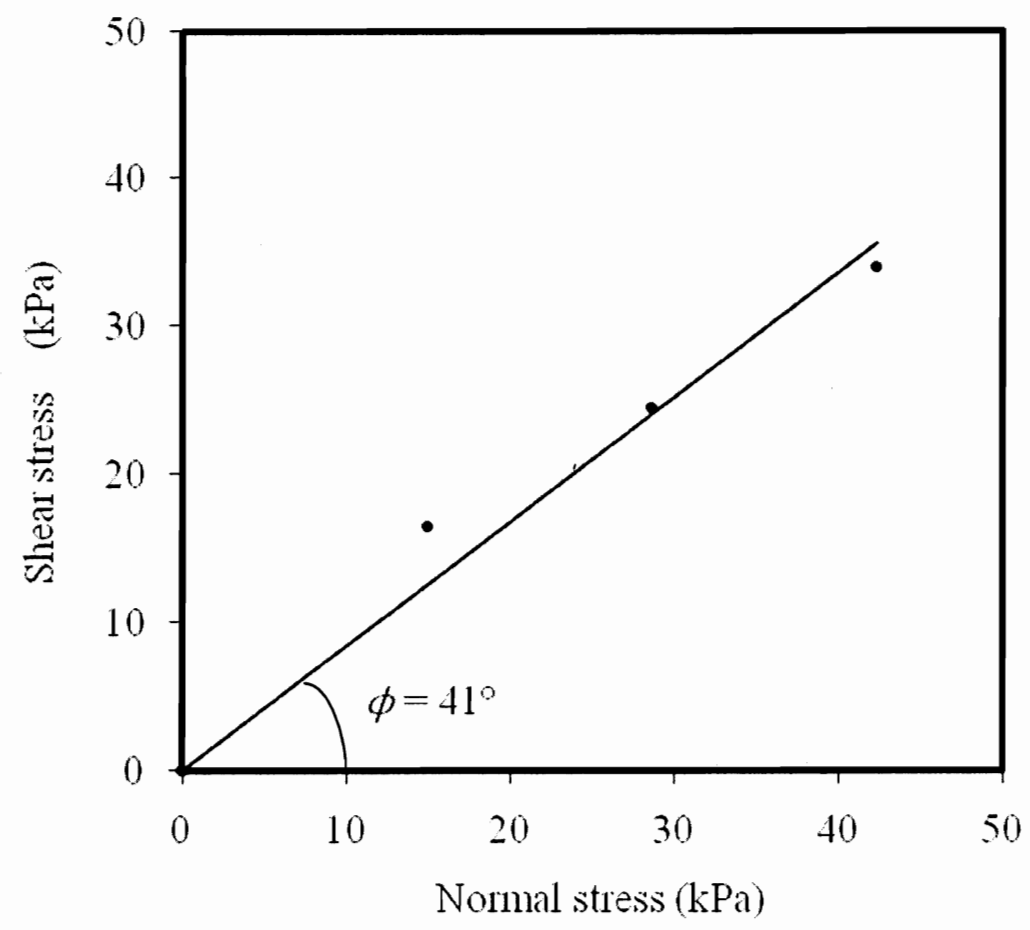

Figure C.2 Shear stress versus normal stress 


\section{Appendix D \\ LOAD CELLS}

Aluminum single point load cells were calibrated to monitor the lateral earth pressure acting on the model shaft through a data acquisition system. They had a maximum capacity of $0.2 \mathrm{~kg}$ and a precision of $\pm 0.02 \%$. Figure E.1 shows a photo of the load cell and the dimensions provided by the manufacturer are shown in Figure E.2.

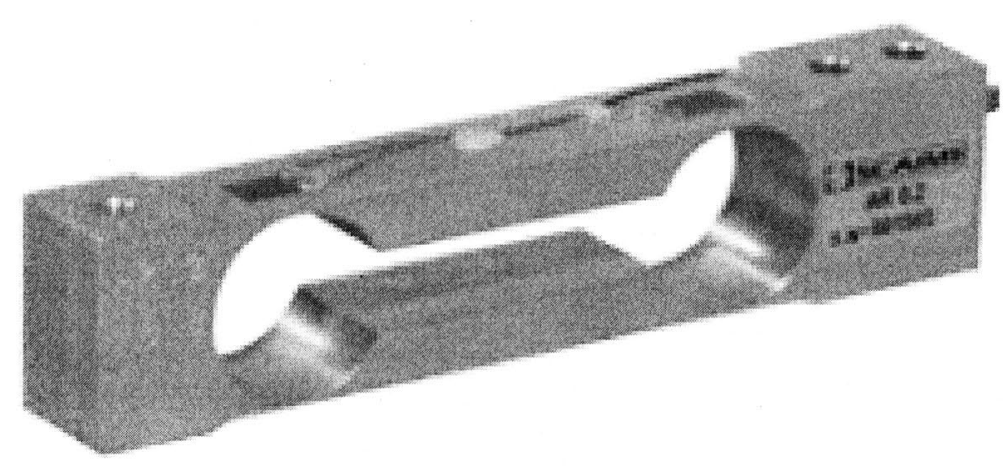

Figure E.1 Load cell (www.scaime.com) 

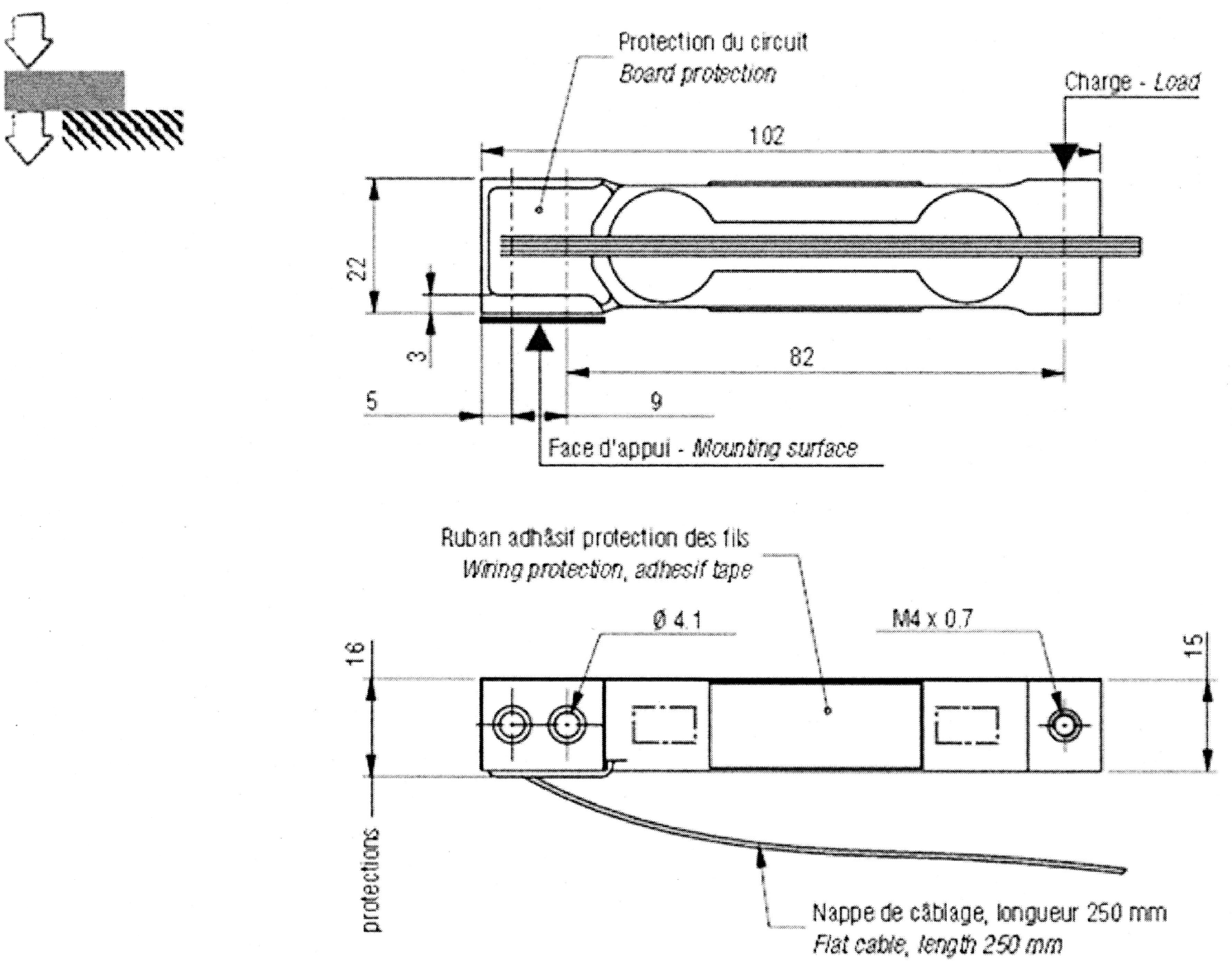

Toutes dimensions en mm - Alt dimensions in mm

Figure E.2. Load cell details and dimensions (www.scaime.com) 


\section{Appendix E \\ LASER GAUGE SENSORS}

Laser displacement sensors LG5 series manufactured by Banner ${ }^{\mathcal{O}}$ were used to monitor the surface settlements through a data acquisition system. They have a sensing distance of 45 to $60 \mathrm{~mm}$ from the sensor lens, and a precision of $\pm 0.05 \mathrm{~mm}$ over the sensing range. A schematic of the sensor is shown in Figure F.1.

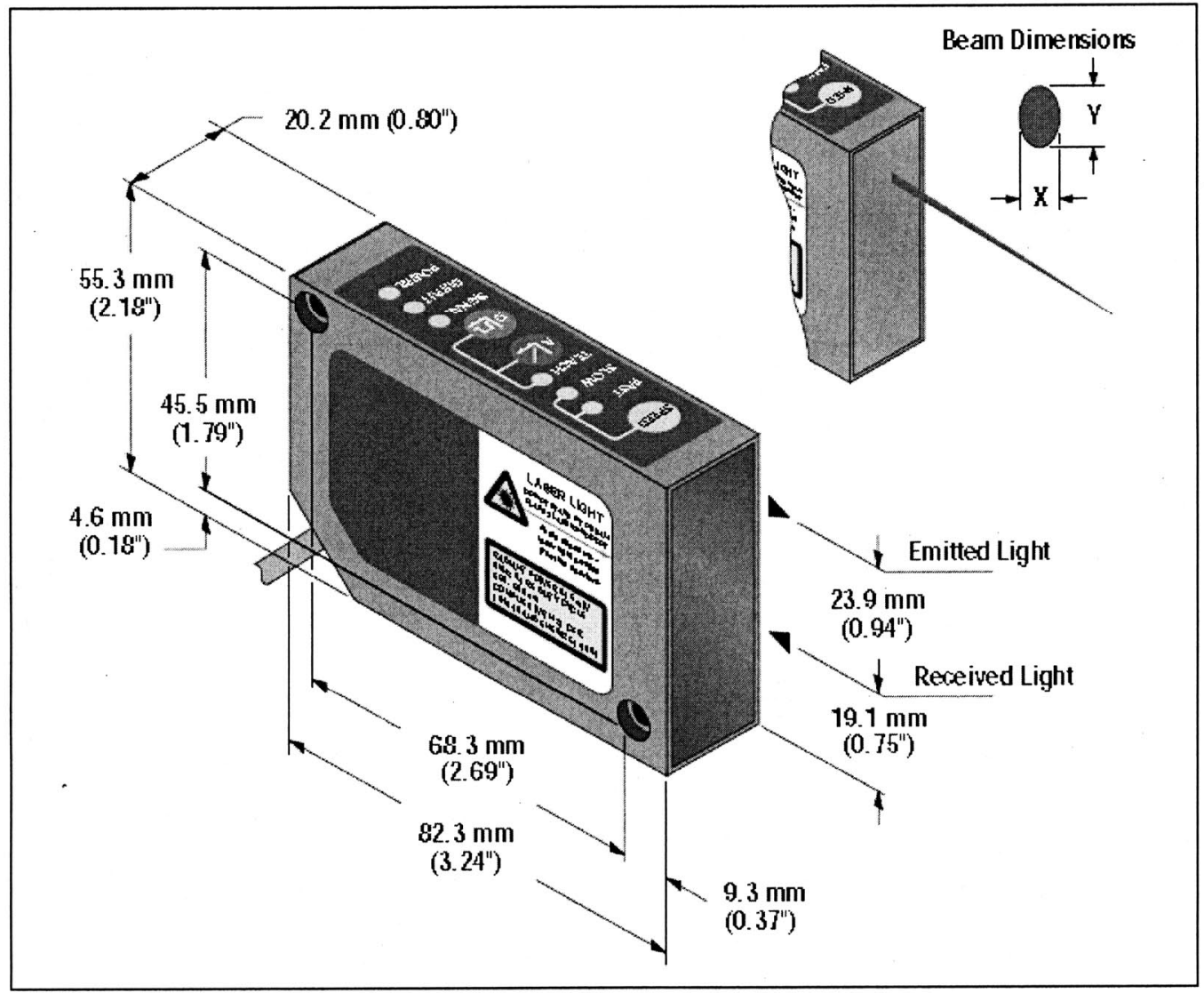

Figure F.1. Schematic of LG5 gauging laser sensor (www.bannerengineering.com) 


\section{Appendix $\mathrm{F}$}

\section{EXPERIMENTAL DATA}

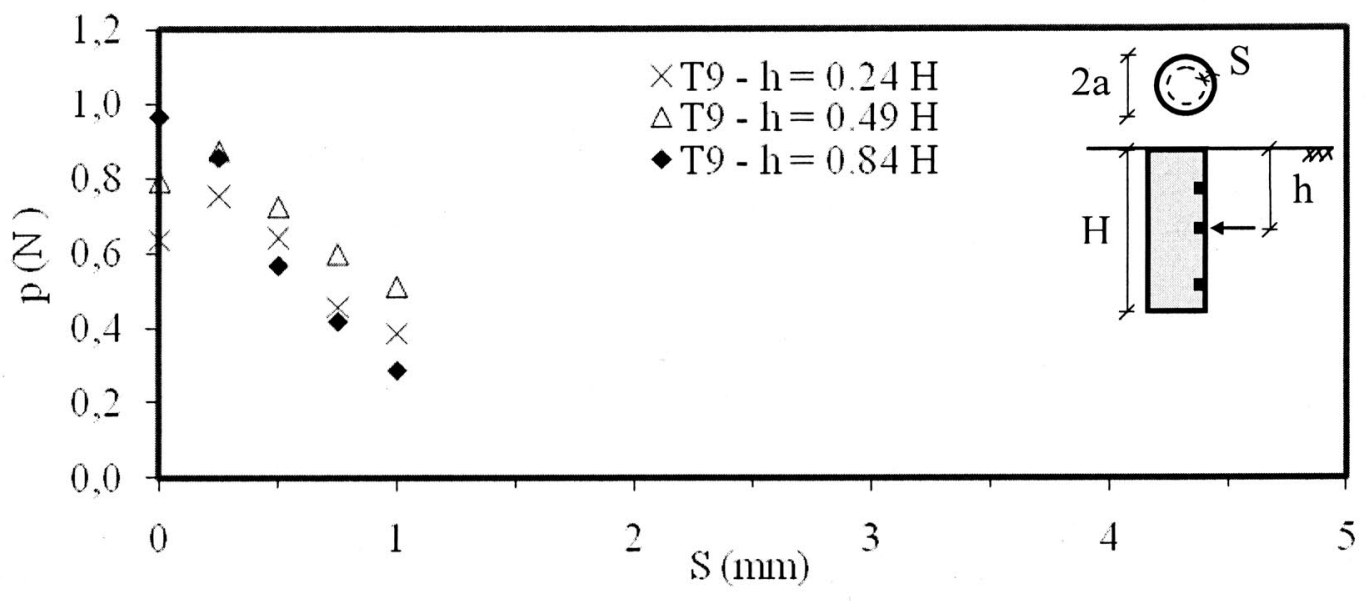

Figure F.1 Measured lateral load versus wall displacement, T9.

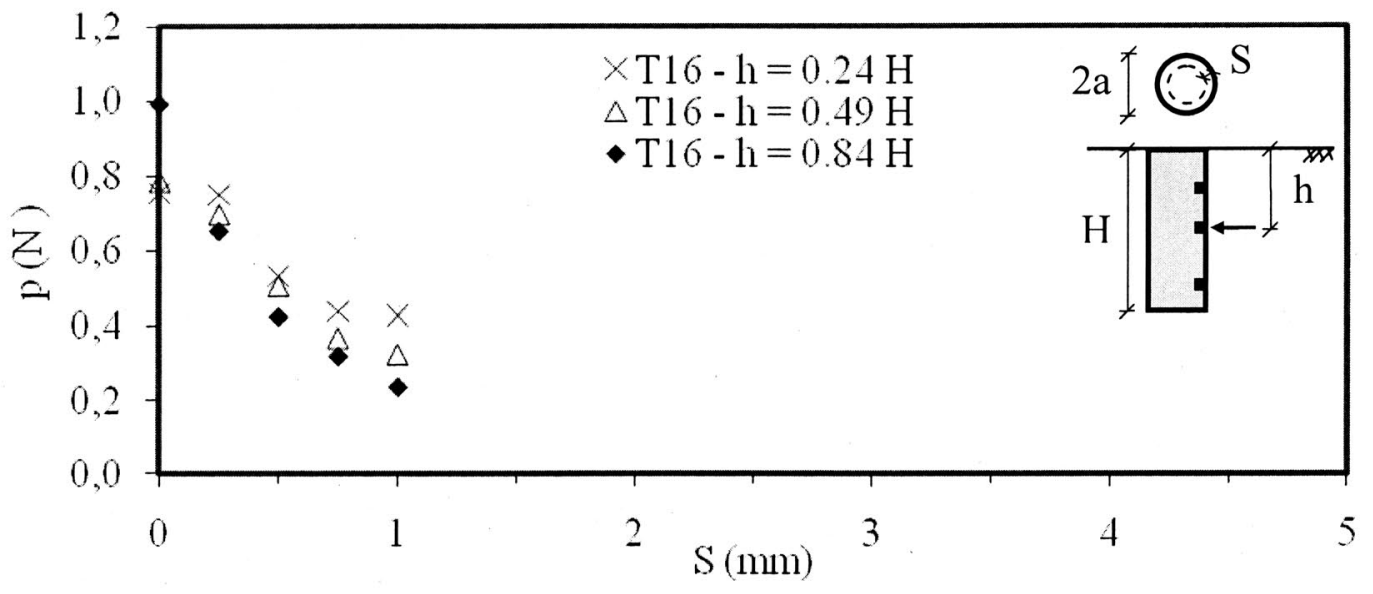

Figure F.2 Measured lateral load versus wall displacement, T16. 


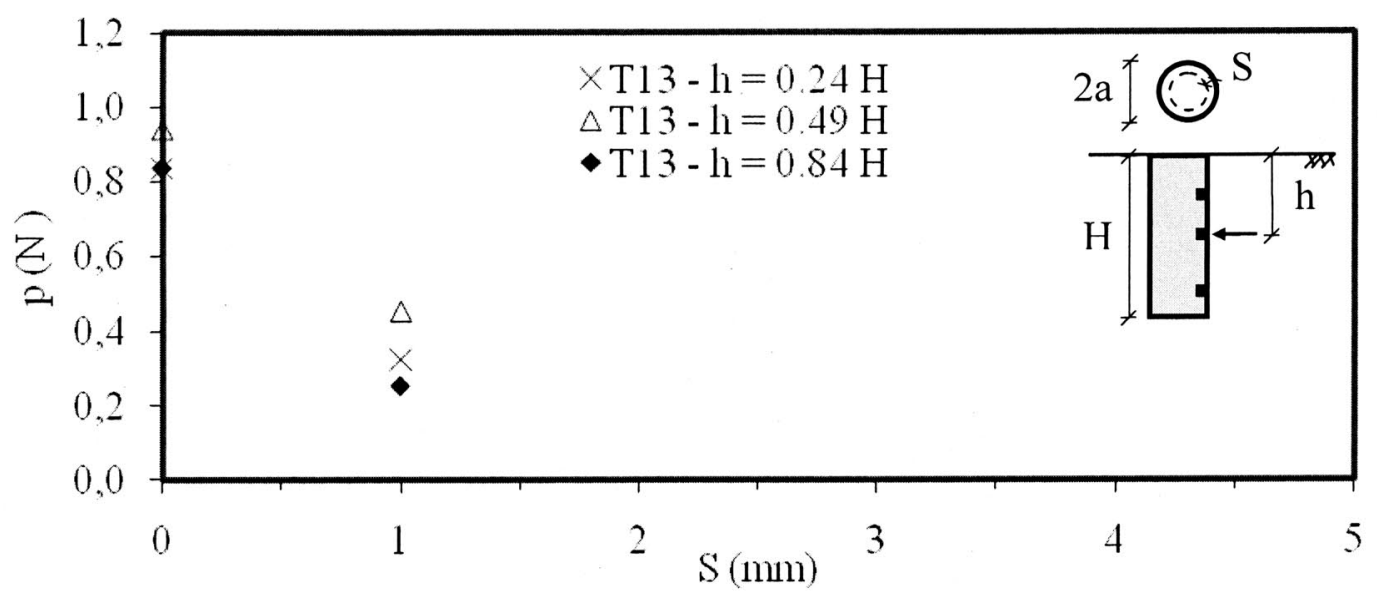

Figure F.3 Measured lateral load versus wall displacement, T13.

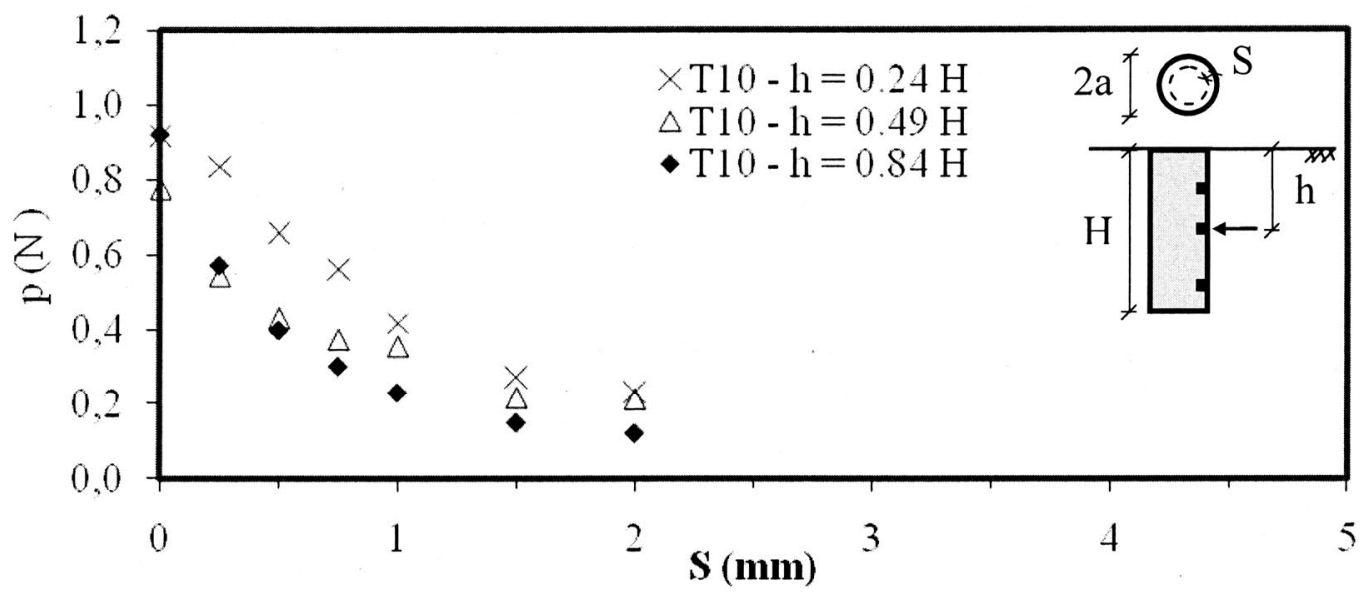

Figure F.4 Measured lateral load versus wall displacement, T10.

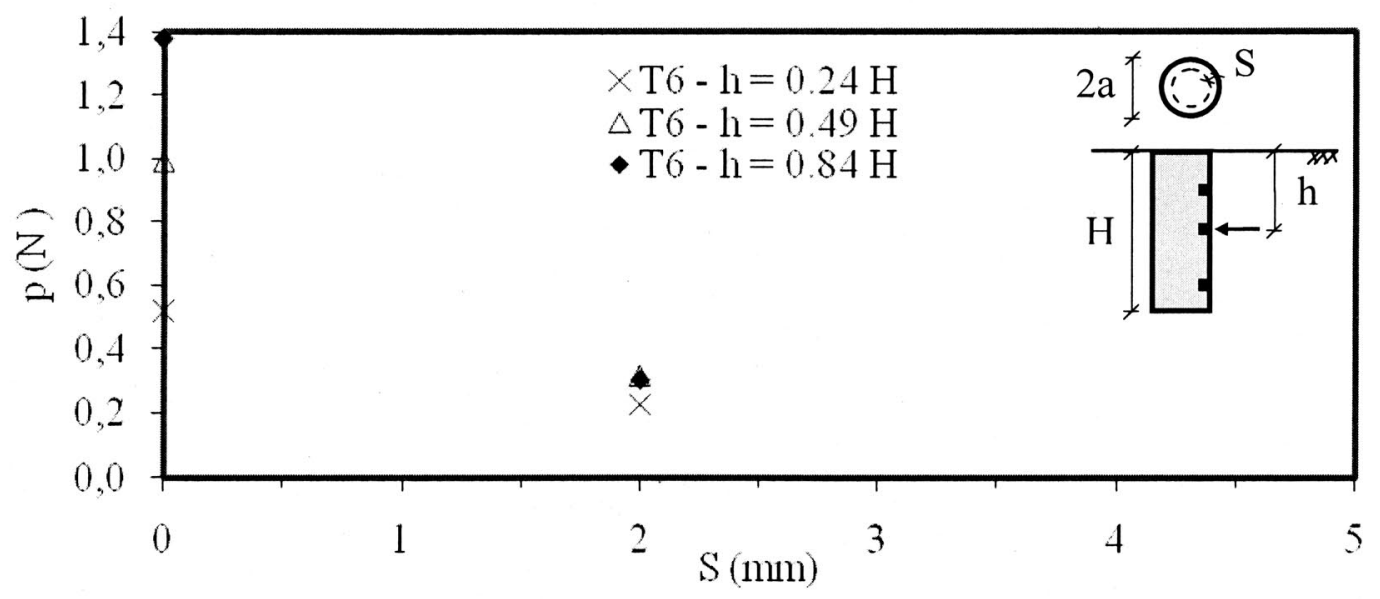

Figure F.5 Measured lateral load versus wall displacement, T6. 


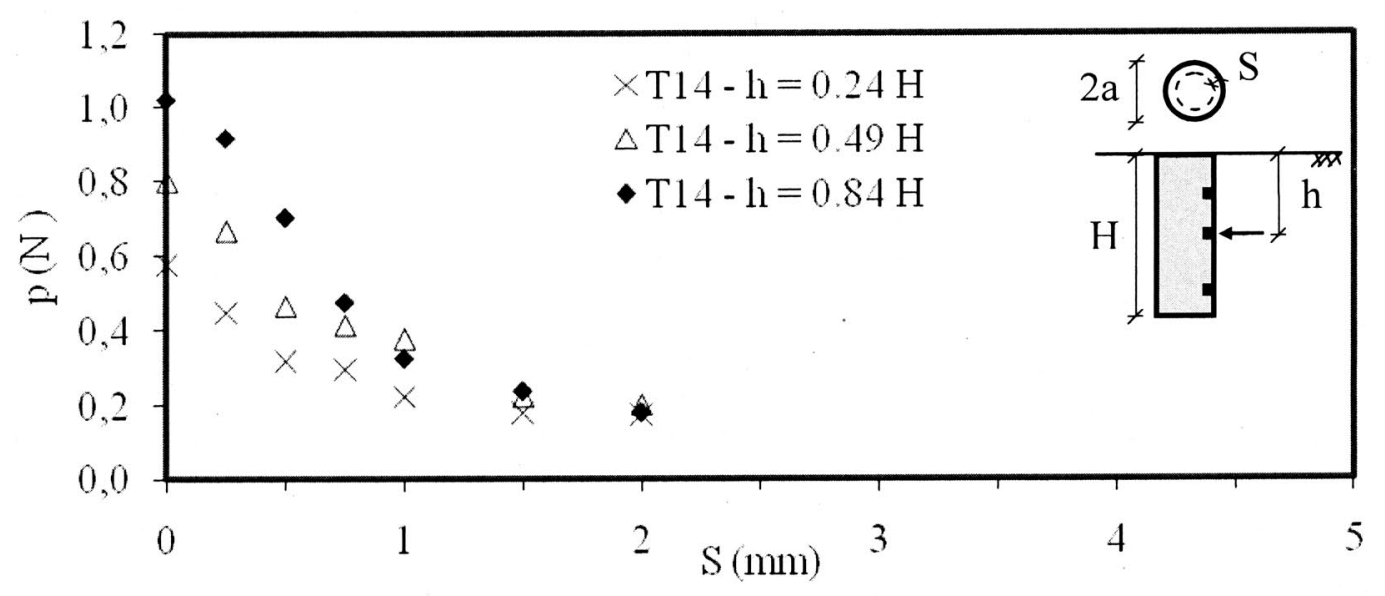

Figure F.6 Measured lateral load versus wall displacement, T14.

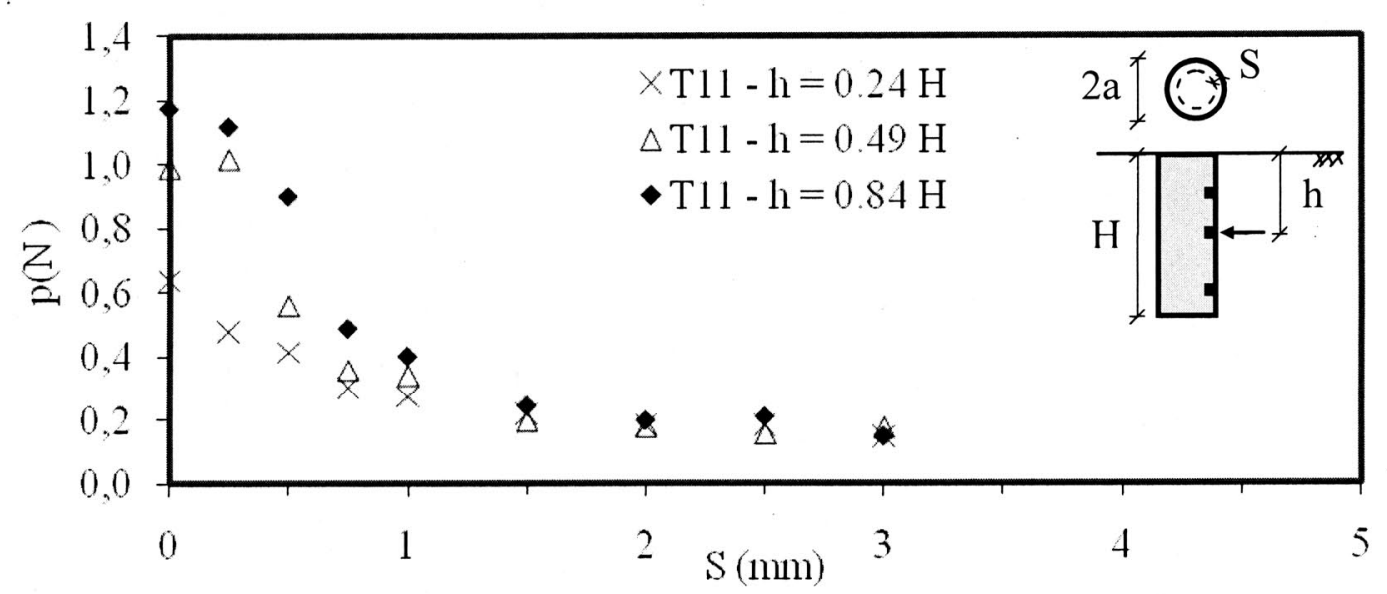

Figure F.7 Measured lateral load versus wall displacement, T11.

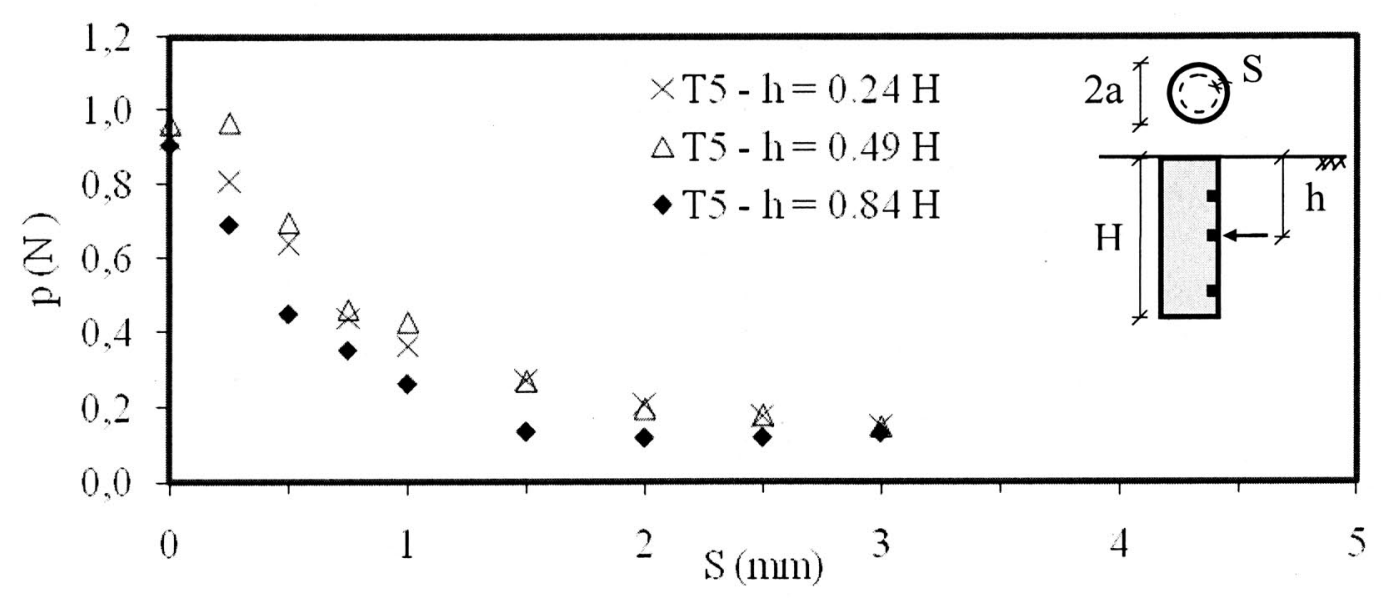

Figure F.8 Measured lateral load versus wall displacement, T5. 


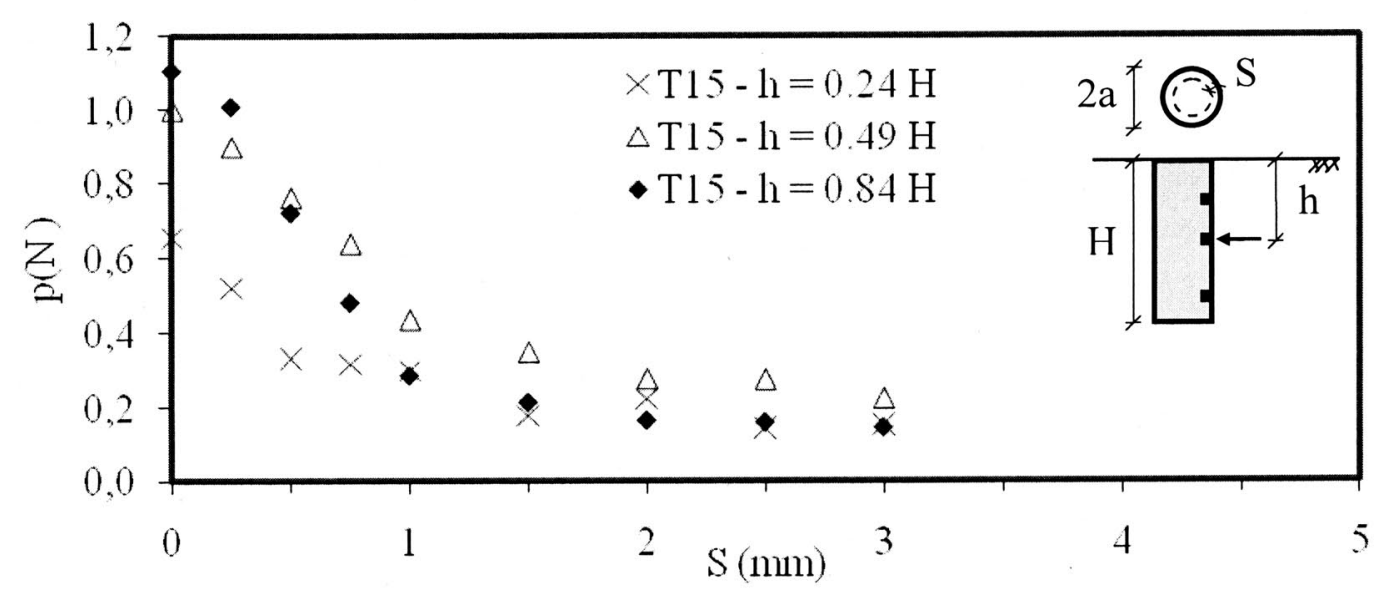

Figure F.9 Measured lateral load versus wall displacement, T15.

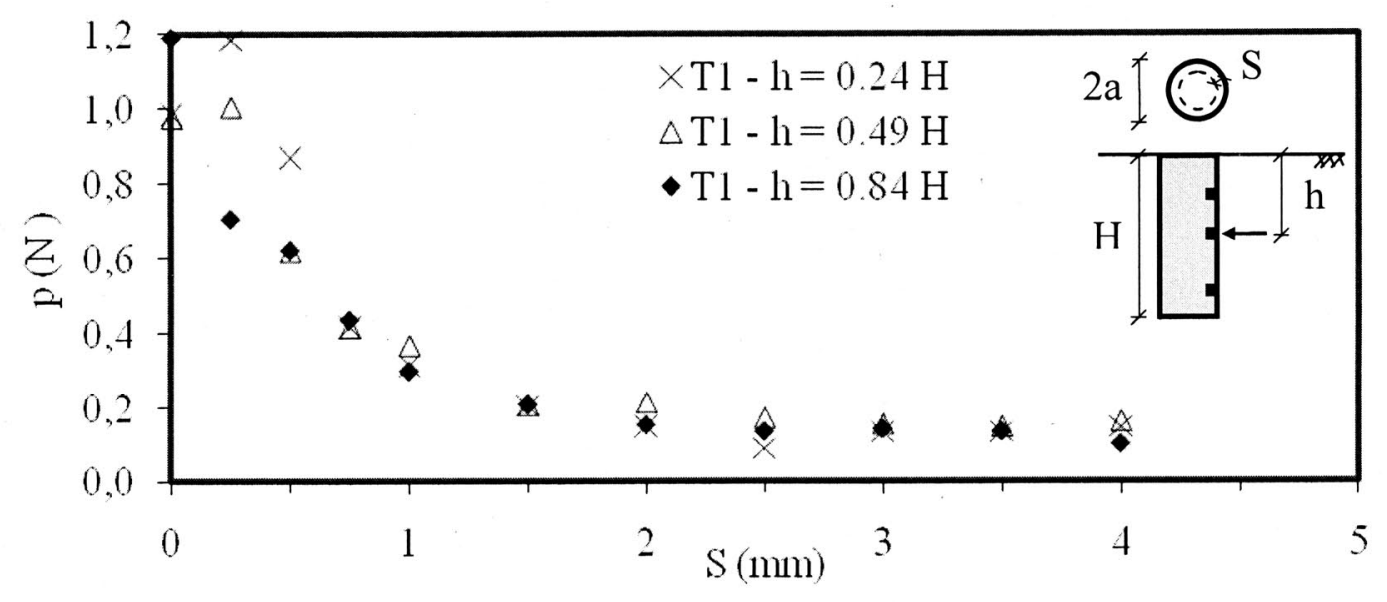

Figure F.10 Measured lateral load versus wall displacement, T1.

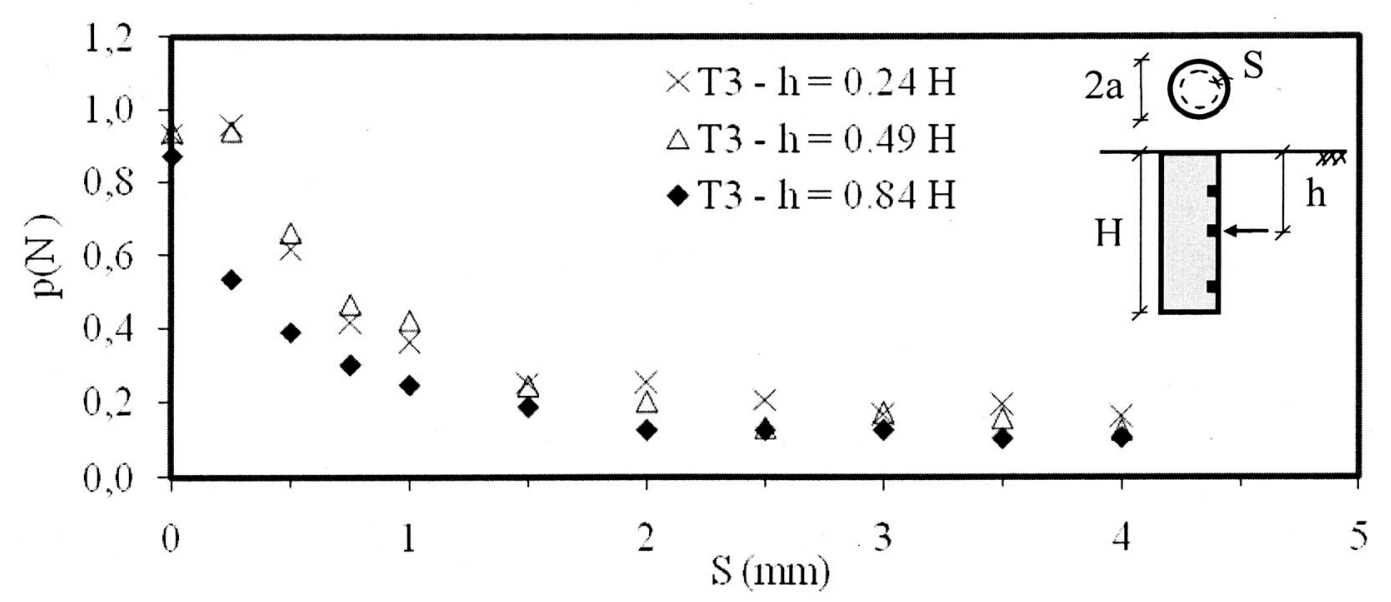

Figure F.11 Measured lateral load versus wall displacement, T3. 


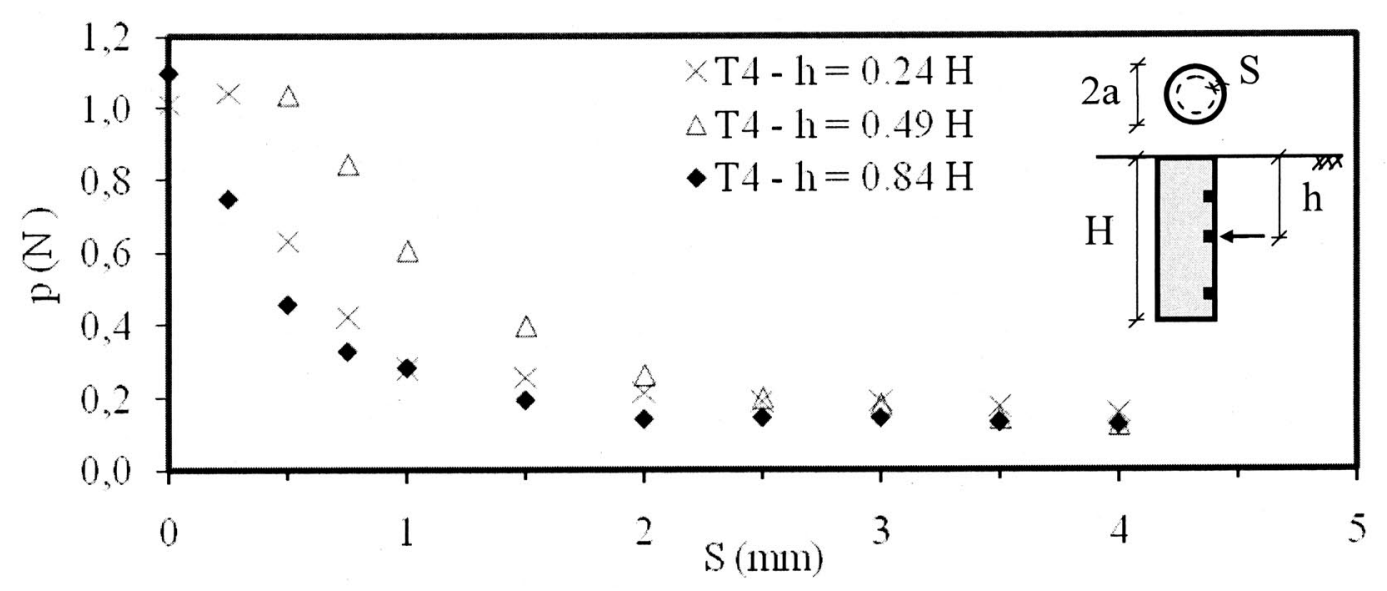

Figure F.12 Measured lateral load versus wall displacement, T4. 